\title{
MATEO FLECHA EL VIEJO EN LA CATEDRAL DE VALENCIA: SUS DOS PERÍODOS DE MAGISTERIO DE CAPILLA (1526-1531? Y 1539-1541) Y SU ENTORNO MUSICAL ${ }^{*}$
}

Francesc Villanueva Serrano

Universitat Politècnica de València

\section{Resumen:}

La biografía actual de Mateo Flecha el Viejo, autor clave del género vocal hispano de la ensalada, está construida sobre escasos datos fehacientes, que dejan grandes lagunas en el conocimiento de su trayectoria profesional. El presente trabajo presenta, pø primera vez, documentos que atestiguan su, hasta ahora solamente intuida, presencia en la ciudad deValencia, donde ejerció, fundamentalmente, como maestro de capilla de su catedral durante dos períodos: 1526-1531? y 1539-1541A partir de ellos, se estudia detenidamente su estancia en la seo y se reflexiona sobre algunas cuestiones de su identidad. Con el fin de conocer mejor el medio donde desarrolló Flecha su actividad principal, también se analizan ciertos aspectos musicales de la catedral valenciana durante el intervalo temporal en que se enmarca su presencia en esa institución (1526-1541). Finalmente, se aportan nuevas ideas, a la luz de los datos ahora presentados, que puedan sumarse a las ya planteadas sobre la cuestión abierta del contexto creativo de algunas de sus ensaladas.

Palabras Clave:

Mateo Flecha, maestro de capilla, catedral de Valencia, capilla musical, ensalada, Pere Vila, Pere Alberch, duque de Calabria, siglo XVI.

\begin{abstract}
:
The current biography of Mateo Flecha the Elder, the most outstanding composer of the Spanish genre of the ensalada, has been based on a fe w confirmed data. As a result, there are big gaps in his kno wn professional career. In this article, documents about his presence in the City of Valencia, as chapel master of the cathedral in tw o periods (1526-1531? and 1539-1541), are presented for the first time. From them, his stay in the cathedral and some questions about his identity are studied. In order to know better the background where Flecha de veloped his principal activity, certain musical aspects of the Valencian cathedral are analyzed during the period included between the first and last year of his presence in this institution (1526-1541). Finally , new ideas are presented, on account of the information now presented, that could add to the already raised ones about the opened issue on the creative context of some of his ensaladas.
\end{abstract}

Key Words:

Mateo Flecha, chapel master, cathedral of Valencia, chapel of music, ensalada, Pere Vila, Pere Alberch, Duke of Calabria, 16 th century.

* Agradezco al Dr. Antonio Ezquerro, director de mi tesis doctoral, su amabilidad al realizar una lectura crítica a este artículo previa a su publicación. Asimismo doy las gracias al Dr. Vicent Pons, canónigo archivero de la catedral de Valencia, así como a sus colaboradores Juan y Juan Ignacio, por su talante siempre colaborador durante la investigación. 


\author{
Ante el juez singular \\ del cabildo de Valencia, \\ adonde por excelencia \\ lo siente, \\ yo, la Música presente, \\ doy querella criminal
}

Mateo Flecha: La viuda

\title{
1. INTR ODUCCIÓN
}

El nombre de Mateo Flecha ${ }^{1}$, llamado modernamente "el Viejo" para distinguirlo de su sobrino homónimo, está íntimamente unido al género literario-musical hispano de la ensalada. La trascendencia del autor en la historia del género así como el prestigio del que disfrutó ya en su época se traslucen con sólo comprobar la notable cantidad de obras conserv adas y de fuentes que las transmiten. La reciente edición crítica completa de las ensaladas con música conocida de Mateo Flecha y de otros autores hispánicos del siglo XVI, a cargo de Maricarmen Gómez Muntané, e videncia la supremacía numérica del autor con once piezas de su autoría -localizadas en tres impresos y cuatro manuscritos- sobre un total de diecinueve obras del género conservadas de esa centuria ${ }^{2}$.

1 En el presente trabajo se ha optado por utilizar el nombre de este autor en su forma castellanizada, transmitido por las fuentes de sus obras y por el cual es conocido. El resto de músicos figuran con el nombre de pila normalizado en la lengua en que redactan sus albaranes y el patronímico en la forma encontrada con más frecuencia en los documentos.

2 Entre las fuentes impresas destaca Las Ensaladas de Flecha, maestro de capilla que fue de las Serenissimas Infantas de Castilla (Praga, Jor ge Ne grino, 1581), lle vada a la imprenta por su sobrino Mateo Flecha, llamado "el Joven". Los otros dos impresos son Le difficile des chansons. Second livre contenant. XXVI. Chansons nouvelles a quatre parties en quatre livres de la composition de plusieurs Maistres (Lyon, Jacques Moderne, 1544) y el Libro de Música para Vihuela intitulado Orphenica lyra (Se villa, Martín de Montesdoca, 1544) de Miguel de Fuenllana, que incluye adaptaciones vihuelísticas de tres ensaladas de Flecha. Las fuentes manuscritas son: E-Bc, 588/1; E-Bc, 588/2; E-P Abm, 6832 y E-Bn, 3876/34-35 [F lecha, Mateo: Las Ensaladas (Praga, 1581) con un Suplemento de obras del género, ed. por Maricarmen Gómez Muntané, 2 v ols. (Valencia, Institut Valencià de la Música, Generalitat Valenciana, 2008), pp. 3339]. Este completísimo trabajo de Gómez Muntané, prácticamente def initivo por lo que se ref iere a la edición musical de las ensaladas conocidas del siglo XVI, incluye un amplio estudio, edición musical y f acsímil del fundamental impreso de Praga. Otras ediciones modernas de ensaladas musicales de Flecha, el Viejo, pueden encontrarse en: P EDRELL, Felip: Catàlech de la Biblioteca musical de la Diputació de Barcelona, vol. II (Barcelona, Palau de la Diputació, 1919) pp. 210232; Flecha, Mateo: Mateo Flecha (†1553). Las Ensaladas (Praga, 1581), ed. por Higinio Anglés (Barcelona, Diputación Provincial de Barcelona, Biblioteca Central, 1954); F LechA, Mateo: Fletxa, Mateu (1481?-1553?): La Viuda (Ensalada), ed. por Maricarmen Gómez Muntané (Barcelona, Biblioteca de Catalunya, 1992). Además de los correspondientes estudios introductorios de las ediciones anteriores, se ha tratado especialmente sobre la caracterización del género en otros trabajos como: Romeu Figueras, Josep: "Mateo Flecha el Viejo, la corte literario musical del duque de Calabria y el Cancionero llamado de Upsala”, en Anuario Musical, XIII (1958), pp. 25-101; ÍD.: “«El toro», ensalada poético musical inédita. Estudio sobre temas taurinos y v aqueros en la lírica tradicional”, en Anuario Musical, 20 (1965), pp. 25-58; Q UEROL GAVALDÁ, Miguel: “«Las ensaladas» de Mateo Flecha el Viejo (ca. 1481-1553): estudio histórico-técnico de este género musical”, en 
A pesar de la importancia de su le gado, la biografía actualmente conocida de Mateo Flecha el Viejo, es a la $\mathrm{v}$ ez parca en detalles e inse gura en su base documental, $\mathrm{f}$ actores que han $\mathrm{f}$ avorecido las especulaciones de sus biógrafos sobre su trayectoria vital, basadas en no pocas ocasiones en los textos literarios de sus obras, con los riesgos que ello conlle $\mathrm{va}^{3}$. Una de las conjeturas que ha gozado de mayor aceptación es la que concierne a una posible estancia del autor en la ciudad de Valencia, vinculada especialmente a la corte del duque de Calabria don Fernando de Aragón, virrey de Valencia en el período 1526-15504. Esta hipótesis de estancia en la capital de Turia, sin base documental alguna hasta el presente, se ha basado en gran parte en las concordancias identificadas de fragmentos de los textos de algunas de sus ensaladas con obras literarias conocidas creadas en el entorno ducal por los escritores Lluís del Milà y Joan Fernández de Heredia. Asimismo, en este sentido han recibido especial atención algunos de los v ersos de la ensalada titulada La Viuda, en la que e xplícitamente aparecen referidos de forma laudatoria tanto el duque de Calabria como el cabildo de la catedral metropolitana valentina $^{5}$. Más allá ha ido la perspicacia de Ferran Muñoz, quien ha apuntado la hipótesis de que la

Anuario Musical, 43 (1988), pp. 67-79; Gómez Muntané, Maricarmen: “The Ensalada and the Origins of the Lyric Theater in Spain”, en Comparative Drama, 28/3 (1994), pp. 367-393.

3 Es especialmente significativa la e xpresión de Josep Romeu a este respecto, quien, a pesar de ser consciente de los peligros del intento, afirma que "la pobreza documental que de su vida tenemos, nos obliga a prestar mayor atención a su obra, para intentar esclarecer algo la borrosa circunstancia biográfica” [RomeU FiguERAs, Josep: "Mateo Flecha el Viejo...,", op. cit., pp. $25,27]$.

4 Don Fernando de Aragón (*Andria, 1488; †Valencia, 1550), duque de Calabria, fue el hijo primogénito de Federico III, -último rey de Nápoles de la rama bastarda aragonesa que había iniciado Ferrante I, hijo ile gítimo del rey de Aragón Alfonso $\mathrm{V}$ el Magnánimo (*1396; †1458)-, e Isabella del Balzo. Tras capitular para la entrega de la plaza napolitana de Tarento (1502), que el duque defendía frente a las tropas de Fernando el Católico, el jo ven heredero fue hecho prisionero y trasladado a los domini os ibéricos del rey hispano. En 1506 fue nombrado Lugarteniente Real en Cataluña, aunque sometido a estrecha vigilancia. Tras un intento de huída, fue encarcelado en el castillo de Xàti va (1512) en el reino de Valencia. En 1523, poco después de finalizar la guerra de las Germanías de Valencia, fue puesto en libertad por el emperador Carlos v, en recompensa por haber mantenido su fidelidad a la corona durante dicho conflicto. Durante los siguientes años, el duque de Calabria se inte gró en los círculos de la alta nobleza castellana. En 1526 casó, bajo los auspicios del emperador , con Germana de F oix (*1488; †1536), viuda que había sido de Fernando el Católico y posteriormente de Enrique de Nassau, y fueron nombrados conjuntamente virre yes en el reino de Valencia. Tras la muerte de su esposa, contrajo nuevas nupcias en 1541 con doña Mencía de Mendoza $(* 1508 ; \dagger 1554)$. Los duques se establecieron en el palacio del Real de la capital v alenciana, residencia tradicional de los re yes en sus estancias en la ci udad, donde dispusieron de una corte que desarrolló una notable acti vidad humanística, literaria y musical. En el terreno de la músic a, frecuentó la corte el noble vihuelista y escritor Lluís del Milà y formaron parte de su numerosa capilla compositores de la tal la de Pedro de Pastrana, Bartolomé Cárceres y Juan Cepa. Sobre la acti vidad musical en la corte v alenciana del duque de Calabria existen diversos trabajos entre los que se pueden destacar: R OMEU Figueras, Josep: "Mateo Flecha el Viejo...", op. cit.; Moll, Jaime: "Notas para la historia de la corte del Duque de Calabria", en Anuario Musical, 18 (1963), pp. 123-135; GómEZ MunTANÉ, Maricarmen: "San Miguel de los Reyes y la capilla musical de don Fernando de Aragón, duque de Calabria (1488-1550)", en San Miguel de los Reyes: de Biblioteca Real a Biblioteca Valenciana (Valencia, Biblioteca Valenciana, Generalitat Valenciana, 2000), pp. 91-111; SchWARTz, Roberta Freund: En busca de liberalidad: music and musicians in the courts of the Spanish nobility, Tesis Doctoral (Urbana, Illinois, Uni versity of Illinois at Urbana-Champaign, 2001), pp. 246-333; G ÓMEZ MunTANÉ, Maricarmen: El Cancionero de Uppsala, 2 vols. (Valencia, Biblioteca Valenciana, Generalitat Valenciana, 2003); Nelson, Bernadette: "The court of don Fernando de Aragón, Duke of Calabria in Valencia, c.1526-c.1550: music letters and the meeting of cultures", en Early Music, 32 (2004), pp. 195-222.

5 El fragmento concreto referido al duque reza como sigue: "El duque de Calabria es / con quien no ha habido re vés: / es su amiga muy amada [la Música] / «Viuda enamorada, / gentil amigo tenéis: / ¡por Dios, no le maltratéis!»”. El que se refiere al cabildo es el que encabeza este trabajo [la transcripción del texto utilizada en ambos casos ha sido tomada de FLECHA, Mateo: Las Ensaladas (Praga, 1581) con un Suplemento..., op. cit., vol. I, p. 120]. La relación que la obra de Flecha pudo tener con Valencia y con la corte del duque de Calabria es objeto especial de análisis en M uÑoz, Ferran: Mencía de Mendoza y la Viuda de Mateo Flecha (Valencia, Institució Alfons el Magnànim, Diputació deValència, 2001), pp. 26-39; Romeu Figueras, Josep: "Mateo Flecha el Viejo...", op. cit., pp. 28-34. 
viuda a la que de forma no explícita se estaría refiriendo Flecha fuese doña Mencía de Mendoza ${ }^{6}$. Esta noble de origen castellano, residía en Valencia desde 1538, donde, tras ciertas reticencias iniciales, casó en segundas nupcias con el duque de Calabria en 1541.

En el presente trabajo se aportarán, por vez primera, evidencias documentales sólidas de la estancia de Mateo Flecha el Viejo en la ciudad de Valencia, fundamentalmente como maestro de capilla de su catedral, en los dos períodos de 1526-1531? y 1539-1541. Los nue vos datos vendrán precedidos de una breve síntesis de la biografía conocida del autor hasta la actualidad. Asimismo, con el fin de conocer mejor el medio en que se desarrolló la actividad del compositor, serán posterior objeto de estudio diversos aspectos de la acti vidad musical en dicha catedral durante esta época. Finalmente, se realizarán ciertas consideraciones sobre el conte xto creativo de algunas de sus ensaladas a la luz de los nue vos datos biográficos.

\section{ESTADO ACTUAL DEL CONOCIMIENTO BIOGRÁFICO DEL AUTOR}

Sin tener en cuenta la escasa información contenida en el propio impreso praguense de Las Ensaladas, los primeros datos biográficos de Mateo Flecha el Viejo fueron aportados por François Joseph Fétis (*1784; †1871). Con anterioridad a la contribución del musicólogo belga, habían aflorado detalles de la trayectoria vital de su sobrino Mateo Flecha el Joven, en ocasiones confundido con su tío, fundamentalmente gracias a los historiadores de la orden carmelitana, en la cual profesó éste último ${ }^{7}$. Fétis nos informa por primera $\mathrm{v}$ ez de que el célebre autor de ensaladas fue un monje nacido en 1481 en Prades (actual provincia de Tarragona), discípulo en Barcelona de Joan Castelló, y que falleció a los setenta y dos años de edad en el monasterio de Poblet (actual provincia de Tarragona) ${ }^{8}$. No obstante, el autor no aporta justificación documental alguna de estos datos, que tampoco se han podido confirmar posteriormente ${ }^{9}$. Por esta razón, la información de Fétis es todavía hoy considerada como no definitiva.

6 MuÑoz, Ferran: op. cit. Doña Mencía de Mendoza (*Jadraque, 1508; †V alencia, 1554) fue hija primogénita de don Rodrigo Díaz de Vivar y Mendoza, hijo del influyente cardenal Mendoza y primer marqués de Cenete, y de doña María de fnseca y Toledo. A la muerte de su padre, en 1522, heredó el título de marquesa de Cenete. Dos años después casó en primeras nupciaøn Enrique de Nassau, vizconde deAnvers, señor de Breda y consejero del emperador Sus estancias en los Países Bajos le permitieron establecer contactos con humanistas de la talla de Joan Lluís Vives, a través de los cuales enriqueció su vasta formación cultural. A la muerte de su esposo en 1538 regresó a Valencia, donde había vivido su infancia y disponía de posesiones. Allí fue propuesta en matrimonio con el duque de Calabria, viudo de Germana de F oix desde 1536, por el propio Carlos v. Casó con el duque en 1541, instalándose así en el palacio del Real. Sólo sobrevivió cuatro años a su marido, manteniendo entonces su capilla musical y finalmente recibió sepultura junto a sus padres en la Capilla Real del convento de Santo Domingo en Valencia.

7 Más detalles sobre esta cuestión pueden se guirse en el estudio introductorio de Higinio Anglés a su edición F LECHA, Mateo: Mateo Flecha (†1553). Las Ensaladas..., op. cit., pp. 17-20, donde además se ofrece un recorrido historiográfico de los datos biográficos conocidos de ambos Flecha hasta la fecha de la publicación de Anglés (1954).

8 FÉTIS, François Joseph: Biographie universelle des musiciens et bibliographie generale de la musique . Vol. III (París, Firmin-Didot et Cie, $2^{\text {a }}$ edición, 1878), p. 270. La primera edición de esta obra está datada en 1835-1844.

9 No obstante ha sido observado por Josep Maria Gregori, que Jaume Castelló (y no Juan), antiguo cantor del ræ Juan II de Aragón, poseía a su muerte en 1493/1494 un beneficio en la iglesia del palacio del Gobernador en Barcelona. Gregori apunta su posible identificación con el personaje referido por Fétis [G REGORI, Josep Maria: "Jaume Castelló, un cantor de la capella reial de Joan II present en el setge de la Força de Girona", en Annals de l'Institut d'Estudis Gironins, vol. xxxIV (1994), p. 80]. A esto podemos ahora añadir que al mismo Jaume Castelló, presbítero, le fue otorgado el cargo de succentor (sochantre) de la 
Sin datos completamente fiables sobre su origen y formación musical, el documento conocido de mayor antigüedad que da luz sobre su trayectoria lo sitúa en la catedral de Lleida. El 17 de diciembre de 1522, Mateo Flecha es nombrado cantor y tenorista de dicha seo, indicándose en el documento de nombramiento su procedencia de la diócesis tarraconense, lo cual no contradice los datos de Fétis. Antes de que transcurriese un año, el 30 de septiembre de 1523, Flecha obtuvo el cargo de maestro de canto de la misma catedral ${ }^{10}$. No se conoce con e xactitud la duración de este magisterio, aunque no fue prolongado ya que es conocido que otro músico, el presbítero Joan Molló, recibía sólo dos años después, el 31 de octubre de 1525, el nombramiento de la catedral como maestro de canto o de capilla, que había desempeñado Flecha ${ }^{11}$.

Tras esta etapa en la ciudad de Lleida, no se dispone de nue vas noticias del músico hasta el año 1533, cuando aparece entre los testigos de las Constituciones Sinodales del Obispado de Sigüenza, publicadas en Alcalá de Henares al año siguiente ${ }^{12}$. En 1539 Mateo Flecha recibe un pago de 4375 mara vedíes de la misma catedral "d[e] lo q[ue] servio de ma[estr]o de capilla". Teniendo en cuenta que, según la nómina de la capilla de música catedralicia, en el período 15341535 el magisterio estuvo ocupado por Juan de Arentana (o Aremana) y en 1536 estaba vacante, Flecha pudo ejercerlo desde algún momento no anterior a 1535 y hasta, como máximo, $1539{ }^{13}$. En 1537, dentro de este período, el duque del Infantado don Íñigo López de Mendoza, cuya corte residía en la cercana Guadalajara, recibió de Mateo Flecha cierta música escrita que el compositor le había prometido ${ }^{14}$.

catedral de Barcelona el 4 de marzo de 1483 [ Arxiu Diocesà de Barcelona, Col-lacions, nº76, fols. 20v-21r, 22v-23r.]. En la catedral de Barcelona de esta época era elsuccentor un miembro capitular -surgido originalmente como sustituto del precentor (chantre) en sus funciones de encabezar el coro-, a quien correspondía la presentación y retribición del maestro de canto como superior jerárquico de éste. Pocas semanas después de la posesión del car go de sochantre por Jaume Castelló, el 10 de abril de 1483, es ele gido Mateu Ferrer en el puesto de maestro de canto, quien desempeñará dicho oficio hasta su muerte en 1498. Ferrer era un antiguo conocido de Castelló por haber sido su compañero en la capilla real de Aragón. Anteriormente, desde 1477, Ferrer ya desempeñaba funciones de tenorista de la catedral [G REGORI, Josep Maria: "Mateu Ferrer, tenorista i mestre de cant de la Seu de Barcelona", en Recerca musicològica, 3 (1983), pp. 7-37]. Si se tiene en cuenta que Ferrer era laico y un mero contratado para realizar estas funciones de entonación y docentes, de las que precisamente Castelló era el responsable, se reforzaría la hipótesis de Gre gori respecto a que éste pudiese ser el Castelló que menciona Fétis, e incrementaría el grado de fiabilidad de su información. Por consiguiente, si ello fuese así, se podría situar la formación musical de Flecha en el entornde la catedral de Barcelona. No obstante, como ya se ha indicado, no hay datos suficientes para confirmar definitivamente ninguno de estos extremos.

10 La transcripción del acta de nombramiento como maestro de canto fue primeramente publicada por Higinio Anglés en F lecha, Mateo: Mateo Flecha (†1553). Las Ensaladas..., op. cit. , pp. 22-23. El mismo documento, junto con el nombramiento previo de cantor, pueden encontrase en M uJAL Elías, Juan: Lérida. Historia de la música (Lleida, Dilagro, 1975), pp. 72-73.

11 La noticia de este nombramiento de Molló es dada en EECHA, Mateo: Mateo Flecha (†1553). Las Ensaladas..., op. cit, p. 23. La transcripción parcial del mencionado documento se proporciona en Mujal Elías, Juan: op. cit., p. 74.

12 Villalba, Luis: “Las «Ensaladas» de Mateo Flecha”, en La Ciudad de Dios, vol. LXII (1903), pp. 120-121.

13 Las referencias a los magisterios de capilla de Flecha y Juan de Arentana (o Aremana) en la catedral de Sigüenza proceden de Á vila Padrón, Ana y José R ogelio Buendía: "Datos sobre la música del renacimiento en la catedral de Sigüenza: Mateo Flecha «el Viejo» y Hernando de Cabezón”, en Recerca Musicologica, 1 (1981), p. 199.

14 Archivo Histórico Nacional, Nobleza, Osuna, Le. 2296, nº 6 [SchwARTZ, Roberta Freund:op. cit., p. 385]. El documento se refiere a "Mateo Flera". Maricarmen Gómez ha intentado localizar posteriormente el citado documento sin consguirlo [FLECHA, Mateo: Las Ensaladas (Praga, 1581) con un Suplemento..., op. cit., vol. I, p. 16, nota 7]. 
Parece que en 1541 el músico tuv o intención de re gresar a la catedral de Lleida como cantor a tenor de un documento conservado en esa institución y fechado el 5 de marzo de dicho año ${ }^{15}$, aunque hasta ahora se ha ignorado si llegó a cumplir este deseo.

El último empleo musical conocido del músico fue el de maestro de capilla de las inf antas doña María y doña Juana, hijas del emperador Carlos v y su primera esposa Isabel de Portugal. Poseían las infantas una pequeña corte, creada en junio de 1539 tras la muerte de su madre e inicialmente constituida en el castillo de Arévalo, que contaba con una capilla a la que pertenecieron desde el principio músicos de tecla de la talla deAntonio de Cabezón o Francisco Soto, junto a algunos cantores que habían formado parte de la capilla de la emperatriz Isabel ${ }^{16}$. La nómina del personal al servicio de las inf antas del se gundo tercio del año 1544 re vela la presencia por primera v ez de "Matteo de Frecha, maestro de la capilla", quien habría ejercido durante ese cuatrimestre completo ${ }^{17}$. Puesto que se dispone de las cuatro nóminas anteriores (año 1543 completo y primer tercio de 1544), donde no aparece su nombre, podría suponerse que su lle gada a la corte tuv o lugar al principio de ese se gundo cuatrimestre de $1544^{18}$. Flecha aparecerá en las siguientes nóminas ininterrumpidamente hasta el año 1546 inclusive $^{19}$. En el verano de este año se produjo el traslado provisional de la corte de las infantas a Guadalajara, ciudad que era residencia del duque del Infantado. Se desconoce si este desplazamiento pudo tener alguna relación con el hecho de que ya no aparezca el nombre de Flecha en una relación de cantores de la capilla de las inf antas datada en 1547, ausencia que persiste en la nómina del se gundo tercio del año $1549^{20}$.

Según la información no documentada aportada por Fétis, Mateo Flecha habría finalizado sus días en 1553 ó 1554 como monje en el Monasterio de Poblet, cenobio situado a sólo $20 \mathrm{~km}$ de su Prades natal y panteón de los re yes de Aragón ${ }^{21}$. A pesar de las dudas que suscitan los datos de Fétis, parece claro que el músico había fallecido el 16 de abril de 1557, cuando un clérigo de Valencia llamado Pere Pujol recibía licencia de la infanta doña Juana para publicar las obras de canto por él recopiladas que Mateo Flecha "quondam maestro de capilla de la Magestad, hizo"22.

15 Mujal Elías, Juan: op. cit., pp. 75-76.

16 Sobre la música en la casa de infintas, véase Anglés, Higinio: La música en la Corte de Carlosv, vol. i (Barcelona, CSIC, Instituto Español de Musicología, 1944), pp. 59-82.

17 Ibid., p. 72.

18 Ibíd., pp. 67-71. No obstante, es constatable la presencia con anterioridad-desde, al menos, el inicio de 1543- de un mozo de la capilla llamado "Mateo de Fletes" (o "Fle ytes"), a quien se le identifica con su sobrino Mateo Flecha el Jo ven. Éste formará parte de la capilla hasta 1552, año en que la infanta Juana partió hacia Portugal al desposarse con el príncipe de Portugal João Manoel. La segunda nómina de dicho año registra que Mateo de Fletes "quedó frayle francisco en Castilla" [Ibíd., p. 81].

19 Ibid., pp. 71-74.

20 Ibid., pp. 75-76 y 78.

21 Ello si interpretamos que la condición de monje de la que habla Fétis fue adquirida tras su etapa en la capilla de las infantas, ya que ninguna documentación conocida permite ni siquiera intuir dicha condición eclesiástica. El año deaflecimiento que se infiere de la información de Fétis, por la que tenía setenta y dos años en el momento de su óbito, habría que fijarlo en 1553 (como tradicionalmente se ha considerado en los estudios posteriores), aunque también es compatible con dicha edad el año de 1554.

22 Flecha, Mateo: Mateo Flecha (†1553). Las Ensaladas..., op. cit., p. 31. La e xpresión "maestro de capilla de la Magestad" plantea dudas sobre su exactitud. Parece claro que el documento se está refiriendo a Mateo Flecha el Viejo, dado que su sobrino fallece en 1604, casi medio siglo más tarde. Ahora bien, como se ha visto, se tiene constancia de su car go de maestro de capilla de las infantas pero no del emperador, u otro rey, por lo que la expresión podría ser incorrecta. No obstante, las lagunas que todavía existen en su biografía no permiten por el momento concluir en que se trate de un error. 
En definitiva, la biografía actual contrastada de Mateo Flecha se inscribe en un período inferior al cuarto de siglo (1522-1546) que, además, presenta algunos lapsos temporales notables de completa oscuridad. Los nue vos datos que ahora se presentan vienen a rellenar precisamente dos de esas lagunas.

\section{MATEO FLECHA EN LA CATEDRAL DE VALENCIA}

Los versos de la ensalada La viuda de Mateo Flecha que se han elegido como apertura a este trabajo fueron también los que incitaron a la realización de la investigación cuyos resultados ahora se presentan. A través de ellos, Flecha erige al cabildo v alenciano en la destacadísima posición de juez de la querella que la Música interpone contra el mal gusto musical. Tal privilegiada consideración de esta institución por parte del músico invitaba a pensar en la existencia de una relación cercana con la catedral y por tanto, planteaba la posibilidad de que Mateo Flecha hubiese formado parte del personal músico de esta sede metropolitana. La consulta al archivo de la seo valenciana ha confirmado plenamente este indicio, ya que se ha podido localizar al músico como maestro de su capilla en dos períodos temporales ${ }^{23}$.

\subsection{Primer período de magisterio (1526-1531?)}

E1 9 de diciembre de 1522, el virrg de Valencia don Diego Hurtado de Mendoza, conde de Mélito, logró entrar en Alzira, último reducto agermanado, tras la capitulación de esta población $\mathrm{v}$ alenciana ante las tropas reales ${ }^{24}$. Se iniciaba así una posguerra en el reino de Valencia caracterizada por la represión sobre los rebeldes -más de 800 ejecuciones públicas- y las confiscaciones de sus bienes, ejercidas de manera especialmente intensiva bajo el virreinato de Germana de Foix a partir de 1523, y que se prolongó hasta el perdón general de 1528. Aunque ello significó una fuerte presión económica sobre las clases populares, protagonistas del levantamiento, se inició un período de ficticia prosperidad económica para las clases nobles dirigentes, cuyo máximo reflejo sería la suntuosa corte de los Duques de Calabria, activa desde finales de 1526.

En este conte xto político y socio-económico en la capital del reino, se produjo el primer nombramiento de Mateo Flecha como maestro de capilla y cantor de la catedral déalencia, acordado

23 Josep Romeu ya barajó que "Flecha pudo pertenecer a la capilla de la seo", aunque posteriormente no se ha profundizado en esta posibilidad [Romeu Figueras, Josep: "Mateo Flecha el Viejo...", op. cit, p. 52].

24 El conflicto de las Germanías en el reino de Valencia fue una re vuelta de artesanos y labradores, paralela a la de las Comunidades en Castilla, contra el sistema feudal imperante. Se distinguen dos períodos. El primero, de signo moderado, se extiende de septiembre de 1519 a julio de 1520, y se caracteriza por el intento de realizar cambios dentro del sistema foral establecido. El escaso éxito de esta política propició una se gunda etapa más radical en que tuv o lugar la guerra abierta de los agermanados contra el rey y la nobleza, que finalizó en diciembre de 1522 con la victoria de estos últimos. 
por el cabildo el 6 de septiembre de $1526^{25}$. Aunque su contratación respondió a la doble condición de maestro de capilla y cantor, en los documentos del archi vo catedralicio su nombre se asocia fundamentalmente al primero de los oficios. El salario asignado al músico fue el correspondiente a seis señales de la administración catedralicia de la Almoina, retribución equivalente a 45 libras valencianas anuales ${ }^{26}$, una cantidad muy alta en relación a lo que percibían el resto de cantores ${ }^{27}$. Además, se le concedió el derecho a cobrar los percances, o ingresos por asistencia a actos extraordinarios, que para un cantor podían representar otras 15 libras anualeš ${ }^{8}$. Por tanto, por ambos conceptos Flecha v endría a percibir unas 60 libras v alencianas anuales, que equi valían a 21.287 maravedíes castellanos ${ }^{29}$. Para la catedral deValencia, éste era un trato retributivo especial que podría explicarse por el prestigio de que ya en en este momento gozase el músico, que lo hiciera merecedor

25 "Die vi mensis septembris anno a nati vitate Domini MDXXVI. Reverendi domini de capitulo in quo erant presentes Guillermus Desprats, vicarius generalis, Michael Dassio, Manfredus scri va, Gaspar Casanova, Hieronimus Ribelles, Hieronimus Carros, Andreas Castello, Ludovicus Castellvi et Franciscus Torrella, omnes canonici prebendati dicte sedis, in capitulo eiusde $\mathrm{m}$ capitulariter congre gati ad infrascripta specialiter con vocati, unanimes et concordes et nemine discrepante, acceptarunt in magistrum capelle sedis Valencie ac eciam in cantorem dicte sedis v enerabilem Matheum Fle xes, cui pro sustentatione seu pro salario assignarunt se $\mathrm{x}$ signa anno quolibet et annuatim racione predicta sibi solv enda. Nechnon concederunt percassia dicte ecclesie. Quequidem sex signa sunt tenoris sequentis: duo signa de hiis que possidet enerabilis Joannes Picart; unum signum qud possidet venerabilis Miquel Joan; aliud signum quod possidet v enerabilis (...) Assensi; aliud signum quod possidet v enerabilis Bartholomeus Vidal; aliud signum quod impresenciarum vacat per obitum nobilis Gilaberti Centelles. Quequidem signa acumulata sumam capiunt predictorum sex signorum. Ffiat large, etc. Actum Valencie, etc. “ [E-VAc, Not. Gaspar Joan Abella, n 3704,6 de septiembre de 1526]. Un acta más simplificada del mismo nombramiento puede encontrarse en E-VAc, Not. Gaspar Joan Abella, $\mathrm{n}^{\circ} 3709,6$ de septiembre de 1526. Las transcripciones que se ofrecen en este trabajo se han realizado respetando, en general, la ortografía del original. No obstante, para f acilitar la lectura, se ha lle vado a cabo la normalización del uso de mayúsculas / minúsculas, resolución de las abre viaturas, separación de palabras, acentuación se gún la normati va actual, añadido moderado de signos de puntuación, normalización de las grafías c-ç, i-j, u-v , y transcripción de "i" lar ga ("j") como "i”". En el caso de los textos valencianos se ha utilizado el punto volado $(\cdot)$ para indicar elisiones. Asimismo, se han adoptado los siguientes convenios: [ ]: reconstrucción del te xto o añadidos aclaratorios del transcriptor; [...]: te xto ilegible, pérdida del te xto u omisión de te xto intrascendente en principio o final de fragmento; (...): blanco en el texto; (sic): textual, expresión defectuosa; $<>$ : texto añadido al margen o entre lineas; [?]: duda o lectura dudosa; [xx]: folio xx. Fexto: texto tachado en el original. Las transcripciones de textos antiguos tomados de ediciones modernas se han copiado literalmente de éstas.

26 Cada señal era una pensión que equi valía en este tiempo a siete libras y media anuales en la catedral de Valencia. El dinero de cada señal procedía, normalmente, de rentas de bienes legados por una persona instituidora y su concesión, que siempre correspondía al cabildo, recaía sobre personas con necesidades económicas, preferentemente de la parentela del instituidor . No obstante, existían también señales a libre disposición del cabildo que concedía a servidores de la seo, fundamentalmente a los cantores. Las señales eran gestionadas por la administración catedralicia denominada Almoina (Limosna). El pago de las señales podía realizarlo, al menos, el procurador mayor y el bosser (bolsero) o pagador dels senyals de esta administración. El primero entregaba cantidades que cubrian períodos de $\mathrm{v}$ arios meses, preferentemente de seis o doce, mientras que el se gundo pagaba diariamente a los perceptores la ración correspondiente. Sólo el bolsero, administraba 348 señales en la catedral, de las cuale s 24 estaban a libre disposición del cabildo, como se indica al principio de las listas de perceptores de señales que elaboraba cada año [E-VAc, Almoina, Pagador dels senyals, ${ }^{\circ}$ 5614-5615].

27 En esos años, los salarios de cantor más habituales eran de dos o tres señales. Sobre las retrib uciones de los cantores de esta época, ver más abajo.

28 E-VAc, Almoina, Procura Major, no 5692, año 1526, f. 55r; Ibíd., año 1529, f. 50r.

29 La transformación de la moneda valenciana a la castellana se ha realizado suponiendo el cambio mara vedí castellano/ dinero valenciano $=34 / 23$, teniendo en cuenta que, en moneda ylenciana, 1 libra $=20$ sueldos $=240$ dineros [RLMIRENO, Lorenzo: Vocabulario del humanista (Valencia, Pedro de Huete, 1569), p. 51]. Los 21.287 maraedíes pueden parecer una cantidad bastante baja si tenemos en cuenta que muchas de las catedrales castellanas de la época ofrecían un salario de, al menos, el doble [SUÁREZPAJARES, Javier: "Dinero y honor: aspectos del magisterio de capilla en la España de Francisco Guerrero", en John Griffiths y Javier Suárez-Pajares (Eds.), Politicas y prácticas musicales en el mundo de Felipe II (Madrid, ICCMU, 2004), pp. 163-170]. No obstante, esta suma no puede considerarse como el total de los ingresos de Flecha en la catedral hasta que no se tenga un profndo conocimiento del complejo sistema retributivo de los servidores de la seo, entre los que estaban los cantores, que se basaba engran número de cajas o administraciones independientes, del cual no existe, por el momento, un estudio satisfactorio en profundidad. 
de este salario. Dicha posibilidad se v ería reforzada por el hecho de que, para poder contar con el nuevo maestro de capilla, el cabildo se decidiese a tomar la inusual y delicada decisión de pri var a cuatro de sus cantores - Juan Picart, Miquel Joan Fonat, Jaume Asensi y Bertomeu Vidal- de señales que venían disfrutando.

Su llegada a la catedral se produjo en un momento de especial aflicción por el robo de sagradas formas en la iglesia parroquial de Xilx es por parte de un numeroso grupo de moriscos rebeldes que se refugiaron en la Sierra de Espadán. El hecho, que tuv o lugar el día de la víspera de Pentecostés de 1526, trajo como consecuencia la determinación del estamento eclesiástico valenciano de celebrar a la cartujana todos los oficios, en voz baja y con vestimentas negras como en Semana Santa, así como la suspensión de la festiva procesión del Corpus Christi ${ }^{30}$.

La procedencia de Mateo Flecha no se conoce con se guridad, aunque parece v erosímil la posibilidad de que proviniese de la ciudad castellana de Cuenca. De hecho, sólo dos días después de su nombramiento, el cabildo valenciano le concedió treinta días de licencia para ausentarse de la ciudad, con el privilegio de no descontarlos a efectos del pago de las señaleș. Al cabo de otros dos días más, el músico compareció ante notario para que diera fe de que su marcha a la ciudad de Cuenca se producía ese mismo día ${ }^{32}$. Este viaje a Cuenca, por ser inmediato a su nombramiento en la catedral v alenciana, podría sugerir la vuelta a la ciudad de su anterior residencia con el objeto de recoger sus pertenencias antes de instalarse definitivamente en Valencia.

30 El motivo de este robo de sagradas formas se encuentra en la rebelión morisca que tuv o lugar como consecuencia del decreto de Carlos v, publicado en Valencia el 8 de octubre de 1525, por el cual se otor gaba validez a los bautizos forzosos de los musulmanes realizados poco antes por los agermanados y se ordenaba el bautizo de aquellos que aún no lo estuvieran. Los rebelde musulmanes, en desacuerdo con el decreto, se refugiaron en la Sierra de Espadán, situada en el interior del norte del reino, y en una incursión hacia la zona costera tuvo lugar el episodio de Xilxes, población situada a unos $45 \mathrm{~km}$ al norte deValencia. Después de diversas batallas y escaramuzas, la rebelión fue sofocada violentamente el día 19 de septiembre de 1526 por parte de las tropas reales encabezadas por el duque de $\mathrm{Se}$ gorbe y el gobernador Lluís de Ca vanilles. El ejército v encedor entró triunf almente en Valencia en día 25 de septiembre de 1526 con sones de "molts tabals e píf anos" y el acompañamiento de "los tabals y trompetes y ministrés" a la bandera portada por el Justicia Criminal de la ciudad. Sobre todo este episodio tratan las principales fuente $\mathrm{s}$ memorialísticas valencianas: C ARRERES, Salvador (Ed.): Libre de Memories de diversos sucesos e fets memorables e de coses senyalades de la ciutat e Regne de Valencia (1308-1644), vol. 2 (Valencia, Acción Bibliográfica Valenciana, 1935), pp. 806-808; Soria, Jeroni: Dietari de Jeroni Soria (Valencia, Acción Bibliográfica, 1960), pp. 101-105; M ARTí Mestre, Joaquim (Ed.): El libre de Antiquitats de la Seu de València (Valencia/Barcelona, Institut Inter-universitari de Filologia Valenciana, Publicacions de l’Abadia de Montserrat, 1994), pp. 98-112.

31 "Die VIII mensis septembris anno predicto. Re verendi domini de capitulo sedis Valencie in quo erant presentes Guillermus Desprats, vicarius generalis, Hieronimus Castella, archidiaconus Algezire, Gaspar Casano va, Manfredus Scri va, Franciscus Borja de Cardador, episcopus teanensis, Hieronimus Carros, Andreas Castello, Petrus Frigola, Ludovicus de Castellvi et Franciscus Torrella, omnes canonici prebendati dicte sedis, concederunt licenciam v enerabili Matheo Flexa per triginta dies standi extra civitate, et dentur percassia a die servitutis in antea et eciam pro viderunt quod signa sibi concessa per re verendum incipiant currere a die presenti in antea. Ffiat large, etc. Actum Valencie, etc. Testes venerabiles Joannes Congrust, presbiter, et honorabilis Joannes Riudaura, notari,Valencie habitatores.' [E-VAc, Not. Gaspar JoanAbella, no 3704, 8 de septiembre de 1526] Una versión simplificada del mismo acta puede encontrarse en E-V Ac, Not. Gaspar Joan Abella, n 3709 , 8 de septiembre de 1526.

32 "Die x septembris anno predicto. Venerabilis Matheus Fle xa, cantor sedis, requisi vit quatenus per me, notarium et scribam reverendi capituli, fieri instrumentum publicum de eius recessu ad ci vitatem conquensem prout confessi e go, dictus notarius. Ffiat large, etc. Actum Valencie, etc. Testes honorabiles P aulus de la Cuesta, notari, et Franciscus Guerau, Valencie habitatores." [E-VAc, Not. Gaspar Joan Abella, n 3704, 10 de septiembre de 1526]. Una v ersión simplificada del mismo acta especifica que la partida fue ese mismo día: "Instante domino Matheo Flexes, cantori, requisivit me, notario, quod die presenti iter duxit ad civitatem conquensem“ [E-VAc, Not. Gaspar Joan Abella, nº 3709, 10 de septiembre de 1526]. 
Sólo unos días después de su re greso a la capital v alenciana, Flecha vivió su primera procesión del Corpus Christ en esta ciudad, que excepcionalmente tuvo lugar con varios meses de retraso el 18 de Octubre de 1526, tras concluir el conflicto morisco de la sierra de Espadán y la asimilación por parte de la sociedad de la pérdida definitiva de las sagradas formas de Xilxes.

No habrían de transcurrir sino escasas semanas para que se produjera la llegada a la ciudad de los recién casados, y nombrados simul et in solidum virreyes de Valencia, Fernando de Aragón y Germana de Foix, que hicieron su entrada solemne en la capital del reino el 28 de no viembre de 1526. Tras un caluroso recibimiento en la puerta sur de la ciudad, llamada de Sant Vicent, los recién lle gados, quienes "portaren grans tabals y trompetes y ministrés d'ells matexos", acompañados de una numerosa comitiva se dirigieron en procesión a la catedral para jurar sus car gos de virre yes. A la entrada al templo por la puerta de los Apóstoles, en el interior del cual estaría seguramente esperando Flecha con su capilla, "entonaren lo Te Deum laudamus, ab lo orgue" 33 .

El 31 de diciembre de 1526, "Mateo Flecha, maestro de capilla de la seo de Valencia" redacta su primer albarán autógrafo, en el cual manifiesta haber recibido 46 sueldos y 4 dineros por tres meses y veintidós días por una señal correspondientes a "los meses de octubre, y nohembre y desiembre" ${ }^{34}$. A lo largo de 1527, el músico otor gó diversos albaranes para liquidar períodos de diferente duración, normalmente de dos o cuatro meses, correspondientes a esa señal, que cobraba a través del procurador mayor de la Almoina ${ }^{35}$. Hay que hacer notar que, aunque Flecha escribe sus albaranes preferentemente en castellano, algunos de ellos estan escritos en catalán o incluso en una mezcla de ambas lenguas. Teniendo en cuenta el prácticamente nulo uso que de esta última se hacia fuera de los territorios valencianos, catalanes o baleares, su conocimiento y utilización por parte del músico encaja bien con el origen catalán que Fétis le adjudica. El uso preferente del castellano por parte de Flecha podría explicarse por una previa asimilación lingüística, que tendría lugar en tierras de Castilla anteriormente a su llegada a Valencia, unida a la distinción que otorgaba en la Valencia de la época la utilización de la lengua que representaba el poder de la monarquía, y que se extendía entre la nobleza local.

33 CARreres, Salvador (Ed.): op. cit., pp. 808-809; Martí Mestre, Joaquim (Ed.): op. cit., pp.115-116.

34 "[Al mar gen, no autógrafo] Chantre. [En el cuerpo, autógrafo] Yo, Mateo Flecha, maestro de capilla de la seo de Valencia, e recibido del señyor Fernando Martínez, procurador de laymo yna pro por tres meses y venyte y dos días de un señyal, quarenta y seys sueldos y ocho dineros por los meses de octubre, y nohembre y desiembre. Hecho el postrero de desiembre del presente añyo DXXVII." [E-VAc, Almoina, Procura Major, no 5692, año 1526, f. 53v, 31 de diciembre de 1526]. El año indicado en el documento (1527) es el de la Nati vidad, que comienza el 25 de diciembre, por lo que se trata del año natural de $1526 . \quad$ Ver reproducción gráfica en la Figura 1.

35 El 17 de abril de 1527 cobra 2 libras, 9 sueldos y 2 dineros por los meses de enero a abril de 1527 [E-V Ac, Almoina, Procura Major, $\mathrm{n}^{\circ}$ 5692, año 1526, f. 54v]. El 6 de julio de 1527 cobra 25 sueldos y 5 dineros por los meses de mayo y junio [EVAc, Almoina, Procura Major, no 5692, año 1527, f. 83r]. El 9 de septiembre de 1527 cobra 25 sueldos "por dos meses" [Ibídem, f. 86v]. El 19 de octubre de 1527 cobra 50 sueldos "por quatro meses" [Ibídem, f. 87v]. El 29 de diciembre de 1527 cobra 2 libras y 10 sueldos, aparentemente de modo anticipado, "por quatro messes" [ Ibídem, f. 91v]. Las restantes cinco señales de su salario las percibía a través del bolsero de la Almoina. 


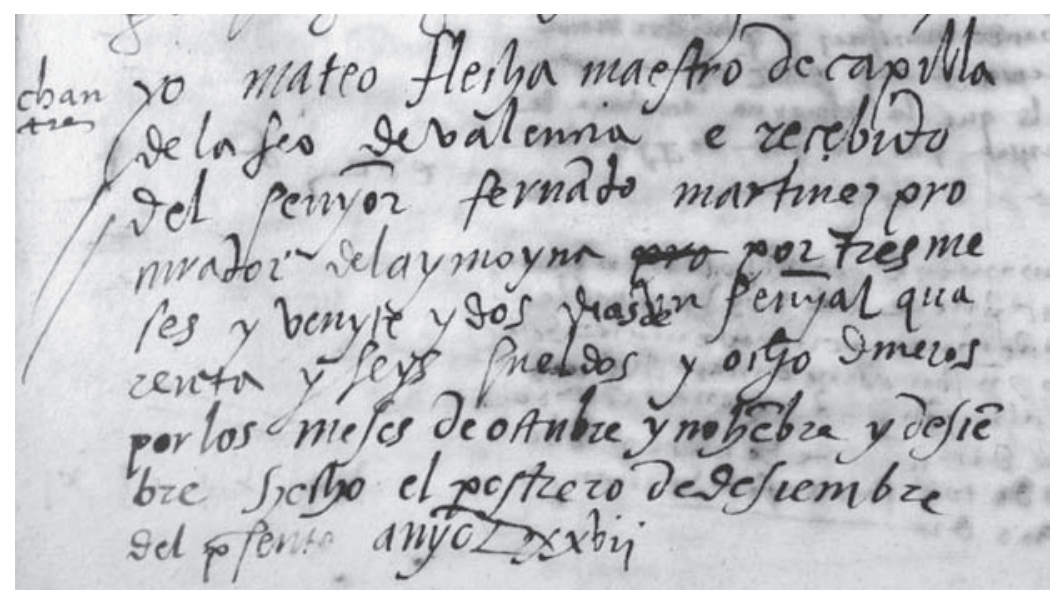

Figura 1. Primer albarán de Mateo Flecha en la catedral de Valencia (31-dic-1526) ${ }^{36}$

Entre los mecanismos que favorecieron este fenómeno lingüístico destacó el nombramiento, por parte del emperador, de nobles castellanos en altos car gos de la administración del reino v alenciano. Dos de los más relevantes fueron miembros de la influyente familia Mendoza, hijos ambos del poderoso cardenal Pedro González de Mendoza, y tuvieron un destacado papel a favor de la monarquía durante las Germanías: el conde de Mélito don Die go Hurtado de Mendoza (*Manzanares el Real, 1468?; $\uparrow$ Toledo, 1536), virrey de Valencia de 1520 a 1523, y el marqués de Cenete don Rodrigo de Mendoza y Díaz de Vivar (*Guadalajara, 1466?; †Valencia, 1523), gobernador de Valencia desde 1521 y padre de doña Mencía de Mendoza ${ }^{37}$.

E1 8 de febrero de 1527, el cabildo otor gó a Flecha la cantidad de 10 libras, aparte de su salario, sin indicar el motivo de tal concesión, las cuales fueron efecti vamente cobradas al día siguiente ${ }^{38}$. No sería la última vez que el músico recibiese una ayuda puntual de este tipo al igual que también lo hacían otros cantores de la catedral.

Durante el mes de mayo del año 1527 tuvieron lugar dos acontecimientos e xtraordinarios en la catedral. El primero acaeció el día 19 con motivo de la fiesta promovida por los frailes dominicos por la canonización de san Antonino, arzobispo de Florencia ${ }^{39}$. Tras una procesión del clero, que partió del convento de Santo Domingo, en que participó el propio duque de Calabria, acompañado de sus

36 Ver transcripción y referencia archivística en nota 34.

37 Esta acumulación de miembros de la familia castellana de los Mendoza en Valencia, en cuya línea principal se sitúa el ducado del Infantado, podría tener relación con las posibles coneiones de Flecha con este ducado que sugieren detalles como elya mencionado envío de música al duque, la proximidad de Sigüenza -donde trabajó el músico- con la corte ducal en Guadalajara o la mención al duque en la ensalada La Viuda: "¡Oh duque del Infantazgo, / "que fuiste la mejor lanza / que en Francia comía pan!" / -“iQué marido perdí, mezquina, / qué marido y qué af anador!” [Tomado de F LechA, Mateo: Las Ensaladas (Praga, 1581) con un Suplemento..., op. cit., vol. I, p. 120]. Si se confirmase la procedencia de Cuenca de Flecha, podría unirse a éstos el marqués de Cañete don Diego Hurtado de Mendoza (*1490; †1542), residente en esta ciudad como Guarda Mayor de Cuenca.

38 E-VAc, Not. Gaspar Joan Abella, no 3705, 8 de febrero de 1527; Ibídem, 9 de febrero de 1527.

39 La canonización había tenido lugar en Roma en 1523 por el papa Adriano vI. 
ministriles, trompetas y atabales, se celebró en la catedral una misa obispal de san Antonino, que fue cantada por "los chantres de la Seu, y los del dit viry in simul" mayo, llegó a Valencia la notícia del nacimiento del príncipe Felipe, futuro rey Felipe II, que se había producido tres días antes. A las 9 de la noche del día 24 llegaron los virreyes a la catedral para asistir al Te Deum por el feliz alumbramiento. El Libre de Antiquitats de la catedral reseña que "digueren lo Te Deum entorn de la Seu ab los ministrés, trompetes y tabals dels senyors vireys, y lo orgue y los chantres de la Seu y dels vireys"41. Así pues, el contacto musical de Mateo Flecha con los músicos de la capilla del duque de Calabria, se guramente mucho más intenso de lo que nos han transmitido las crónicas de la época en estos dos acontecimientos e xtraordinarios, parece un hecho suficientemente probado.

El 5 de febrero de 1528, el cabildo decidió otogar 15 libras anuales adicionales al maestro Flecha, a percibir en este caso excepcionalmente a través de la administración de la Fàbrica u Obra ${ }^{42}$, ya que ningún otro miembro de la capilla de cantores recibía ingresos fijos de esta administración. Este gesto fue una demostración del interés de la catedral en mejorar las retribuciones del músico.

Sólo tres meses más tarde, la ciudad de Valencia vivió uno de sus momentos más rele vantes del siglo XVI, con la llegada del emperador Carlos v para cumplir su obligación del juramento de los fueros del reino. Su entrada en Valencia, celebrada con claro sabor medieval, se produjo el día 3 de mayo de 1528.

Al portal de Quart, per hon entrà, féu la Ciutat hun casalici larch, fins a l'abeurador, de tela pintada al romano, ab un cel enmig que s'obria, per hon a vallaren tres deputats vestits com a àngels. Lo hu ab hun camís de cetí groch a la dreta, ab les claus; l'altre ab hun camís de cetí blau, a la esquerre, ab lo ceptre, qui avallaren cantant ab hun artifici fins a l'emperador, cantant ${ }^{43}$.

Los diputats, o niños cantores, que protagonizaron el e vento fueron servidores de la catedral, según nos aclara el dietarista Jeroni Soria, por lo que la participación de Flecha en su adiestramiento, e incluso en la composición de la música que se cantó, parece bastante probable ${ }^{44}$. El clero de la ciudad, en procesión por un recorrido engalanado con elementos triunf ales de naturaleza efímera, acompañó al monarca hasta la catedral.

40 "Acabada la professó, los escolans de les parròquies arrimaren les creus entorn de l'altar major , e digueren la missa bisbal de sent Anthonini, ut in comuni unius confessoris pontifices, ab les oracions pròpies. E cantaren la missa los chantres de la Seu, y los del dit virey in simul, e sermonà lo reverent mestre Loís Castellolí, de Preÿcadors, famosíssim preÿcador, y docte y bon religiós.” [Martí Mestre, Joaquim (Ed.): op. cit., pp.117-118].

41 Ibid., pp. 118-119.

42 "Prefati reverendi domini de capitulo pro viderunt quod, de cetero, per procuratorem f abrice seu suboperarium dentur quindecim libre annuatin (sic) pro salario dando v enerabili Matheo Flexa, cantori. Fiat large, etc. Actum Valencie, etc.” [E-VAc, Not. Gaspar Joan Abella, no 3706, 5 de febrero de 1528].

43 Martí Mestre, Joaquim (Ed.): op. cit., p. 122

44 "Diumenge a 3 de maig, 1528, depres dinar, entre 4 e 5 hores, entra la Magestat del Emperador don Carlos Rey nostre per lo portal de Quart perque v enia de Madrit de xant alli la Emperatris pren yada de 7 mesos, se gons se deya, de que·s feu gran reçebiment. On feren un portal de tela al portal de Quart, pintat al roma, fins al abeurador, e dos chichs dels Deputats de la Seu revestits com angels devallaven del sel del dit portal: la hu ab huna corona e laltre les claus del portal e devallava cantant." [SoRIA, Jeroni: op. cit., p. 119]. Como puede observarse, Soria indica que sólo fueron dos los ángeles. 
E més, provehí lo reverent Capítol que al portal del Campanar, per hon era concertat entrar, que fessen alguna cosa que paregués bé. E mestre Bernat Cetina, ar genter de la Seu, féu una in venció molt bella al dit portal, que tenia tota la longeta ab quatre nayes, tot guarnit de brocat y tapeceria, en les quals nayes staven ministrés y cantors, y lo deputats qui havien servit al portal ${ }^{45}$.

Aunque no se especifica en las fuentes memorialísticas analizadas cuáles fueron los cantores que estaban en las galerías de este portal, lo más lógico es pensar que fuesen los de la propia catedral, con Mateo Flecha al frente, con la más que probable añadidura de los del duque de Calabria con sus ministriles, de cuya actuación conjunta el año anterior en e ventos de menor trascendencia ya se ha dado noticia. La procesión entró en el templo mientras el clero cantaba el Te Deum acompañado del órgano ${ }^{46}$. Tras una ceremonia de benedicción, Carlos v abandonó la catedral por la puerta de los Apóstoles o puerta oeste, poniéndose fin al acto.

El domingo 10 de mayo, el emperador acudió de nuevo a la seo a escuchar misa. En este caso, se sabe que fueron los propios cantores de Carlos v los encargados de poner la música al acto litúrgico ${ }^{47}$. Esta misa constituye el primer momento, conocido hasta ahora, en que Mateo Flecha pudo escuchar la prestigiosa capilla de cantores flamencos del emperador, con cuyos af amados músicos, entre los que se encontraban compositores como Nicolás Gombert o Nicolás P ayen, tendría oportunidad de intercambiar ideas y repertorio.

La ceremonia de juramento de los fueros se produjo finalmente el día 16 de mayo en la misma catedral.

Vingué lo emperador entre quatre y cinch hores, y los ministrés y trompetes sta ven dins lo cor. Y a l'entrar per la Seu per la porta dels Apòstols, sonaren les trompetes, y aprés los ministrés, fins que fon seÿt en sa cadira ${ }^{48}$.

Tras el juramento de los fueros por parte del emperador, los tres brazos o estamentos del reino -eclesiástico, militar y real-juraron fidelidad al monarca. Al finalizar el acto, Carlosv volvió al palacio del Real, acompañado de las trompetas y ministriles, donde Germana de F oix había or ganizado un sarao con más de doscientas damas que se prolongó hasta las dos de la madrugada ${ }^{49}$. El 20 de mayo, el emperador partió de Valencia, acompañado del duque de Calabria, hacia la villa de Monzón, donde había convocado cortes a los reinos hispánicos de la Corona de Aragón.

Una semana más tarde de la partida de la comiti va imperial, el cabildo ordenó, sin moti var, el pago de siete libras y media a Flecha, al parecer de modo puntual y e xtraordinario. El esfuerzo del

45 Martí Mestre, Joaquim (Ed.): op. cit., pp. 122-123. Jeroni Soria nos especifica que "la Seu avia fet hun portal a la porta de la Seu de brocats e sedes ab les armes del Emperador, molt rich.” [SoRIA, Jeroni: op. cit., p. 120].

46 Martí Mestre, Joaquim (Ed.): op. cit., p. 126. También es muy posible la participación de los ministriles municipales, ya que entre sus obligaciones estaba "sonar en qualse vol entrada e recepcio del S. M t de son primogenit y persones reals y de qualsevol altre gran que la ciutat e xira a rebre." [Ruiz DE LiHory, José: La Música en Valencia. Diccionario Biográfico y crítico (Valencia, Establecimiento tipográfico Doménech, 1903), p. 136].

47 Ibid., p. 129.

48 Ibid., p. 132.

49 Ibíd., p. 134; Soria, Jeroni: op. cit., pp. 122-123; CARreres, Salvador (Ed.): op. cit., pp. 813-814. 
cabildo por mejorar los ingresos del músico parece que no contaba con unanimidad en el seno de este órgano rector, ya que el canónigo Gaspar Casanova se opuso claramente a este otorgamiento ${ }^{50}$.

A finales de 1528, el 18 de diciembre, Flecha recibió 5 libras del procurador mayor de la Almoina, siendo la mitad de dicha cantidad en calidad de anticipadas. P ara responder de dicho adelanto económico frente a un posible incumplimiento, actuó como fiador el cantor de la catedral Gonzalo de Espinosa.A su vez, Mateo Flecha actuaba como fiador de Espinosa por la cantidad de 5 libras que se le anticipaban a éste ${ }^{51}$.

El 2 de agosto de 1529, lle gó a Valencia la noticia de que el emperador se había embarcado en Barcelona, rumbo a Géno va. El mismo día, después del oficio de completas, se hizo un procesión de plegarias alrededor de la catedral para rogar por el buen viaje del soberano. Con el mismo fin, se decidió, entre otras determinaciones, que se leyese el salterio y la letanía de noche y de día en el altar mayor por capellanes de la catedral hasta su lle gada a puerto. Aunque finalmente sólo se le yó durante el día, esta situación extraordinaria se prolongó hasta que Carlosv desembarcó en Génova a principios de septiembre. El 10 de septiembre se cantó elTe Deum en la catedral en acción de gracias, y al día siguiente se hizo una procesión a la capilla de la virgen María de Gracia, con la asistencia del duque de Calabria ${ }^{52}$.

El 15 de septiembre del mismo año, el cabildo decidió permutar la señal instituida por la familia noble Centelles que el maestro Flecha poseía desde su nombramiento en 1526, por otra que estaba a disposición del cabildo sin que ello supusiese merma económica alguna en su salario ${ }^{53}$.

Una resolución capitular fechada el 1 de enero de 1530, concede a su maestro de capilla una cantidad extraordinaria de 6 ducados. Asimismo, en la misma se determina que, puesto que por asuntos

50 "Reverendi domini de capitulo sedis Valentie providerunt quod abstrahantur ab arca comune septem libre cum dimidia ad opus dandi et solv endi venerabili domino Matheo Flexa, cantori. Fiat large, etc. Actum Valentie, etc."; "Reverendus et nobilis dominis Gaspar Cassano va, canonicus predictus, protestatus fuit quod non consentiebat, ymmo dissentiebat, in pro visione facta per reverendum capitulum de super designata abstraendi peccuniam ab arca ad opus solvendi et dandi dicto Flecha" [E-VAc, Not. Gaspar Joan Abella, nº 3706, 28 de mayo de 1528].

51 Los compromisos autógrafos de ambos fiadores, que figuran tras los correspondientes albaranes del perceptor, rezan como sigue: "Yo, mossén Espinosa, salgo fiador por cincuenta sueldos que v os, mossén Pere Villar, aveys dado anticipados a mosén Flexa, prometiendo sacarlos libre yndemne. Fecho año e día sobredicho."; "Yo, mosén Frexa, salgo fiador por sinco libras que vos, mosen Pere Villar, aveys dado anticipadas a mosén Espinosa, prometiendo sacaros libre y endempne. Hecho an yo e día sobredicho" [E-VAc, Almoina, Procura Major , n 5692, año 1528, f. 71v]. Durante el año 1528, además, pueden encontrarse documentos que justifican cobros de Mateo Flecha de su salario ordinario en: E-V Ac, Not. Gaspar Joan Abella, $\mathrm{n}^{\circ} 3706,25$ de mayo de 1528; E-VAc, Almoina, Procura Major, n 5692, año 1528, f. 67r.

52 "A dos de agost del any mil DXXvIII" vingué nova que·l emperador se era embarcat en Barcelona per passar en laYtalia, y lo reverent capítol provehí se legís lo psaltiri e letania e fessen altres pregaries com se acostuma alt en lo altar maior de la seu, y fossen pagats nou diners a cascun capella per cascuna stació, y foren quatre capellans en cascuna stacio. Començaren a gè dilluns dit dia fins a cinch de setembre aprés se güent" [E-VAc, Fàbrica, no 1488, año 1529, f. 38r]. "En la Seu le gien quatre capellans a cascuna stació, y dura va cascuna stació tres hores. Y donaven a cascun capellà nou diners, pagà-u lo sots-obrer per pro visio del reverent Capítol. Legiren de dia y no de nit, y durà fins que vingué lo correu com era desembarcat en Gèno va. Y arribà lo correu a X de setembre, DXXVIII. Y cantàrem Te Deum. Y l'endemà fèrem professó a la Verge Maria de Gràcia, en la qual anà lo duch de Calàbria, virey.” [MARTí Mestre, Joaquim (Ed.): op. cit., p.136].

53 " [...] revocaren lo senyal de Flexa com sia de Centeles, sia restituhït com a घgat. Provehiren lo procurador major pague a Flexa consemblant quantitat" [E-VAc, Not. Gaspar JoanAbella, $n^{\circ}$ 3710, 15 de septiembre de 1529].A finales de ese mismo año, Flecha extiende albarán: "Yo, mosén Frexa, maestro de capilla, atorgo aver recebido de vos, señor mosén Luis Vives, procurador mayor de l'Almoina, quatro libras y tretze sueldos y nueve dineros per resta d'un senyal que·l capítol a proveído que lo paguasse la procura mayor, la qual començà a pagar a XVI de setembre any MDXXVIIII. Y perque és veritat fas lo present de ma mà. Fet dia e any damunt dit [26 de diciembre de 1529]" [E-V Ac, Almoina, Procura Major, no 5692, año 1529, f. 73v]. Otros documentos justificativos de cobros de Flecha en libros de cuentas del año 1529 se encuentran en: E-VAc, Fàbrica, no 1488, año 1529, f. 30r; E-VAc, Almoina, Procura Major, no 5692, año 1529, ff. 48v, 69r. 
propios el músico tenía previsto salir de la ciudad con licencia del cabildo, si algún pagador de la catedral le adelantase alguna cantidad económica y se diese el caso de que se produjese su óbito en el ínterin, se computasen todos los días hasta su muerte aunque en ese momento Flecha no estuviese sirviendo ${ }^{54}$. Desconocemos el moti vo de la ausencia que el músico planeaba, así como adónde pensaba dirigirse. Incluso no sabemos con se guridad si finalmente realizó ese viaje y, en ese caso, cuál fue su duración. No obstante, puede darnos algún dato el hecho del pago a Flecha, de 6 libras y 6 sueldos $\mathrm{v}$ alencianos -cantidad equivalente a los 6 ducados castellanos concedidos- en fecha de 3 mayo de 1530, estando el músico presente en la ciudad ${ }^{55}$. Ello significa que, si se produjo ese viaje, no se prolongó más de esos, aproximadamente, cuatro meses que median entre la resolución capitular y el cobro de Flecha.

Durante el verano de 1530, la peste castigó duramente a la ciudad deValencia. Ante tal situación, muchos miembros de la nobleza y de la alta jerarquía eclesiástica huyeron a otros lugares para pægatese del contagio. La catedral quedó tan huérf ana de dirigentes, que el arzobispo confió la re gencia de la vicaria general de la archidiócesis, así como todas las pecunias catedralicias, al subsacristán Pere Martí, quien ni siquiera era canónigo ${ }^{56}$.

En la parte final de 1530, Mateo Flecha debió de obtener la colación en una de las dos plazas de sochantre de la catedral, se gún se desprende de un acuerdo capitular fechado en 14 de diciembre de 1530. El ejercicio de este oficio, sin embargo, parece que no le impidió continuar con su empleo de maestro de capilla, pese a la disminución del número de señales del salario que cobraba por el magisterio, que quedaron reducidas a cuatro, a cobrar a tra vés del bolsero ${ }^{57}$. Quince días después, el cabildo confirmó la cantidad de cuatro señales, aunque estableció una modificación consistente en encargar al procurador mayor de la Almoina el pago de una de ellas, permaneciendo las otras tres a cargo del bolsero ${ }^{58}$. Económicamente, el nue vo nombramiento debió de suponer una nue va mejora

54 "Reverendi domini de capitulo in quo erant presentes Guillermus Desprats, vicarius generalis, Hieron ymus Castellar, archidiaconus Algezire, Michael Dassio, Gaspar Casanova, Bernardus Munyos, Franciscus Borja de Cardador episcopus elanensis, Hieronymus Carros, Andreas Castello, Petrus Frigola, Michael Hieron ymus Vich et Julianus Cezaris de Barci, omnes canonici prebendati, per via subvencionis providerunt quod venerabilis Ludovicus Vives, presbiter in sede beneficiatus, ut procurator major dicte elemosine det et solv at venerabili (...) Flexa, magistro capelle dicte sedis, se x ducatos et eciam pro viderunt quod, si dic tus Flexa reperire potuerit quod de redditibus sibi assignatis aliquis procurator bistraxrit et interim morietur non obstante nonservierit dictus Flexa, sibi ponatur in compotum, e x eo quod recedit a presenti ci vitate pro ne gociis propiis ipsius Fle xa de concensu et licencia reverendi capituli. Fiat large, etc. Actum Valencie, etc." [E-VAc, Not. Gaspar Joan Abella, no 3706, 1 de enero de 1530].

55 E-VAc, Not. Gaspar Joan Abella, n 3710, 3 de mayo de 1530.

56 Martí Mestre, Joaquim (Ed.): op. cit., p. 137.

57 "Reverendi de capitulo. Del dia que fonc collat la sotscabiscolaya $($ sic $)<[\ldots]$ xv lliures de la obra $>$ a mossèn Flexa sia pagat de tot lo que rebrà com a mestre, $\mathrm{y}$ del dia que li es pro vehït ensà no reba sinó quatre sen yals com a mestre ab los matin es que sta sien dades, y que pague lo bocer quatre senyals" [E-VAc, Not. Gaspar Joan Abella, n³710, 15 de diciembre de 1530]. La fecha exacta de la colación del oficio de sochantre se desconoce con exactitud, aunque es posible que tuviese lugar el día 14 ó 15 de octubre de 1530 ya que, en un albarán autógrafo fechado el 21 de enero de 1531, escasas semanas más tarde de la mencionada orden de liquidación de su salario hasta el día de dicha colación, Flecha reconoce haber recibido seis libras, diecinue ve sueldos y dos dineros por dos señales en el período desde mayo hasta el 14 de octubre. "Y o, mossèn Frexa, mestre de capella de la seu de València, atorgue aver rebut de vos, señor mossèn Gaspar Mançana, com a procurador de LAlmoyna, sis liures y denou sous y dos diners VIL XVIIIS II, y són per dos señyals que·m f a dita procura, y só pagat desde <mes $>$ mag fins a quatorze de octubre de l'an y MDXXX. Y perquè és veritat fas lo present de mà mia. Fet a XXI de giner any MDXXXI." [E-VAc, Almoina, Procura Major, ${ }^{\circ}$ 5692, año 1530, f. 75r]. Ver reproducción gráfica en Figura 2.

58 "Prefati re verendi domini de capitulo concesserunt quatuor signa $\mathrm{v}$ enerabili domino Fle xa solv endo hoc videlicet modus: quod procurator major elemosine solv at unum et alia tria solv at bocerius elemosine [...]" [E-V Ac, Not. Gaspar Joan 
al poder sumar las retrib uciones de sochantre con las cuatro señales que mantenía como maestro de capilla. Por otra parte, en el terreno musical, el hecho de reunir en su persona los dos oficios pondría en sus manos toda la responsabilidad de la práctica $v$ ocal en la catedral: canto llano y polifónico. Asimismo, la obtención de la plaza de sochantre, como oficio fijo de la catedral, mejoraba su posición honorífica en la comunidad catedralicia.

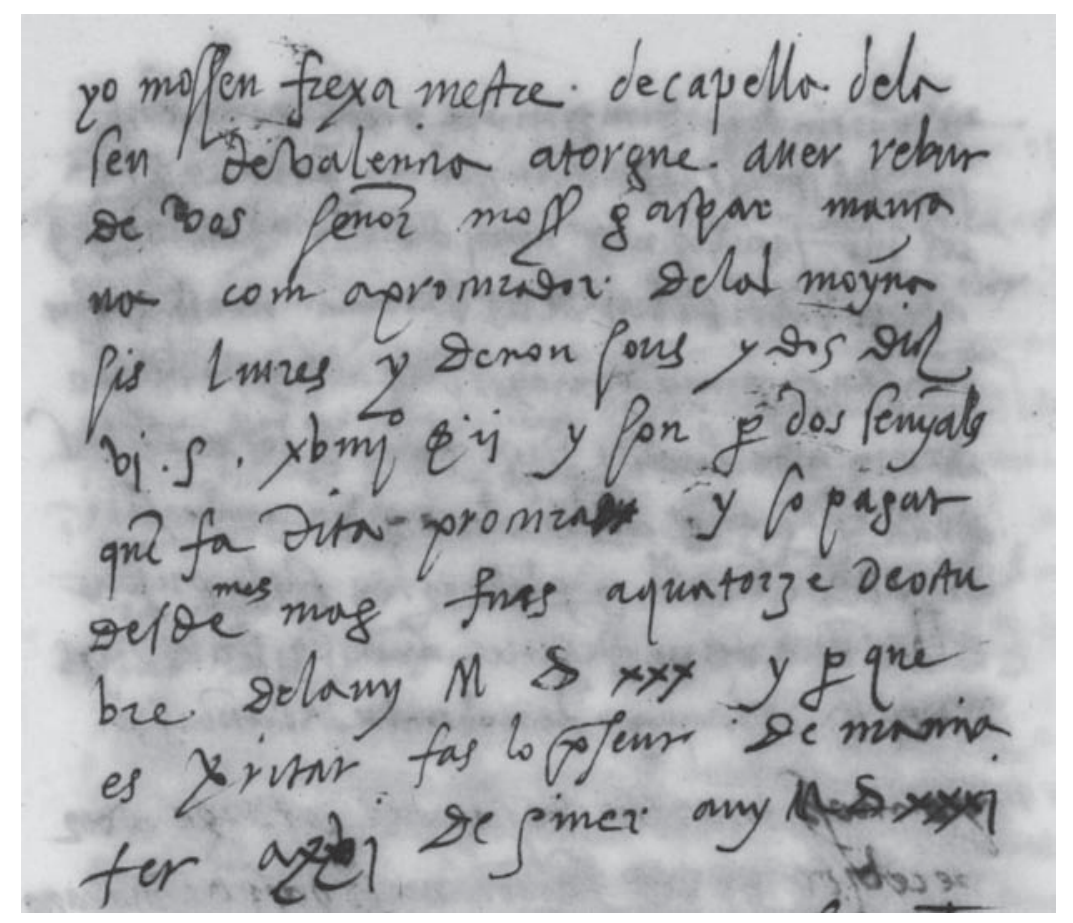

Figura 2. Albarán de Mateo Flecha en la catedral de Valencia (21-ene-1531) ${ }^{59}$

A pesar de todos los esfuerzos del cabildo vlenciano para mejorar la situación económica ystatus de su maestro de capilla, poco tiempo iba a seuir contando con sus servicios. De hecho, el postrer documento encontrado que testifica la presencia de Mateo Flecha en la catedral deValencia en este primer período está fechado sólo seis meses después, el 3 de julio de 1531. Se trata de un apunte del notario capitular en el que se indica que el maestro había firmado recibo de haber percibido 11 libras y 10 dineros de la administración de la Fàbrica como prorrata de la cantidad que recibía anualmente a través de ésta (15 libras) ${ }^{60}$.

\footnotetext{
Abella, $\mathrm{n}^{\circ}$ 3706, 30 de diciembre de 1530]; "Re verendi domini de capitulo pro viderunt quod boceris elemosine solv at venerabili Flexa tria signa sibi concessa [...]" [Ibíd.]. En los libros de cuentas de 1530 se registran otros pagos a Flecha en: E-VAc, Fàbrica, $n^{\circ}$ 1489, año 1530, f. 26v; E-VAc, Not. Gaspar Joan Abella, n 3710, 23 de junio de 1531.

59 Ver transcripción y referencia archivística en nota 57.

60 "Matheus Flexa afermavit apocam reverendo capitulo [...] de XI lliures, 10 diners de porrata de la obra" [E-VAc, Not. Gaspar Joan Abella, $n^{\circ} 3710,3$ de julio de 1531].
} 
Se desconoce la fecha exacta de su partida así como su siguiente destino. El hecho de no contar con documentos de cobro posteriores invita a pensar que la partida pudo ser inmediata. En todo caso, y con toda seguridad, no permaneció en la catedral valenciana más allá del 30 de abril de $1532^{61}$. Como ya es conocido, en 1533 Flecha estaba presente en la catedral de Sigüenza, lugar que bien pudo haber sido su siguiente destino.

\section{2. ÍNTERIN (1531?-1539)}

Una anotación de pago sin fechar en un libro de cuentas correspondiente al ejercicio administradi catedralicio de 1532 -de 1 de mayo de 1532 a 30 de abril de 1533- hace mención a "mossèn Cristofol, chantre e mestre de la capella" " ${ }^{2}$. El documento se refería a Cristòfol Sabater, quien ejercía de cantor en la catedral desde el 1 de octubre de $1514{ }^{63}$. Las anteriores y posteriores referencias documentales a este músico aparecen con el tratamiento exclusivo de cantor, lo cual hace pensar que esta anotación no reflejase la e xistencia de un nombramiento formal de maestro en Sabater , aunque tal v ez sí una situación funcional de hecho. De una u otra manera, este documento parece dejar claro que Mateo Flecha ya no estaba presente en la catedral de Valencia el 30 de abril de 1533, día final del ejercicio de 1532.

Por otra parte, el cantor Jaume Asensi fue nombrado maestro de canto de la catedral el 17 de octubre de 1533, con la única obligación explícita de enseñar el arte del canto a los capellanes de la seo y a los familiares de los canónigos ${ }^{64}$. Las obligaciones específicas que se detallan en el nombramiento, en correspondencia con el bajo salario que se le concede, nos muestran que sus funciones se circunscribieron exclusivamente al ámbito de la enseñanza musical del clero catedralicio en general, que se centraba en el canto llano. Las clases eran impartidas por Asensi en la denominada casa de l'Almoina d'en Conesa, edificio sede de la administración de la Almoina, separado de la parte norte de la catedral por la denominada plaça de la Llenya. Se registran pagos a Asensi por este concepto sólo hasta el año administrativo $1534^{65}$.

En el cabildo v alenciano volvió a sonar el nombre de Mateo Flecha durante su ausencia. En efecto, en una escritura notarial de 1 de octubre de 1535 se pone de manifiesto que Flecha había

61 En el libro de administración del bolsero de la Almoina del año administrativo eclesiástico de 1531 (de 1 de mayo de 1531 a 30 de abril de 1532), aparece la indicación añadida de que "anà-se'n en lo present any" bajo su nombre [E-VAc, Almoina, Pagador dels senyals, $\mathrm{n}^{\circ} 5614$, año 1531, s.f.].

62 E-VAc, Almoina, Procura Major, n' 5693 , año 1532, f. 50v.

63 E-VAc, Not. Felip Abella, no 3699, 1 de octubre de 1514.

64 "Dicti domini de capitulo eligerunt in magistrum canti eclesie Valentiae Jacobum Assensi, qui tenetur graciose docere artem canti cappellanis eclesie Valencie, et eciam familiaribus canonicorum concedendo eidem per salario VII L 10s ex fabrice. Fiat large, etc. Actum in capitulo, etc." [E-VAc, Not. Gaspar Joan Abella, n 3707, 17 de octubre de 1533].

65 "Ítem, paguí al reverent mossèn Assensi, quatre lliures en paga rata de aquelles set lliures e deu sòlidos que la fàbrica li fa per lo mostrar de cant en la Almoina d'en Conesa, segons consta ab albara per ell fet a cartes." [E-VAc, Fàbrica, no 1489 , año 1534 , f. 23v]. 
rechazado un puesto en la catedral después de ser admitido y que, en consecuencia, en su lugar se nombraba a otra persona, cuyo nombre no figura en el acta, a quien se le adjudicaba un salario de dos señales, así como el derecho a percibir los percances. Asimismo, el cabildo concedió a "dicto cantori novo acceptato" una cantidad económica puntual de 1 ducado de oro y 4 reales castellanos ${ }^{\S 6}$. Esta última resolución permite conocer el nombre del cantorel "tenor castellà del duquat" Francisco Pérez, quien aparece en los libros de cuentas de la Almoina por primera v ez ese mismo año, con explícita mención del otogamiento de salario y ayuda indicadoş?. Sin poseer más datos para dilucidar a qué ducado se estaba refiriendo el escribano al señalar la procedencia de Pérez, se plantean dos posibilidades razonables. Por proximidad, hay que considerar que se pudiese tratar de un cantor castellano del duque de Calabria, aunque el desconocimiento de relaciones e xhaustivas de cantores de su capilla anteriores a 1546 impide contrastar esta posibilidad por el momento. No obstante, hay que recordar que el duque de Calabria era un duque sin señorío sobre un territorio ducal, sin ducado, lo cual le restaría $v$ erosimilitud a esta hipótesis. Una se gunda posibilidad razonable establecería conexión con el ducado del Infantado, cuya titularidad ostentaba en ese momento el ya mencionado don Íñigo López de Mendoza, quien disponía de una af amada capilla musical. En este caso, podría haber sido el propio Flecha, a quien se le localiza cercano a la corte ducal puntualmente en 1533 y $1539^{68}$, quien proporcionara su propio sustituto a la catedral de Valencia en la persona de Francisco Pérez. Desgraciadamente tampoco e xisten datos disponibles que permitan v alorar esta se gunda posibilidad $^{69}$.

De cualquier modo, parece claro que Mateo Flecha fue inicialmente admitido como cantor en la catedral de Valencia, lo que sugiere la existencia de un acuerdo previo, aunque poco después rechazó el puesto, hecho que queda reflejado en el acta de 1 de octubre de 1535 . Se desconocen más detalles de este episodio.

\subsection{SEgundo Período de MAGisterio (1539-1541)}

El 27 de marzo de 1538, el papa Pablo III, otorgó a Jorge de Austria (*1504?; †1557) el arzobispado de Valencia, que había quedado vacante por muerte de su anterior posesor Erardo de la Marca $(\dagger 1538)$. El

66 "Dictis die et anno, dicti reverendi domini de capitulo providerunt quod admissio per eis facta de persona Mathei Flexa ex eo quia renuit acceptare officium sibi concessum revocatur et loco eius concedunt dictum officium (...) cum duobus signis et percassis cotidianis, diurnis et dicturnis ( sic). Xpistoforus Frigola non concensit. Fiat lar ge. Actum in capitulo, etc."; "Dictis die et anno, dicti reverendi domini de capitulo providerunt quod dicto cantori novo acceptato tradatur unum ducatum auri et quatuor regalia castellania venerabili Joanni Ridaura, ex pecunie procure majoris elemossine. Actum in capitulo, etc. [E-VAcp, Not. Pere Ferrando, $\mathrm{n}^{\mathrm{o}}$ 309, 1 de octubre de 1535].

67 E-VAc, Almoina, Procura Major, no 5694, año 1535, f. 101v.

68 Como ya se ha indicado, en 1533 y 1539 se tiene la constancia de que el músico estaba localizado en la catedral de Sigüenza, muy cercano a la corte del duque en Guadalajara, con el que además es conocido que se carteó en 1537. 394.

69 Se ha tratado sobre la música en la corte de este duque del Inf antado en Schwartz, Roberta Freund: op. cit., pp. 378- 
nombramiento había sido propuesto por el propio emperador Carlos $\mathrm{v}$, quien era su sobrino ${ }^{70}$. El nue vo arzobispo llegó a su sede el 12 de enero de 1539 y , sólo escasos días después, el 1 de febrero, el cabildo valenciano otorgó el cargo de maestro de capilla a Mateo Flecha, que comenzó así su segundo período de magisterio en la catedral de Valencia ${ }^{71}$. No hay datos para determinar si el nombramento del músico pudo tener relación con la arribada del nuevo arzobispo, quien acaso pudiese haber recibido consejo del entorno de su sobrino Carlos v para recibir a Flecha, aunque la proximidad temporal entre ambos sucesos permite, al menos, no descartar esta posibilidad. Lo que parece más probable es que el lugar de procedencia fuese Sigüenza, donde en el mismo año 1539 todavía recibía un pago, como ya se ha mencionado.

El salario que se le asignó en esta ocasión, como maestro pero no como cantor ${ }^{72}$, fue bastante inferior al que tuvo en su primer período al frente de la capilla. Una única señal y el derecho a cobrar las distribuciones que percibían los beneficiados -que podían suponer unas 15 libras anuales- fue todo lo concedido, muy por debajo de las seis señales y los percances que recibió al obtener su primer nombramiento en 1526. Desconocemos si pudo haber influido en este inferior salario el rechazo que el músico había hecho cuatro años antes de la oferta de la catedral.

Flecha traía en esta ocasión un criado llamado Martín Ruiz que fue admitido en la catedral sólo dos meses después, el 27 de marzo, como cantor tiple con un salario de 25 libras anuales ${ }^{73}$. Sin duda, se trataba de un cantor tiple adulto, por los tratamientos de "v enerable" y "mossèn" que recibe en la documentación catedralicia, además de que los menores eran simplemente llamados diputats en la

70 Jorge de Austria era hijo natural del emperador del Sacro Imperio Romano Germánico Maximiliano I de Austria, padre de Felipe el Hermoso, progenitor a su vez de Carlos v. Fue arzobispo de Valencia hasta 1544, un año después de haber sido nombrado príncipe-obispo de Lieja, cargo éste último que desempeñaría hasta su muerte. Fue el primer pontífice de Valencia que residió en su diócesis desde Hug de Lupià (1397-1427).

71 "Die prima mensis februari anno a nati vitate domini MDXXXVIII. Re verendi domini canonici et capitulum sancte metropolitane sedis Valencie, in quo erant presentes Michael Pereci de Miedes, archidiaconus muri veteris, vicarius generalis, Michael Dassio, Manfredus Scri va, Baltazar Rosell, Hieronimus Ribelles, Hieronimus Carros, Ludo vicus Castellvi, Franciscus Torrella, Gaspar Joannes, Honoratus Pellicer Xpistoforus Frigola, Bartholomeus Parent et Melchior de Cassanova, omnes canonici prebendati dicte sedis, precedente con vocacione facta per v enerabilem Baptistam P astor, presbiterum subdiaconum dicte sedis, prout ipse retulit et michi, notario publico infrascripto, fecit se die externa [hesterna] convocasse ad presentem diem specialiter ad infrascripta per agenda et capitulo congregato capitulum facientes et repressentantes confidentes ad modum de ydoneitate, pericia, industria et habilitate venerabili Mathei Flexa, idcirco scienter, etc., eligerunt et acceptarunt prelibatum enerabilem Matheum Flexa in magistrum capelle in choro dicte sedis, constituerunt eidem pro salario unum signum solv endum per procuratorem majorem elemossine dicte sedis, et etiam pro viderunt quod dentur eidem v enerabili Matheo Flexa omnis distribuciones prout beneficiatis dicte sedis soluti sunt, dati, et nichilominus pro viderunt quod procurator denarii minuti det et solv at anno quolibet procurato ri duplarum et anniversariorum dicte sedis quindecim llibras, monete rgalium Valentie, in recompensam et pro subrencione dictarum distribucionum. Fiat large. Actum Valencie, etc.” [E-VAc, Not. Gaspar Joan Abella, n 3616, 1 de febrero de 1539; otra v ersión simplificada del mismo nombramiento: Ibíd., $\mathrm{n}^{\circ} 3713,1$ de febrero de 1539].

72 No obstante, aunque en sus albaranes autógrafos Flecha siempre se califica como "maestro de capilla", las anotaciones del administrador de la Almoina indican "cantor" al lado de su nombre en todos los asientos de pago de este período [E-V Ac, Almoina, Procura Major, n 5695, año 1539, ff. 49v, 50v, 51r; Ibíd., año 1541, f. 50v].

73 Los miembros del cabildo "concordes et nemine discrepante confidentes ad modum de ydoneitate, pericia, industria et habilitate venerabilis Martini Roys, scienter, etc., eligerunt et acceptarunt prelibatum venerabilem Marti Roys en tiple in choro dicte sedis" [E-V Ac, Not. Gaspar Joan Abella, no 3616, 27 de marzo de 1539]. En la misma sesión "unanimes et concordes, et nemine discrepante nomini eorum propiis scienter, etc., promisserunt et obligarunt eidem dare et solv ere venerabili Martino Rois $<$ licet absenti, etc. Stipulante, etc. $>$ anno quolibet viginti quinque llibras monete re galium Valencie pro salario quamquidem promissionem obligacionem fecerunt [...]" [ Ibíd.]. La condición de criado de Flecha, señalada en la e xpresión "mosèn Martín, criat de Flexa", aparece en una anotación de pago en los libros del procurador mayor de la Almoina, que se hacía cargo del pago de su salario [E-VAc, Almoina, Procura Major, n 5695, año 1539, f. 67v]. 
catedral valenciana. Su origen era se guramente castellano por utilizar e xclusivamente esta lengua en sus albaranes autógrafos y, además, por haber llegado acompañando a Flecha desde Castilla ${ }^{74}$.

El 1 de mayo de 1539 moría de parto la emperatriz Isabel de Portugal, esposa de Carlos v, y la noticia llegaba a Valencia el día 10 del mismo mes. Las campanas de la seo hicieron toques fúnebres durante ocho días, hasta que fue concluido el monumento funerario que se construyó en la catedral. Dicho capell ardent, que representaba la tumba real, estaba guarnecido de ricos tejidos ne gros e iluminado por antorchas y cirios amarillos, que en número de ochocientos también se disponían hacia las puertas del templo. El día 16 el cabildo or ganizó un desfile fúnebre y en los dos días sucesi vos hicieron lo propio las instituciones del reino ( Diputació de la Generalitat ) y ciudad. El día 18 se celebró la misa fúnebre en la catedral con la ausencia del arzobispo, quien estaba en la corte ${ }^{75}$.

E1 19 de diciembre de 1539, el cabildo concedió una cantidad e xtraordinaria y puntual a Flecha de 15 libras que, al parecer, el músico percibió tres meses después ${ }^{76}$. Una nueva concesión, fechada un año más tarde, consolidó esa misma cantidad mediante la asignación de dos nuæas señales a pagar por el procurador mayor de la Almoina ${ }^{77}$.

El otoño de 1540 estuv o marcado en la ciudad de Valencia por una gran a venida del río Turia, producida entre les tres y las cuatro de la tarde del día 7 de octubre, que desbordó su cauce natural e inundó algunos de los edificios más ribereños, como el palacio del Real o los monasterios de la Trinidad y del Remedio. El cabildo hizo sonar las campanas y los miembros de la catedral, así como las autoridades civiles, salieron en procesión con la custodia y el Lignum Crucis hasta el puente de la Trinidad, donde se hicieron plegarias durante una hora. Al regreso, ordenaron que se salmease ante el altar mayor hasta que la crecida menguó ${ }^{78}$.

Un año más tarde se repitieron las plgarias en la catedral, en esta ocasión con motvio de la partida del emperador desde Génova, con una flota preparada para tomar Argel a los turcos. Las lecturas y el canto de los salmos ante el Lignum Crucis y la imagen de la Virgen en el altar mayor, se combinaron con gran número de procesiones a di versos templos de la ciudad que tenían a la catedral como punto de inicio y conclusión. Esta situación de e xcepción se mantuv o desde que se conoció la salida de Carlos v, el 26 de septiembre de 1541, hasta la lle gada de la notícia de la adv ersa noticia del fracaso de la expedición imperial, que aconteció el 10 de no viembre, la cual moti vó una procesión de tintes fúnebres y una misa rezada a la cartujana ${ }^{79}$.

74 Los albaranes autógrafos de Ruiz localizados en el período de se gundo magisterio de Mateu Flecha se encuentran en E-VAc, Almoina, Procura Major, no 5695 , año 1539, ff. 67v, 75r; Ibíd., año 1541, ff. 72v, 85v, 88r, 92r.

75 Martí Mestre, Joaquim (Ed.): op. cit., pp. 153-154.

76 E-VAc, Not. Gaspar Joan Abella, n 3713, 19 de diciembre de 1539; E-V Ac, Almoina, Procura Major, nº 5695, año 1539, f. 51r; Ibíd., f. 125r, 29 de marzo de 1540. Otros pagos a Flecha durante el año 1539 están reflejados en: Ibíd., año 1538, ff. 54v, 115r; Ibíd., año 1539, ff. 49v, 67v.

77 "[...] providerunt que a Flexa sien dats xv lliures per dos senyals [...]" [E-VAc, Not. Gaspar Joan Abella, no 3713,17 de diciembre de 1540]. Durante el año 1540 consta consta otro pago a Flecha en E-V Ac, Almoina, Procura Major, $n^{\circ} 5695$, año 1539 , ff. 50v, 81r.

78 Martí Mestre, Joaquim (Ed.): op. cit., pp.155-156.

79 Ibid., pp. 156-159. 
En este tiempo, con una catedral sumida en contínuas súplicas, Mateo Flecha escribió su último albarán autógrafo al procurador mayor de la Almoina, por el que reconoció haber recibido la cantidad de 6 libras, 18 sueldos y 10 dineros "por lo que e servido asta que me partí a Castilla", fechado el 23 de octubre de $1541^{80}$. Sólo unos meses antes, el músico había demostrado su intención de vlver a la catedral de Lleida, como ya se ha indicado. Este intento infructuoso de salida hacia Lleida y su salida definitiva de la catedral valentina hacia Castilla, sólo meses después, parecen sugerir que el músico no se encontraba excesivamente satisfecho en Valencia, acaso por no ver colmadas sus expectativas económicas en la seo, que nunca estuvieron a la altura de las percibidas durante su primer período de magisterio.

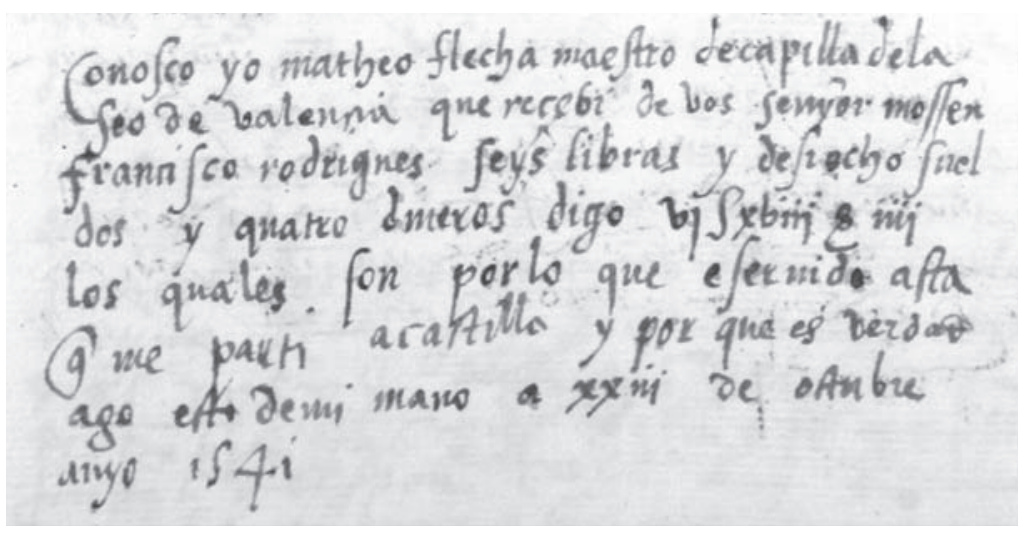

Figura 3. Albarán de Mateo Flecha en la catedral de Valencia (23-oct-1541) ${ }^{81}$

La expresión utilizada por Flecha en este albarán denota una partida inmediata de la ciudad de Valencia. Considerando que el músico aparece por primera $\mathrm{v}$ ez en las nóminas de la capilla de las infantas doña María y doña Juana en el se gundo tercio de 1544, su siguiente destino conocido, se deduciría de este nuevo documento que Flecha habría servido en algún otro lugar de Castilla antes de acceder al magisterio de esta capilla, ubicada entonces en el castillo de Arévalo, a $55 \mathrm{~km}$ de Ávila.

La marcha de Flecha fue se guramente el moti vo que produjo el nombramiento de un nue vo maestro de canto llano para enseñar a los beneficiados, que en esta ocasión recayó en el presbítero Miquel Sanç el 28 de no viembre de 1541, por cuyo trabajo le fue asignada una señal a pagar por el procurador mayor de la Almoina ${ }^{82}$.

80 "Conosco yo, Matheo Flecha, maestro de capilla de la seo de Valencia, que recebí de v os, señyor mossèn Francisco Rodrigues, seys libras y desiocho sueldos y quatro dineros, digo VIL XVIIIS IIII, los quales son por lo que e servido asta que me partí a Castilla. Y porque es verdad, ago esto de mi mano axxiII de octubre, anyo 1541" [E-VAc, Almoina, Procura Major, $\mathrm{n}^{\circ} 5695$, año 1541, f. 79r]. La anotación del administrador referente al mismo pago: Ibíd., f. 50v.

81 Ver transcripción y referencia archivística en nota 80.

82 E-VAc, Not. Gaspar Joan Abella, n 3713, 28 de noviembre de 1541. En un albarán autógrafo del 14 de julio de 1542 reconoce haber recibido 3 libras, 2 sueldos y 6 dineros "per part de aquell sen yal que los sen yors canonges me an pro veit per a mostrar cant pla als venerables beneficiats de la dita seu" [E-VAc, Almoina, Procura Major, nº 5695, año 1541, f. 93r]. 


\section{CONSIDERACIONES SOBREALGUNAS CIRCUNSTANCIAS PERSONALES DE MATEO FLECHA}

El patronímico del famoso compositor de ensaladas se halla en la documentación hasta el presente conocida bajo di versas v ariantes ortográficas, entre las que pueden citarse Flecha, Frecha, Fletes, Fleytes, Flexa o Fletxa ${ }^{83}$. Los nuevos documentos valencianos presentan semejantes vacilaciones ${ }^{84}$. Sin embargo, se introduce ahora un nuevo elemento del que no se disponía, la documentación autógraf del propio músico, que debe de tener un valor especial para explicar este fenómeno.

La Tabla 1 refleja el número de v eces que aparece cada una de estas formas ortográficas en los documentos localizados en Valencia, distinguiendo cada uno de los dos períodos de magisterio, por un lado, y entre aquellos que son autógrafos del músico y los escritos por otros escribanos, por otro. De su análisis, se pueden extraer algunas conclusiones:

\begin{tabular}{|c|c|c|c|c|}
\hline \multirow{2}{*}{ Forma } & \multicolumn{2}{|c|}{ Período 1526-1531 } & \multicolumn{2}{c|}{ Período 1539-1541 } \\
\cline { 2 - 5 } & Autógrafos & No autógrafos & Autógrafos & No autógrafos \\
\hline Flecha & 2 & 1 & 5 & 1 \\
\hline Flexa-Fflexa & & 29 & & 3 \\
\hline Flexas & & 1 & & 1 \\
\hline Flexes-Fflexes & & 9 & & \\
\hline Flex & & 1 & & \\
\hline Frexa & 9 & & & \\
\hline
\end{tabular}

Tabla 1: Formas del patronímico de Mateo Flecha en la nueva documentación valenciana

- La forma "Fle xa" es la preferida por los escribanos v alencianos en ambos períodos catedralicios del músico, coincidiendo en ello con la documentación de Lleida, del mismo dominio lingüístico valenciano/catalán. La forma "Flecha", mayoritaria en la documentación castellana o castellanizante hasta ahora conocida, parece ser la adaptación de la "x" v alenciana/catalana, cuyo fonema no existe en castellano, por la "ch", cuyo sonido sería más familiar a los hablantes de esta lengua ${ }^{85}$.

- La forma que el propio músico utiliza mayoritariamente en sus albaranes del primer período es "Frexa". Las únicas dos reces que no lo hace, en que emplea la castellanizada "Flecha", se corresponden con los dos primeros albaranes del período, mientras que escribe los restantes nue ve como "Fre xa".

83 Las cuatro primeras aparecen en documentación de la capilla de las inf antas [FLECHA, Mateo: Mateo Flecha (†1553). Las Ensaladas..., op. cit., pp. 67-76], mientras que las dos últimas se utilizan en la catedral de Lleida [MuJAL Elías, Juan: op. cit., pp. 72-76].

84 Las formas encontradas en Valencia son Flecha, Flexa, Fflexa, Flexas, Flexes, Fflexes, Flex y Frexa.

85 La forma ortográfica según la normativa actual en valenciano/catalán de esta " $x$ " interv ocálica se corresponde con el dígrafo "ix", que se pronuncia con los fonemas [j] o [j]], dependiendo del territorio. Son ejemplos que contienen dicho dígrafo las palabras caixa, baixa o així, que se solían encontrar durante el siglo xvI escritas como caxa, baxa o axi. 
El empleo de la forma castellana, se justificaría por su procedencia inmediata de tierras de Castilla, probablemente de Cuenca, como se ha visto. Por otra parte, la sustitución de la letra "l" por la "r", intercambio de consonantes líquidas muy frecuente en las dos lenguas, nos re vela un apellido común en Cataluña, que siguiendo la normati va ortográfica actual toma la forma "Freixa". A la vuelta de su nueva etapa en Castilla (1531?-1539), el músico ya sólo hará uso de la forma castellana "Flecha", por la que ya debía de ser conocido en la península.

- El resto de formas ortográficas que aparecen en la documentación no son nunca utilizadas por el propio músico, por lo que su existencia únicamente demuestra el grado de desconocimiento que del apellido tenían los diferentes escribanos que las usaron.

Por tanto, todo apunta a que fuese "Freixa", escrito en la ortografía actual, el original patronímico del músico, mientras que la forma "Flecha" habría sgindo como resultado de dos cambios consonánticos, uno fruto de la castellanización ("ch" por " $x$ ”) y otro como fenómeno lingüístico habitual en ambas lenguas ("l" por "r").

Un se gundo aspecto que toda vía nos es desconocido es el de su ordenación eclesiástica. Los diferentes escribanos valencianos se refieren sistemáticamente a él anteponiendo el tratamiento "mossèn" a su nombre, que era utilizado en la época para distinguir a personas de alta catgoría social, entre los que se encontraban los eclesiásticos, independientemente de sus órdenes. Mucho más se concreta en uno de los documentos localizados en la seo, datado en 1528, donde se le reconoce la ordenación presbiteral ${ }^{86}$. Por tanto, salvo error en este documento, se puede concluir que Mateo Flecha era sacerdote ordenado ya en 1528.

Los nue vos documentos $\mathrm{v}$ alencianos también dan luz en relación con la posibilidad, apuntada por Ferran Muñoz, de que el clérigo "Michaelis Fleixa", a quien se otgra un beneficio en la parroquia de san Lorenzo de Valencia el 18 de septiembre de 1537, pudiese tratarse en realidad del compositor Mateo Flecha ${ }^{87}$. Esta posibilidad se ha de descartar rotundamente. De hecho, Miquel Flexa no sólo fue beneficiado de esa parroquia valenciana, sino también cantor tenor de la catedral de Valencia, cuya admisión en este of icio se produjo el 3 de agosto de 1538, aproximadamente medio año antes del se gundo nombramiento como maestro de capilla de Mateo Flecha, con quien coincidió en todo su se gundo magisterio ${ }^{88}$. Mantuv o el of icio hasta su muerte, que aconteció en 1592 tras una dilatadísima trayectoria en la catedral. En su testamento ordenó una obra pía en la seo f inanciada con la venta de su casa e instituyó como heredero universal a Onofre Fle xa, cordelero habitante de Castellfort, población situada en el

86 A través de dicho documento, "Matheus Fle xa, presbiter cantor sedis Valencie" reconoce haber recibido 7 libras y 10 sueldos del procurador mayor de la Almoina en concepto de salario [E-V Ac, Not. Gaspar Joan Abella, n 3706, 28 de mayo de 1528].

87 MuÑoz, Ferran: op. cit., p. 65.

88 Los miembros del cabildo presentes "unanimes et concordes et nemine discrepante, e $\mathrm{x}$ eo cum certis scienciis atque gratis providerunt quod Michael Fle xa admitatur in cantorem capelle eclesiae v alentinae cum duob us signis solv endis terminis ordinariis per bolserium elemosine" [E-V Acp, Not. Pere Ferrando, $n^{\circ}$ 309, 3 de agosto de 1538]. El patronímico de este cantor sufrió en los documentos análoga diversidad ortográfica a la del autor de ensaladas. 
norte del reino $\mathrm{v}$ alenciano ${ }^{89}$. La duda razonable que ahora cabe plantearse $\mathrm{v}$ ersaría sobre una posible relación familiar del cantor con el maestro de capilla y por consiguiente, también con el sobrino de este último, Mateo Flecha, el Joven. Los historiadores de la orden carmelitana sitúan a este, entonces, joven fraile en el convento del Carmen de Valencia a partir de 1552, donde, en todo caso, no permaneció hasta más allá de 1564, año en que ya está localizado en Italia ${ }^{90}$. Si esta hipotética relación familiar resultase cierta, Miquel Fle xa podría haber sido un personaje clave para que se produjese la estancia en Valencia de Mateo Flecha, el Jo ven, ya que ambos coincidieron en esta ciudad durante todo el período que supuestamente pasó el fraile carmelita en la capital del reino valenciano, cuando su tío, el maestro de capilla, hacía ya más de diez años que había dejado la catedral.

\section{ALGUNOS ASPECTOS DE LAACTIVIDAD MUSICAL EN LA CATEDRAL DEVALENCIA (1526-1541)}

\subsection{Músicos al Servicio de la Catedral}

\section{Personal rector y docente}

La música estuvo presente en la litugia católica desde sus orígenes. El canto monódico de los distintos oficios debía de ser conocido y practicado por todo el clero. P ara encabezar el coro, compuesto por toda la comunidad eclesiástica de un templo, se designó entre sus miembros al praecentor. Con el crecimiento de las comunidades eclesiásticas, este oficio ele vó su cate goría jerárquica. En la catedral de Valencia, el praecentor -denominado cabiscol en valenciano/catalán y chantre en castellano- era una de las siete dignidades capitulares en la época de Mateo Flecha. Como tal dignidad, tenía ciertas preeminencias sobre los veinticuatro canónigos, procedentes de las familias más influyentes de la ciudad, que completaban el cabildo $^{91}$. Sin derecho a formar parte de este órgano rector, la comunidad catedralicia contaba también con un colectivo de más de doscientos beneficiados, rentistas de bienes normalmente legados por particulares, además de otros eclesiásticos que servían los oficios de altar y cor8². Debido al gran tamaño de la comunidad

89 Su testamento, otorgado ante el notario Salvador Peres en fecha 22 de septiembre de 1587, y publicado por el notario Lluís Joan Ca valler el 16 de junio de 1592, no ha podido localizarse [E-V Ac, n 2284, 8 de agosto de 1592]. Tenía su casa en la calle de la Xerea, parroquia de san Esteban [E-V Ac, $\mathrm{n}^{\circ}$ 5079, ff. 497r-498r]. Su sobrino y heredero, recibió la liquidación d el salario de su tío, quien, al parecer murió, el 13 de junio de 1592. "Yo, Andreu Martines, fas se com (...) Flexa, en nom de ereu del quondam mossén Miquel Flexa, son oncle, atorga aver rebut del senyor mossén Aierdi set lliures, tres sous, y quatre per un mes y tretse dies que visqué lo dit son oncle, de son salari de la tersa que comensà lo primer de maig 1592. Y per no saber aquel scriure, fiu jo, sobredit Andreu Martines, de sa voluntat, lo present a 27 de octubre de 1592" [E-V Ac, Almoina, Procura Major, ${ }^{\circ}$ 5694, año 1592 , f. 62r].

90 Flecha, Mateo: Mateo Flecha (†1553). Las Ensaladas ..., op. cit., p. 37.

91 El resto de dignidades eran el deán, sacristán, arcediano mayor, arcediano de Morvedre (actual Sagunt), arcediano de Alzira y arcediano de Xàtiva. También existían doce preposituras, una por cada mes del año, que solían recaer en canónigos.

92 Sobre la evolución de los miembros de la catedral puede consultarse SANCHIS y Sivera, José: La Catedral de Valencia. Guía histórica y artística (Valencia, Imprenta de Francisco Vives Mora, 1909), pp. 13-55. 
y el volumen de rentas que administraba la seo, el cabiscol había delegado sus funciones musicales en dos sochantres -cargo denominado en valenciano/catalán sots-cabiscol y en latín succentor-, que ya existían como oficios no canonicales desde antes de $1334^{3}$. Los sochantres eran, pues, dos músicos que poseían los oficios fijos de la catedral cuya responsabilidad, delegada en ellos por el chantre, consistía comúnmente en encabezar el canto llano del coro clerical desde el punto de vista organizativo y práctico.

Para el canto polifónico e xistían otros responsables. El cabildo nombraba anualmente entre sus canónigos a un encargado de la dirección de las escuelas de canto de la catedral, a quien, cuando era mencionado en relación a funciones de dicho car go, se le denominaba "maestro de capilla" ${ }^{94}$. No obstante, atendiendo a que el canónigo responsable no era normalmente un e xperto en música, el cabildo valenciano también nombraba a un músico profesional, que era el que previsiblemente ejercía el magisterio del canto polifónico y su enseñanza, también llamado "maestro de capilla" ${ }^{95}$. Aunque pueda parecer que el uso de una misma nomenclatura pudiese ser origen de confusión, en la época la distinción no debía de presentar e xcesivos problemas puesto que el primero siempre era un miembro capitular, mientras que el segundo no tenía ese alto rango. De todos modos, muy raramente aparece el canónigo con la denominación de "maestro de capilla", que solía estar reservada al músico96.

Los oficios de sochantre y maestro de capilla, con áreas de responsabilidad diferenciadas en el canto llano y canto polifónico, respecti vamente, también solían estar desempeñados por personas diferentes. Sin embargo, en este período hubo una e xcepción en la persona, precisamente, de Mateo Flecha quien, siendo maestro de capilla, en 1530 debió de recibir la colación en plaza de sochantre sin que aparentemente dejase su empleo anterior, como ya se ha señalado.

Mientras que los sochantres eran oficios fijos de la catedral, cuyas plazas se cubrían cuando había alguna baja, no parece que fuese imprescindible para el cabildo tener en todo momento un maestro de capilla nombrado como tal. En el período de estudio 1526-1541, únicamente se han localizado los dos nombramientos de Flecha (1526 y 1539). Durante el ínterin de sus dos magisterios no aparecen en los libros de la administración de la Almoina, otros músicos con tal título con la e xcepción de Cristòfol Sabater, en un documento aislado del que ya se ha tratado.

93 "Succentoribus vero dicte sedis, qui sunt duo [...]" [Pérez de Miedes, Miquel: Constitutiones sive ordinationes insignis metropolitanae ecclesiae valentianae (Valencia, Ioannes Me y, 1546), f. 1v]. Sobre las funciones del chantre y el sochantre castellanos durante el siglo Xvi puede consultarse, por ejemplo,Asensio, Juan Carlos: "El canto llano en la España del sigloxvi. De olvidos y protagonismos", en John Griffiths y Javier Suárez-Pajares (Eds.): Políticas y prácticas musicales en el mundo de Felipe II (Madrid, ICCMU, 2004), pp. 271-276

94 El espíritu de esta costumbre aún se refleja en los "Estatutos de la Catedral de Valencia" de 1952 cuando se indica que "El Maestro de Capilla de esta Santa Iglesia o Director de la Escuela de Canto lo es un Sr . Canónigo que se nombra por turno seguido de antigüedad en el Capítulo P ascual [...]" [citado en C Liment BARBER, Josep: "La capilla de música de la Catedral de Valencia”, en Anuario Musical, XXXVII (1982), p. 57]

95 No se han localizado por el momento documentos de esta época o anteriores que detallen sus funciones concretas en la catedral de Valencia.

96 Como ejemplo de uno de estos infrecuentes casos, en el año eclesiástico 1541 el canónigo nombrado en la regencia de las escuelas de canto era Honorat Pellicer [E-VAc, Not. Gaspar Joan Abella, nº 3713, 22 de abril de 1541]. El 20 de julio de 1541, el cabildo le encarga que, en ejercicio de su oficio encomendado de maestro de capilla, haga que se paguen las deudas a un cierto cantor. "Comisserunt domino canonico Pellicer, ut magistro capelle, que faça pagat a (...), cantor, per les terces y faça pagat lo que li serà degut" [Ibíd., 20 de julio de 1541]. 
No obstante, tras ambas salidas de Flecha de la catedral, se tiene constancia del nombramiento de sendos maestros cuya única función era la de enseñar canto llano a los beneficiados de la catedral o a los familiares de los canónigos. Tales fueron los casos ya mencionados de Jaume Asensi en 1533 y Miquel Sanç en 1541. Otro maestro, el denominado mestre dels diputats (maestro de los infantillos), era el encargado del cuidado y enseñanza de los más pequeños miembros de la comunidad.

\section{Infantillos}

En el período de estudio, la catedral disponía de cuatro inf antillos a su servicio, que en la zona valenciana recibían el nombre de diputats o deputats ${ }^{97}$. La información hallada sobre los diputats de la catedral durante esta época no ha sido ab undante y ello ha impedido a veriguar los nombres de todos ellos. Su número de cuatro queda perfectamente reflejado, entre otros documentos, en la consueta de la catedral de 1527, confeccionada precisamente durante el magisterio de Mateo Flecha ${ }^{98}$. Por ejemplo, cuando se trata de las capas a v estir el primer día de las letanías, se dice que "per als quatre deputats les quatre capetes verdes millors" "En el oficio de vísperas de la fiesta de laAscensión, prevé que se den "als quatre deputats capetes blanques de les millors”100. En referencia a épocas posteriores, José Climent hace mención a la existencia de seis diputats ${ }^{101}$, por lo cual hay que asumir que su número se amplió de cuatro hasta seis con posterioridad a los magisterios de Flecha. Cada uno de los cuatro infintillos tenía derecho a una señal como contraprestación a su trabajo, cuya ración diaria percibían del bolsero de la Almoina ${ }^{102}$.

Sus funciones tenían relación con el canto, pero también con la asistencia en la litur gia, en una proporción que es difícil de determinar . La consueta de 1527 los menciona en di versas ocasiones. La mayor parte de las reces podemos encontrarlos formando parte de ceremonias procesionales en el interior de la catedral -normalmente por parejas o los cuatro juntos- o colaborando en los oficios portando objetos como candelabros o cirios de di versos colores ${ }^{103}$. Muy poca información transmite, en cambio, la consueta sobre sus cometidos musicales que, sin duda, tuvieron, como ya ha podido constatarse por el canto que ofrecieron en la ceremonia de la entrada real de Carlos v en 1528. No obstante, la misma consueta sí que prescribe que el Jueves Santo "en mig de la professo van dos deputats ab capetes verdes sense canalobre y les capetes de domàs cantant o redeptor" ${ }^{104}$, o que al v olver la procesión de Domingo de Ramos “canten los f adrins a la finestra de la sala del sotsagristà, dins una gelosia” ${ }^{105}$. En

97 En ocasiones, también se les puede encontrar en la época como fadrins diputats o, simplemente, fadrins.

98 E-VAc, $n^{\circ} 70$. Agradezco a Xa vier Serra Estellés, quien se encuentra actualmente preparando la edición y estudio de dicho valioso manuscrito, su ayuda en la localización de referencias musicales en éste, así como en la resolución de algunos problemas de transcripción.

99 E-VAc, no 70, 62v.

100 Ibíd., $\mathrm{n}^{\circ} 70,65 \mathrm{r}$.

101 Climent Barber, Josep: op. cit., p. 59.

102 La e xistencia de estas cuatro señales reserv adas a los inf antillos queda reflejada en las listas de los receptores de señales que el pagador elaboraba anualmente [E-VAc, Almoina, Pagador dels senyals, $\mathrm{n}^{\circ}$ 5614-5615]. $72 \mathrm{r}, 87 \mathrm{v}$.

103 Algunos ejemplos pueden encontrarse en E-VAc, $n^{\circ} 70$, ff. 23v, 24v, 27r, 33r, 44v, 55v, 56r, 57v, 62v, 64v, 65r, 69r,

104 Ibid., f. 44v

105 Ibid., f. $37 \mathrm{v}$. 
todo caso, estos testimonios refieren una participación musical puntual y en solitario de los inf antillos, seguramente en canto monódico, sin inte grarse en el canto polifónico con el resto de cantores adultos. De tal integración no se ha podido encontrar ninguna referencia explícita en el período estudiado ${ }^{106}$.

A pesar de ello, se puede inferir que durante su período de diputats, los niños adquirían una formación musical. En efecto, el cabildo prolongaba el derecho a recibir una señal a una parte de los antiguos diputats con el fin de que prosiguieran sus estudios, algunos de los cuales en poco tiempo pasaban a convertirse en cantores de la seo. Onofre Ferrando "qui solia ser diputat" recibió una señal de la Almoina "per a estudiar" el 29 de enero de $1529{ }^{107}$. No obstante, sus funciones en esta época como cantor se traslucen de las anotaciones marginales "cantor" que aparecen junto a los asientos de pago ${ }^{108}$. El 30 de diciembre de 1530, el cabildo le otogó otra señal por mismo motivo de estudios ${ }^{109}$. A partir de 1531, ya no aparece ninguna mención a su antigua condición de infantillo, sino únicamente a la de cantor. Otro caso semejante fue el de Pere Sanchis, diputat, a quien fue adjudicada una señal el 20 de octubre de $1530{ }^{110}$. A partir de 1531 aparece percibiendo su salario en calidad e xclusiva de cantor. Ambos, formados como inf antillos durante el primer período de magisterio de Mateo Flecha, sirvieron su oficio de cantor el resto del período de estudio, lle gando incluso a ordenarse de presbíteros $^{111}$. Un tercer infantillo promovido a cantor en esta época de Flecha fue Joan Macià, quien por primera vez recibió la calificación de cantor contralto en el año eclesiástico 1531, después de un año de cobrar como antiguo inf antillo. Permaneció en ese oficio hasta $1533^{112}$. Por contra, Joan Vich, hijo del cocinero del maestre de la Orden de Montesa, a pesar de recibir una señal en 1538 "com a diputat que hera", desapareció al año siguiente sin que, ni siquiera, alcanzase el grado de cantor"13. Otro caso fue el de Joan de Soria, conocido como "Johanot", quien disponía de una señal del procurador mayor de la Almoina en el año eclesiástico de 1533 todavía siendo infantillo, sin saber ni siquiera escribir ${ }^{114}$. En 1536 seguía percibiéndola aunque ya había dejado de ser diputat ${ }^{115}$. Tampoco accedió a la consideración de cantor.

106 A una conclusión semejante llega Luis Robledo para el caso de los irafitillos de la capilla de Feliper, cuya participación musical considera que, se gún parece, quedaba restringida a interv enciones puntuales no polifónicas, como el canto de algunas lecciones, antífonas y v ersos. [R obledo Estaire, Luis: “ II. Espacios P alatinos. 2. La capilla. 2.2. Composición, estructuras y evolución”, en José Martínez Millán y Santiago Fernández Conti (Eds.):La monarquía de Felipe II: la casa del Rey. Vol. I (Madrid, Fundación MAPFRE-Tavera, 2005), p. 176].

107 E-VAc, Almoina, Procura Major, no 5692, año 1528, f. 81r.

108 E-VAc, Almoina, Procura Major, n 5692, año 1529, ff. 49r, 50r.

109 "[...] necnon Onofrio Ferrando unum signum seu septem libras cum dimidia ex eo fuit diputatus ad opus studendi ut moris est" [E-VAc, Not. Gaspar Joan Abella, $\mathrm{n}^{\circ}$ 3706, 30 de diciembre de 1530].

110 E-VAc, Almoina, Procura Major, n 5692, año 1530, f. 78r.

111 La primera referencia a ambos como presbíteros es del año eclesiástico 1539 [E-V Ac, Almoina, Procura Major, $\mathrm{n}^{\circ}$ 5695, año 1539, ff. 51r, 73v].

112 E-VAc, Almoina, Procura Major, no 5692, año 1530, f. 54v; Ibíd., nº5693, año 1531, f. 143v; Ibíd., año 1532, f. 50v; Ibíd, año 1533 , f. $48 \mathrm{v}$.

113 E-VAc, Almoina, Procura Major, n 5695, año 1538, ff. 53v, 103v.

114 E-VAc, Almoina, Procura Major, n 5693 , año 1533, ff. 47r, 99v; Ibíd., año 1534, ff. 78v, 115v; Ibid., n 5694, año 1535 , ff. $61 \mathrm{v}, 112 \mathrm{r}$.

115 En la documentación aparece "Johanot, diputat olym" o "Janot, onim deputat" [E-V Ac, Almoina, Procura Major, $\mathrm{n}^{\circ}$ 5694, año 1536 , ff. 49v, 80r]. 
Los infantillos estaban bajo la tutela del mestre $i$ administrador dels deputats . Este maestro se encargaba de darles alojamiento en su casa, alimentarlos, prøeerles de ropa y de ser su preceptorDurante el período de estudio fueron tres personas las que ejercieron este oficio, siempre diferentes al maestro de capilla. A la llegada de Flecha, el mestre dels diputats era el presbítero Genís Vinader, uno de los cuatro hebdomadarios ${ }^{116}$ de la catedral. Al poco tiempo, el 27 de abril de 1527, se produjo un relevo en el cargo por cese v oluntario de Vinader. En esta ocasión, el cabildo eligió en "magistrum et administratorem deputatorum sedis" al presbítero cantor Gonzalo Espinosa, con el mismo salario que gozaba Vinader ${ }^{117}$. Espinosa mantuvo el cargo hasta su fallecimiento en el mes de febrero de $1531^{118}$. El primero de mayo de 1532 debió de tomar posesión del car go de mestre dels diputats el presbítero Guillem Sellés, con un salario de 20 libras anuales, pagadas a partes iguales por las administraciones de la Almoina y de Dobles $i$ aniversaris ${ }^{119}$. Sellés también ejercía los oficios catedralicios de diácono y sots-obrer en el año eclesiástico de $1533^{120}$. Mantuvo el magisterio de los infantillos todo el resto de período estudiado, por lo que fue quien se hizo cargo de ellos durante el segundo magisterio de capilla de Mateo Flecha.

Durante el ejercicio de sus funciones, los mestres dels diputats tenían que hacer frente a diversos gastos extraordinarios de sus pupilos, fundamentalmente de ropa y medicinas. El cabildo respondió económicamente a estas eventualidades en muchas ocasiones, retornando a los maestros las cantidades que éstos adelantaban con estos fines ${ }^{121}$. Asimismo, los miembros capitulares fueron sensibles a las situaciones delicadas de la economía general, otoigando cantidades adicionales al maestro por motivos como la carestía del trigo o la carne ${ }^{122}$.

Por último, es importante distinguir los diputats de otro grupo diferente de servidores de la seo, los llamados escolans que, debido al significado actual del término, podrían confundirse con los niños cantores. Según está minuciosamente tratado en la consueta de 1527, los escolanes tenían funciones de asistencia en la liturgia y también fuera de ella, realizando labores que, en no pocas ocasiones, lle vaban aparejada una considerable exigencia física. Entre sus obligaciones, por las cuales cada uno cobraba 12 libras al

116 Los hebdomadarios eran oficios de altar, plazas fijas de la catedral unidas a un beneficio, para cuyas obligaciones de oficiar se establecían turnos semanales.

117 "Venerabilis dominus Genisius Vinader, presbiter epdomodarius (sic) sedis Valencie, administrator deputatorum sedis, renunciavit imposse re verendorum dominorum canonicorum et capituli dicte sedis dictam administrationem, requirens dictam renunciacionem admitti. Ffiat large, etc. Actum Valencie, etc."; "Prefati reverendi domini de capitulo eligerunt in magistrum et administratorem deputatorum sedis v enerabilem Gundisalvum Spinosa, presbiterum cantorem dicte sedis, qui habeat et teneat deputatus dicte sedis, et minister doceat eosdem prout moris est, et eidem solvantur peccunie solite et consulte prout solventuntur dicto Genisio Vinader. Actum Valencie" [E-VAc, Not. Gaspar Joan Abella, nº 3705, 27 de abril de 1527]. El salario que percibía Vinader nos es desconocido. Aunque la expresión utilizada por el escribano es algo confusa, parece que el maestro contaba con una especie de ayudante ("minister") que se encargaba de la docencia.

118 E-VAc, Almoina, Pagador dels senyals, n 5614, año 1531, s.f.

119 El 14 de agosto de 1533 cobró 10 libras del procurador mayor de la Almoina "per aquelles vint lliures que lo re verent capítol me dona per los diputats, e són per tot any present, lo qual fenirà lo darrer de abrir primer vinent" [E-VAc, Almoina, Procura Major, $\mathrm{n}^{\mathrm{o}}$ 5693, año 1532, f. 70v]. El detalle del desglose de su salario por administraciones puede encontrarse en: Ibid., f. 79v.

120 E-VAc, Fàbrica, no 1489, año 1533. El oficio de diácono, como uno de los oficios fijos de ministros del altar , no tenía correspondencia con el grado de órdenes sagradas sino con su función de asistencia en los oficios. En el caso de Sellés, su ordenación no era de diácono, sino de presbítero.

121 Pueden encontrarse gran número de estos pagos en los libros de cuentas de la Tresoreria: E-VAc, Tresoreria, n $1292-1293$.

122 Ejemplos de este tipo pueden encontrarse en E-VAc, Not. Gaspar Joan Abella, nº 3706, 14 de junio de 1529; E-VAc, Almoina, Procura Major, $\mathrm{n}^{\circ}$ 5692, año 1530, f. $71 \mathrm{v}$. 
año ${ }^{123}$, se pueden citar las de tocar las campanas, lle var y devolver los objetos litúr gicos de la sacristía, abrir y cerrar las cortinas y las puertas de la catedral, encender y apagar los cirios y lámparas, portar la cruz mayor en las procesiones, barrer el templo, empaliar la catedral en las festividades, o ayudar a desvestirse al obispo celebrante ${ }^{124}$. Para poder cumplir correctamente algunas de sus tareas, parece ser condición necesaria que fuesen hombres jóvenes o incluso adultos. En esta época, los escolanes propiamente de la seo valenciana eran cinco y estaban bajo las órdenes del subsacristán, también llamado magister en la catedral de Valencia ${ }^{125}$. Tampoco se puede decir que fueran totalmente ajenos al hecho musical, puesto que se sabe que, excepcionalmente, cantaban dos lecciones y un responso en algunos oficios de maitines, previamente examinados por el subsacristán ${ }^{126}$. No obstante, no parece que su participación en el canto trascendiese más allá de este tipo de intervenciones breves, puntuales y no habituales.

\section{Cantores}

A partir de mediados del siglo xv, los libros de cuentas de la catedral dejan clara constancia de la existencia de músicos específicamente contratados como cantores. Éstos aparecen generalmente referidos en la documentación cuatrocentista catedralicia con la denominación de xantres, forma utilizada en la Corona de Aragón que fue siendo progresi vamente sustituída desde finales de esa centuria por la de cantor, que se usaba en Castilla ${ }^{127}$. La f ase final de este proceso de sustitución de vocablos en la catedral v alenciana puede se guirse bien en el período de estudio. En 1526, la generalidad de los cantores ya utilizaban el término "cantor" en sus albaranes autógrafos, incluso en los escritos en valenciano, aunque el escribano del procurador mayor de la Almoina todavía anotaba sistemáticamente "chantre" junto a sus nombres. Al final del período, en 1541, la aparición de la forma xantre es del todo excepcional en los libros de este procurador ${ }^{28}$. El Cuadro 1 muestra los datos que consideramos más significativos de todos los cantores identificados en la catedral en el período de estudio 1526-1541.

123 Puede constatarse el cobro de 60L anuales para los cinco escolanes en cualquiera de los libros anuales de cuentas de la Tresoreria: E-VAc, Tresoreria, ${ }^{\circ}$ 1292-1293.

124 E-VAc, $n^{\circ} 70$, ff. 174r-191r.

125 Cada uno de ellos desempeñaba, de forma rotatoria por semanas, uno de estos cinco oficios: el del altar, el guardián, el segundo, el campanero y el de las [campanas] chicas.

126 "E fet acò, si y a nou liçons a matines, lo de l'altar ha de dir la primera liçó de matines, y lo guardià la se gona. E si és doble, que no sia bisbal, los dos han de dir lo quart respon de matines. Si és duplex o viIII liçons simples, lo de l'altar dia a soles lo quart respon.Y perquè u sàpien bé dir y ben legir, feta la guarda del cor, lo sotsacristà fa'ls cantar davant ell les liçons y lo respons"' [Ibíd., f. 190v].

127 El término xantre se presenta en la catedral v alenciana también en las v ariantes ortográficas de jantre, chantre, chanter o gantre. Se gún Maricarmen Gómez Muntané, en tiempos del re y de Aragón Pere IV el Cerimoniós (1336-1387) se produce, por influencia francesa, la introducción en la corte aragonesa de la denominación dexantre aplicada alcantor profesional, al proceder estos músicos de Aviñón, donde estaba establecida la corte papal [G ÓMEz MunTANÉ, Maricarmen: La música en la Casa Real Catalano-aragonesa durante los años 1336-1432 (Barcelona, Antoni Bosch, 1979), p. 85]. No hay que confundir este significado del vocablo con el contemporáneo castellano chantre, que hacía referencia a la dignidad catedralicia (praecentor) que originalmente encabezaba el coro.

128 E-VAc, Almoina, Procura Major, no 5692, año 1526, ff. 53r-55r, 74r-89v; Ibíd., no 5695, ff. 49r-52v, 71v-92v. En esta fase final de sustitución de este término, sería decisiva la existencia en la ciudad de la corte castellanizante del duque de Calabria, cuyos cantores, en su mayor parte castellano-parlantes a juzgar por sus nombres, eran un colectivo mayor que el de la catedral. 


\begin{tabular}{|c|c|c|c|c|c|c|c|c|c|c|c|c|c|c|c|}
\hline 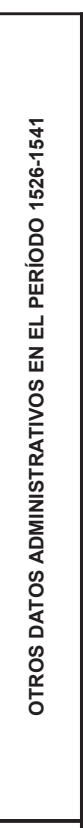 & 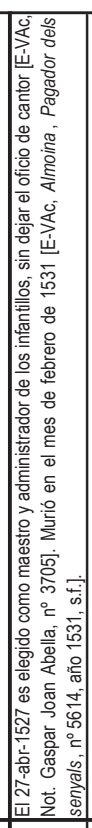 & 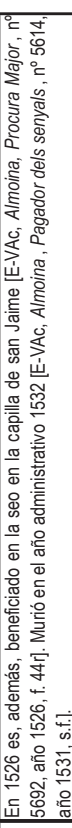 & 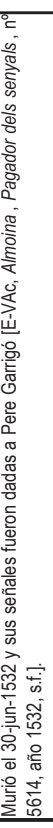 & & 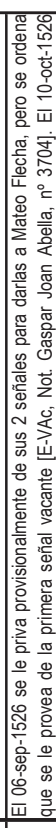 & 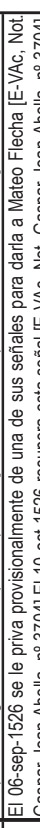 & & 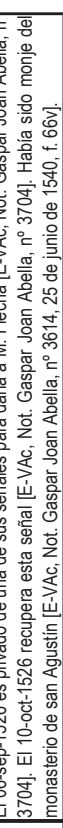 & 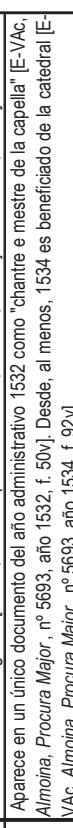 & 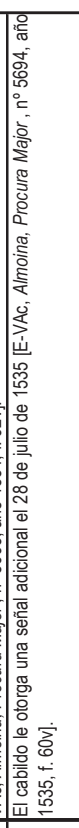 & 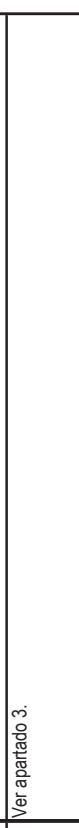 & 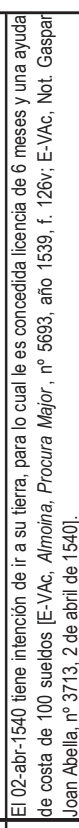 & 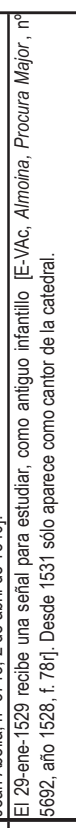 & 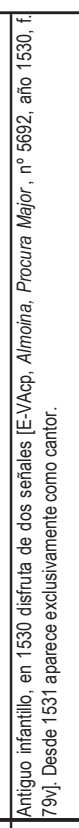 & 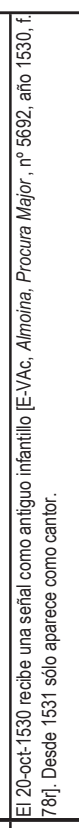 \\
\hline 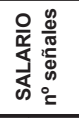 & $\stackrel{m}{\sim}$ & $I$ & m & 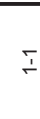 & ป & 2 & & ले & 号 & $\stackrel{f}{q}$ & 产? & $\stackrel{1}{\Upsilon}$ & $\stackrel{t}{\stackrel{I}{\prime}}$ & $\stackrel{?}{+}$ & $\stackrel{I}{I}$ \\
\hline $\mid t \rightarrow G$ & & & & & & & & & $\div$ & $\div$ & $\pi$ & & 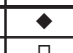 & & $\bar{\pi}$ \\
\hline \begin{tabular}{|l|}
$0 t G l$ \\
$6 \varepsilon$ \\
\end{tabular} & & & & & & & & 4 & 4 & 4 & $\bullet$ & $\stackrel{\bullet}{\square}$ & 마 & & $\frac{1}{\square}$ \\
\hline$\frac{6 \varepsilon S 1}{8 \varepsilon S 1}$ & & & & & & & & $\vec{v}$ & $\div$ & 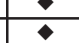 & 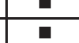 & 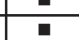 & 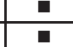 & & 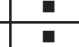 \\
\hline \begin{tabular}{|l|}
$\angle \varepsilon G l$ \\
\end{tabular} & & & & & & 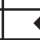 & & & 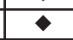 & 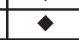 & & & $\pi$ & & I \\
\hline $9 \varepsilon \mathcal{~}$ & & & & & $\pi$ & & & $v$ & $\bullet$ & $\bullet$ & & & $\pi$ & & $\pi$ \\
\hline \begin{tabular}{|l|l|} 
S\&S1 \\
\end{tabular} & & & & & $\bar{\square}$ & & & 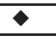 & 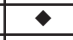 & $\bullet$ & & & $\pi$ & & $\pi$ \\
\hline \& $\nabla \varepsilon S !$ & & & & & 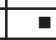 & I & & & $=$ & 무 & & & $\pi$ & & I \\
\hline \& $\varepsilon S$ & & & & $\bullet$ & 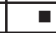 & & & $\nabla$ & 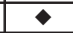 & 4 & & & $\pi$ & $\bullet$ & $\pi$ \\
\hline$z \varepsilon S$ & & & 4 & 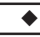 & 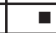 & 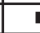 & & $\bullet$ & $\bullet$ & 4 & & & $\pi$ & $\bullet$ & $\pi$ \\
\hline \begin{tabular}{|l}
$\perp \& S \downarrow$ \\
\end{tabular} & & 4 & 4 & 4 & 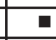 & 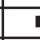 & & 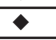 & 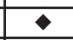 & 4 & 4 & & \pm & \pm & 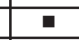 \\
\hline O\&SL & 4 & 4 & 4 & & $\bar{\square}$ & & & 7 & 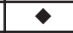 & 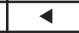 & $\bullet$ & & 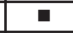 & $\pi$ & $\pi$ \\
\hline 6ZS1 & 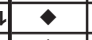 & 4 & 4 & 8 & $\pi$ & 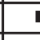 & & $\bullet$ & $\bullet$ & 4 & $\bullet$ & & I & & \\
\hline 825 & $\bullet$ & 4 & 4 & 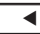 & 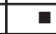 & 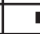 & & $\bullet$ & $\bullet$ & 4 & $\bullet$ & & $\pi$ & & \\
\hline \begin{tabular}{|l|l|} 
LZSL \\
\end{tabular} & 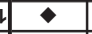 & 4 & 4 & & 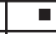 & & & $\bullet$ & 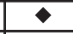 & 5 & $\leftarrow$ & - & & & \\
\hline 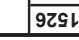 & 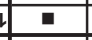 & $\bullet$ & 4 & 4 & \pm & 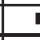 & & 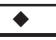 & $\bullet$ & 4 & ت. & & & & \\
\hline N & & & 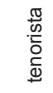 & & & & & & $\stackrel{\frac{0}{ٍ ٍ ~}}{ٍ}$ & $\stackrel{0}{\frac{0}{2}}$ & & & & 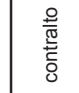 & \\
\hline $\begin{array}{l}\text { 䀫 }\end{array}$ & 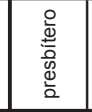 & 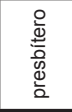 & 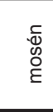 & 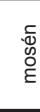 & 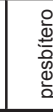 & 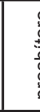 & & 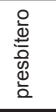 & 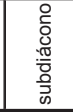 & 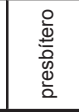 & 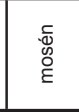 & 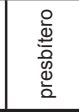 & 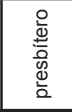 & 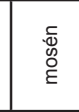 & 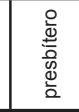 \\
\hline 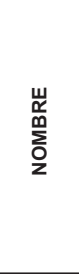 & 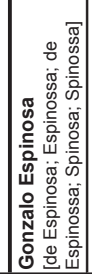 & 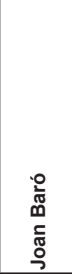 & 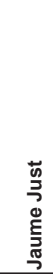 & 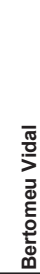 & 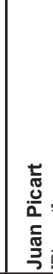 & 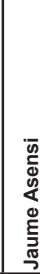 & & 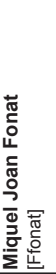 & 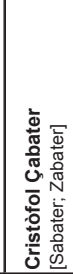 & 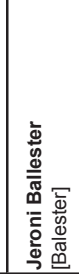 & 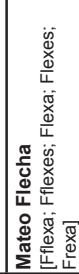 & 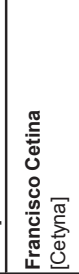 & 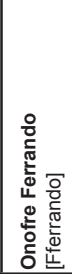 & 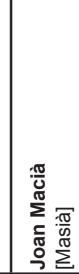 & 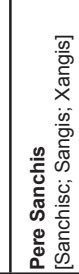 \\
\hline
\end{tabular}




\begin{tabular}{|c|c|c|c|c|c|c|c|c|c|c|}
\hline 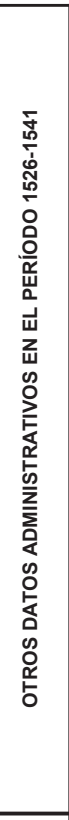 & 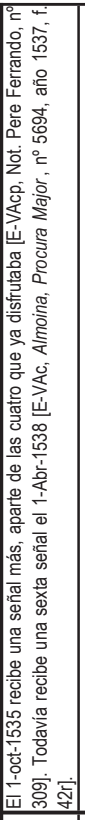 & & 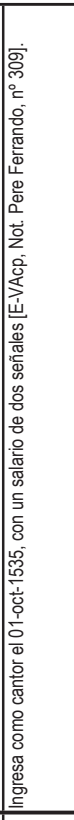 & 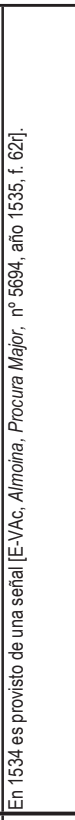 & & & 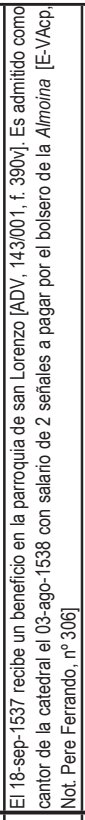 & 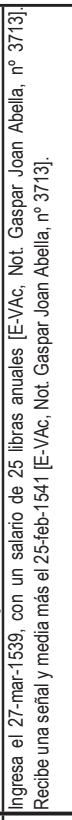 & 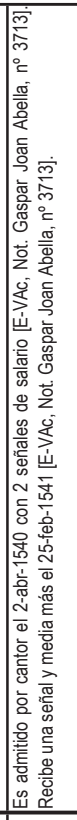 & 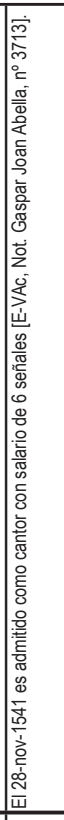 \\
\hline 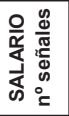 & $\stackrel{\varphi}{\stackrel{1}{\leftarrow}}$ & mे & $\stackrel{m}{\sim}$ & $I$ & $\stackrel{f}{q}$ & $\stackrel{+}{+}$ & $\tilde{\sim}$ & 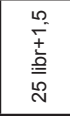 & 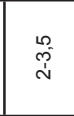 & $\begin{array}{l}0 \\
\dot{1}\end{array}$ \\
\hline$L \nabla S$ & $\bullet$ & & - & $\square$ & 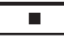 & " & 4 & I & -1. & - \\
\hline $0 \mathrm{tsl}$ & $\bullet$ & & $\bullet$ & $\bullet$ & $\bullet$ & $\bullet$ & 4 & $\bullet$ & $\bullet$ & \\
\hline $6 \varepsilon s 1$ & . & & . & . & ㅁ. & I & 4 & . & 무 & \\
\hline $8 \varepsilon S 1$ & $\pi$ & & $\pi$ & I & $\square$ & $\pi$ & 4 & & & \\
\hline$\angle \varepsilon \subseteq 1$ & I. & & . & $\square$ & . & & & & & \\
\hline 9\&S & $\pi$ & & $\pi$ & I & I & & & & & \\
\hline SES & $\pi$ & & $\pi$ & $\pi$ & & & & & & \\
\hline$\sqrt[6]{t \downarrow \varepsilon s}$ & $\pi$ & & & & & & & & & \\
\hline$\varepsilon \varepsilon S$ & $\pi$ & $\bullet$ & & & & & & & & \\
\hline Z\&s & - & 4 & & & & & & & & \\
\hline 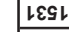 & & & & & & & & & & \\
\hline $0 \& \Omega$ & & & & & & & & & & \\
\hline 6zsl & & & & & & & & & & \\
\hline $8 \mathrm{ZSl}$ & & & & & & & & & & \\
\hline$\angle Z S L$ & & & & & & & & & & \\
\hline 9ZsL & & & & & & & & & & \\
\hline No & 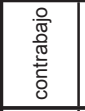 & 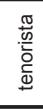 & $\begin{array}{l}\bar{c} \\
\stackrel{\bar{\Phi}}{\Phi}\end{array}$ & 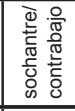 & & 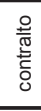 & 高 & $\stackrel{\mathscr{0}}{\stackrel{0}{=}}$ & & \\
\hline $\begin{array}{l}\text { Zu } \\
\text { vo } \\
\text { o }\end{array}$ & , & 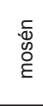 & 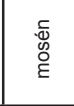 & $\begin{array}{l}\frac{0}{9} \\
\stackrel{0}{0} \\
\frac{0}{0} \\
\frac{0}{2}\end{array}$ & 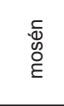 & 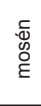 & 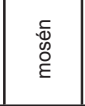 & 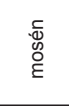 & 兽 & 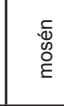 \\
\hline 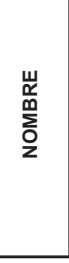 & 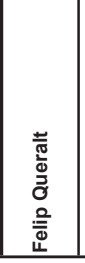 & 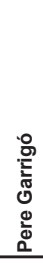 & 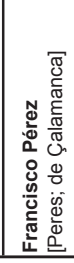 & 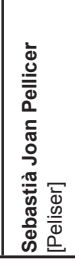 & 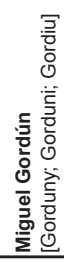 & $\begin{array}{l}\frac{\pi}{\overline{0}} \\
\frac{\alpha}{\alpha} \\
\frac{5}{\sigma}\end{array}$ & 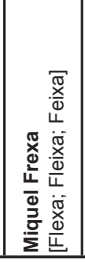 & 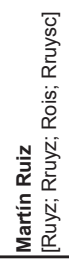 & 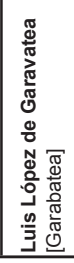 & 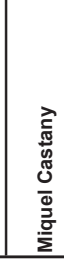 \\
\hline
\end{tabular}

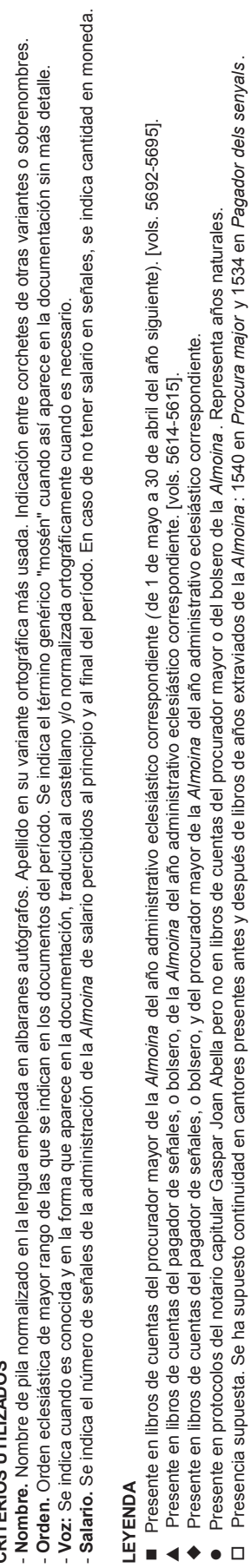

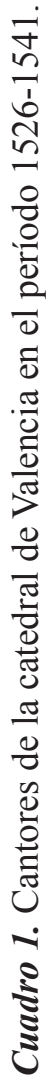


La práctica totalidad de los cantores en esta época debían de poseer alguna orden sagrada. Al menos, la mitad de ellos eran presbíteros con total se guridad. El ingreso de cualquier cantor en la catedral tenía lugar tras la correspondiente admisión por el cabildo, que señalaba en el mismo acto su salario. En la catedral de Valencia de esta época, los salarios de los cantores consistían habitualmente en un número v ariable de señales de la administración de la Almoina $^{129}$. El pago de las señales podía hacerse efectivo por el procurador mayor o por el bolsero de esta administración. Algunos cantores sólo cobraban de uno de estos dos pagadores, mientras que otros cobraban a traés de ambos, quienes se repartían, en este caso, las señales asignadas a estos cantores a efectos de su pago. Este sistema fue el que existió en la seo valenciana hasta la reorganización de la capilla, que tuvo lugar en dos fases en 1554 y 1562, cuando se crearon un total de ocho capellanías específicas para cantores con salarios asignados a las plazas, los cuales, no obstante, siguieron pagándose a través de la Almoina ${ }^{130}$.

Lo más habitual es que el número de señales asignado inicialmente a cada cantor fuese de una o dos. Normalmente, los cantores que habían sido inicialmente diputats y que, una vez habían dejado de serlo, se les había prorrogado la señal que tenían para que continuasen sus estudios, comenzaban su trayectoria de cantor adulto sin más aumento. Con el tiempo de servicio, era común que el cabildo incrementase la cantidad de señales inicial de los cantores, aunque no siempre lo hizo. Así, puede decirse que la mayoría de cantores de la catedral que servían en un momento determinado del período de estudio, poseían de dos a cuatro señales, lo que equi valía a unos ingresos anuales de 15 a 30 libras valencianas (de 5.322 a 10.643 maravedíes castellanos) por este concepto ${ }^{131}$. También se aprecia cierta tendencia al aumento del número de señales asignadas a los cantores desde el principio al final del período de estudio. Fueron pocos los que mantuvieron durante $v$ arios años el salario de una única señal. De igual manera, fueron escasos aquéllos que superaron las cuatro.Aparte del caso del maestro de capilla Mateo Flecha durante su primer magisterio, cuando gozó de seis señales, sólo cinco cantores consiguieron más de cuatro en el período de estudio. Es interesante observ ar que, aunque sólo conocemos la tesitura vocal de tres de los cinco, dos eran tiples -Jeroni Ballester y Cristòfol Sabater- y el tercero contrabajo (bajo) -Felip Queralt-. Por tanto, no es difícil ar reflejado en sus, relativamente, altos salarios la secular escasez de cantores de estos re gistros extremos. Por otra parte, no se observa que un mayor grado de ordenación eclesiástica de los cantores conlle vase un mejor tratamiento salarial.

129 En sólo un caso, se estableció un salario en cantidad fija de moneda con cargo a la Almoina, sin utilizar las señales. Martín Ruiz, criado de Mateo Flecha, recibió un salario inicial de 25 libras valencianas [E-VAc, Not. Gaspar Joan Abella, $n^{\circ} 3713$, 27 de marzo de 1539].

130 E-VAc, nº1631, ff. 3r-5r. Citado en Climent Barber, José: op. cit., pp. 61-62. El estatuto de 1562 de creación de cuatro nuevas capellanías puede encontrarse transcrito en Climent BARBER, José: Juan Bautista Comes y su tiempo (Madrid, Servicio de publicaciones del Ministerio de Educación y Ciencia, 1977), pp. 237-241.

131 A efectos informativos, la mayoría de catedrales castellanas de la época ofrecían a sus cantores entre 15.000 y 30.000 maravedíes al año [SuÁREZ-PAJARES, Javier: op. cit., pp. 162-163]. No obstante, por no conocerse con total e xactitud los posibles ingresos adicionales que podían tener los cantores de la catedral de Valencia en la época, hay que tomar con precaución los datos expuestos, que sólo reflejan su salario fijo, antes de establecer comparaciones. 
El cabildo solía respetar las señales consolidadas. Sólo en dos momentos e xcepcionales del período, ambos relacionados con Mateo Flecha, se redujo el número de señales de un músico. El primero fue precisamente en la primera admisión de Flecha como maestro de capilla y cantonando los miembros capitulares se vieron obligados a desposeer momentáneamente a cuatro de los cantores de algunas de sus señales para poder otorgárselas al recién llegado maestro. Debió de ponerse gran interés en su rápida reposición, ya que al mes se devolvieron a tres de los cantores afectados ${ }^{132}$. La segunda ocasión fue cuando se redujo el número de señales de Flecha de seis a cuatro, justificado por haber acumulado el cargo de sochantre al de maestro de capilla y cantor ${ }^{33}$. La actitud equitativa del cabildo también se demostró en algunas concesiones de pagos atraordinarios a los cantores, en bastantes ocasiones justificados en conceptos tales como indumentaria, enfermedades o viajes ${ }^{134}$.

Adicionalmente a estos salarios fijos, el cabildo podía conceder a los cantores el derecho a recibir los percances del coro, cuyos ingresos deri vados dependían del número de actos $\mathrm{v}$ otivos al que se asistiese en el año. Gozaron de este derecho, que tengamos constancia, Mateo Flecha en su primer período en la catedral ${ }^{135}$, Francisco Pérez ${ }^{136}$, y Bertomeu Vidal. En el caso de éste último, la administración de la Almoina subvencionó varios años a la de Dobles $i$ aniversaris con la cantidad de 15 libras para que se hiciese car go de su pago al cantor, de donde se puede inferir que éste era el montante aproximado que podían suponer dichos percances ${ }^{137}$. La práctica de utilizar los percances como medio para incrementar las retrib uciones debió de extenderse en exceso en la catedral a juicio del cabildo ya que, el 18 de febrero de 1536, una constitución capitular prohibió su concesión a aquél que no fuese auténtico beneficiado ${ }^{138}$.

Algunos de los cantores también poseían beneficios en la catedral o en otras iglesias de la diócesis, que les suponían ingresos adicionales. Sin embago, no se ha podido constatar ninguna relación entre la concesión de estos beneficios y la condición de cantores de sus adjudicatarios ${ }^{39}$. Con seguridad fueron

132 E-VAc, Not. Gaspar Joan Abella, n 3704, 10 de octubre de 1526.

133 Ver transcripción de este acta del cabildo en nota 57.

134 Ejemplo de compra de ropa fue la libra, 7 sueldos y 4 dineros otgrados a Joan Baró por "camises, sabates e calces" [EVAc, Almoina, Procura Major, $\mathrm{n}^{\circ}$ 5692, año 1526, f. 84r]. Ejemplo de subvención por enfermedad fueron las 2 libras y 2 sueldos concedidos a Miquel Joan Fonat “que stà malalt" [E-VAc, Almoina, Procura Major, nº5695, año 1539, f. 126v]. Ejemplo de viaje fueron los 100 sueldos concedidos a Francisco Cetina "per ajuda de costa del camí” [Ibíd.].

135 Ver transcripción de su admisión en nota 25.

136 Ver transcripción de su admisión en nota 66.

137 E-VAc, Almoina, Procura Major, n⿳0 5692, año 1526, f. 55r; Ibíd., año 1529, f. 50r.

138 La "constitutio quod nullus admittatur ad percatia Ecclesiae: nisi fuerit vere beneficiatus" puede consultarse en PÉREZ DE Miedes, Miquel: op. cit., ff. 91v-92r.

139 La vía más frecuente para acceder a los beneficios en la diócesis valenciana pasaba por pertenecer a la parentela de los patronos o formar parte de su red clientelar Estos patronos, que tenían la facultad de presentar a sus candidatos, eran normalmente los sucesores de los instituidores que habían dejado los bienes cuyas rentas constituían los ingresos del beneficiado, y eran mayoritariamente miembros de la pequeña nobleza, los oficios militares y el alto clero. A cambio, el beneficiado asumía ciertas obligaciones en el mantenimiento del culto y decoro en la capilla en que se había instituido el beneficio. Sobre los beneficiados valencianos de esta época, es obra de referencia C Árcel OrTí, Ma Milagros: La Diócesis de Valencia y sus beneficiados (15011538). Tesis Doctoral, 5 vols. (Valencia, Universidad de Valencia, Facultad de Geografía e Historia, 1979). Mientras no aparezcan evidencias en otro sentido, ésta sería también la vía mayoritaria que siguieron los cantores que consiguieron dicha posición, independientemente, por tanto, del desempeño de su oficio. 
beneficiados de la catedral Joan Baró, en la capilla de san Jaime ${ }^{40}$, y Cristòfol Sabater ${ }^{41}$. Miquel Flexa, por su parte, fue beneficiado de la parroquia de san Lorenzo de Valencia, como ya se ha mencionado. Otros beneficiados de la diócesis entre 1501 y 1538 con nombres que coinciden con los de cantores, son Jaume Asensi, Jeroni Ballester, Sebastià Pellicer y Bertomeu Vidal ${ }^{142}$. No obstante, no se ha podido confirmar que estas personas fuesen realmente los cantores de la catedral u otros eclesiásticos homónimos.

Los cantores no ocupaban en esta época plazas fijas en la catedral y, por tanto, el número de cantores que en cada momento servían no era el mismo. El cabildo podía admitir tantos de estos músicos como estuviese dispuesto a pagar Como puede observarse claramente en elCuadro 2, ambos magisterios de Mateo Flecha representaron períodos de e xpansión, con un dos máximos de trece en 1530 y quince en 1539-1540, mientras que en el ínterin el número de cantores disminuyó hasta ocho.

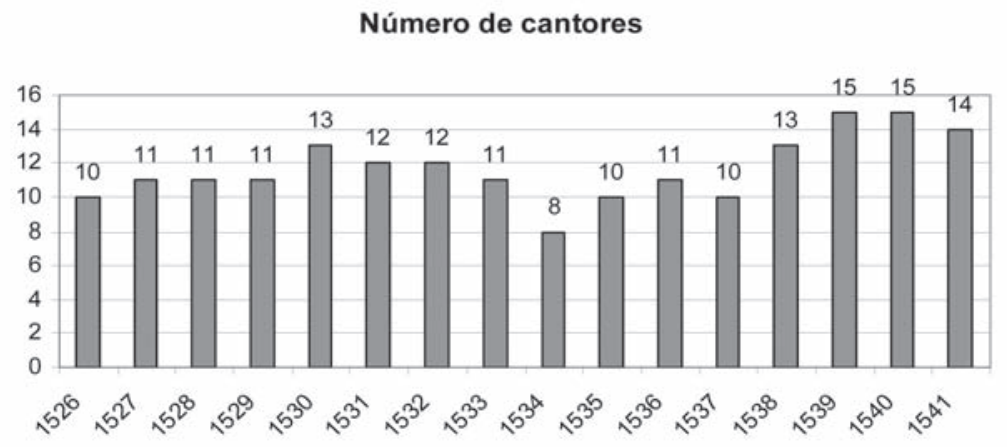

Cuadro 2. Evolución del número de cantores con el tiempo

140 "Mossèn Joan Baró, prevere benefficiat en la seu en la capela de sant Jaume del beneffici instituït per en Johan del Boix [...]" recibe 7 libras y 10 sueldos "per obs de comprar oli y encendre dos llànties que té lo dit beneffici e per set ciris que cascun dia cremen davant lo altar major dient la salve" [E-VAc, Almoina, Procura Major, no 5692, año 1526, f. 55r; Ibid., año 1529, f. 50r].

$141 \mathrm{Su}$ condición de beneficiado de la catedral figura explícitamente en varios albaranes autógrafos en E-VAc, Almoina, Procura Major, $\mathrm{n}^{\circ}$ 5693, año 1534, f. 92v; Ibíd., n 5694, año 1535, f. 122v; Ibíd., año 1536, f. 50v . Se desconoce cuál fue su beneficio en esta época. El nombre de Cristòfol Sabater , clérigo, aparece también en di versas colaciones de beneficios de la diócesis entre 1501 y 1538, sin que se sepa con certeza si se trata del cantor . El 14 de septiembre de 1519 renunció al beneficio bajo la advocación de san Bartolomé en la catedral para permutarlo. El 29 de marzo de 1520 renunció al beneficio en el altar de san Antonio de la iglesia de Santa Catalina deAlzira para permutarlo. El 16 de marzo de 1524 renunció al beneficio bajo la advocación de María Magdalena en la iglesia de san Juan del hospital deValencia [Archivo Diocesano de Valencia (ADV), n 143/001, ff. 177r, $185 \mathrm{v}, 238 \mathrm{v}]$.

142 Jaume Asensi, clérigo recibió el beneficio de la iglesia de Villahermosa bajo la adv ocación de la santísima Virgen María en 23 de enero de 1528. Jeroni Ballester , presbítero, recibió el beneficio de la iglesia de la santa Cruz en el altar de san Vicente el 21 de enero de 1525. El mismo tomó posesión del beneficio de la iglesia del monasterio de santa María Magdalena en el altar de santo Domingo el 5 de marzo de 1533. Sebastià Pellicer , clérigo, recibió el beneficio en la iglesia de san Nicolás de Valencia en el altar del Corpus Christi el 21 de febrero de 1527. BertomeuVidal, clérigo, recibió el beneficio de la iglesia de santa María en Alzira bajo advocación de san Jaime y san Felipe el 1 de marzo de 1504. El mismo, ya como presbítero, renunció a ese beneficio para permutarlo el 4 de mayo de 1509. También renunció al beneficio de la iglesia de Alboraia en el altar de san Lorenzo el 20 de septiembre de 1515. Renunció nue vamente, esta vez al beneficio de san Vicente en la iglesia de santa Catalina de Alzira [Ibid., ff. 278v, 249r, 342v, 271v, 26r, 71r, 126v, 301r]. El libro de colaciones ADv, nº 143/001 ha sido estudiado en profundidad y transcrito en CÁrCEL OrTí, Ma Milagros: op. cit, vols. 4-5. 
A juzgar por las tesituras conocidas de los cantores, todas las v oces necesarias para interpretar el repertorio polifónico de la época estaban representadas de forma aparentemente equilibrada. El sochantre Sebastià Joan Pellicer, aparece como contrabajo (bajo, en terminología actual) en alguna ocasión, lo que nos hace pensar que, además de las funciones propias de su oficio relacionadas con el canto llano, también actuaría en la música polifónica con el resto de cantorełs. Por otro lado, el período de estudio es testigo de la desaparición de la antigua denominación de tenorista en la catedral, forma especial para referirse a algunos xantres desde el siglo XIv ${ }^{144}$. Jaume Just recibía esta denominación hasta su muerte en 1532. El mismo año fue admitido otro tenorista, Pere Garrigó, quien no permaneció más allá del año administrati vo 1533 y fue, se gún los datos de que disponemos, el último de los cantores que tuvieron esta denominación en la catedral, en un momento en que el repertorio había evolucionado hacia una mayor igualdad en la forma de construcción de todas las $\mathrm{v}$ oces, sin tenores estructuralmente diferenciados.

Respecto a la procedencia de los cantores, se observ a que en el momento de la primera lle gada de Flecha a la catedral en 1526, los cantores eran mayoritariamente originarios de territorios de lengua valenciana/catalana. A partir de este momento, casi la mitad de los nue vos admitidos son de lengua castellana. Un ejemplo claro es el de Martín Ruiz, que lle gó desde Castilla como criado de Flecha en 1539. Es muy posible que influyesen en este fenómeno los contactos culturales y políticos con el territorio castellano que se intensificaron con la llegada de los duques de Calabria, quienes precisamente se instalaron en Valencia el mismo año 1526.

De hecho, la capilla de los duques parece que fue un objeti vo profesional para los cantores catedralicios, ya que algunos de ellos sirvieron posteriormente en esa institución. Los superiores salarios que don Fernando de Aragón y, más tarde, doña Mencía de Mendoza ofrecían a sus cantores, comprendidos en su mayoría entre los 30.000 y 40.000 marmedíes anuales, parecían razones poderosas para ello ${ }^{145}$. JuanAbella, si se trata del mismo "JoanAbello" que indica R. F Schwartz, estuvo al servicio

143 También en bastantes documentos se hace alusión a que la señal que recibía era por su salario de "cantor" [Ejemplo en E-VAc, Almoina, Procura Major, n 5695, año 1538, f. 53v].

144 Johannes Tinctoris asevera que "tenorista est ille qui tenorem canit", por lo que se trataría simplemente de un cantor especializado en la parte de tenor . [T Inctoris, Johannes: Diffinitorium musice, Scriptorum de musica medii ae vi no va series a Gerbertina altera, Edmond de Coussemaker (Ed.), vol. 1 (París, Durand, 1864-1876), p. 189]. No obstante, David Fallows y Owen Jander constatan la utilización del v ocablo, en la v ariante francesa (tenoriste) e italiana (tenorista), desde finales del siglo xIV y durante todo el siglo Xv, para referirse al cantor especializado en la interpretación de las partes inferiores de la polifonía, tenor o contratenor [FALlows, David y J ANDER, Owen: “Tenor. 2. The word in early polyphon y", en Grove Music Online, L. Macy (Ed.) (consulta 20 de junio de 2009), http://www .grovemusic.com]. Josep Maria Gre gori opina que esta denominación pudiera haberse originado por un simple proceso de identificación entre la función de entonar la pauta que correspondia atenor en la polifonía desde la época del Ars Antiqua y el propio intérprete. P ara completar el v ocablo se añadiría el sufijo -ista a tenor de manera semejante a como se habían creado palabras como psalmista o paraphonista [GREGORI I CifRÉ, Josep Maria: "Mateu Ferrer, tenorista....", op. cit., pp. 8-9]. No obstante, un par de hipótesis más recientes del mismo autor apuntan hacia el tenor agudo "que habría reforzado la zona de encabalgamiento del falsete con el registro de cabeza de la voz de pecho" o bien al "cantor sopranista" especializado en la interpretación de las partes agudas de la polifonía y "antecesor del falsetista hispánico del siglo xvI", a pesar de que se hace muy difícil su compatibilidad con la definición de Tinctoris [GREGORI I CIFRÉ, Josep Maria: "El "tenorista": un antecesor del falsetista del siglo XvI", en Nassarre, 4/1-2 (1988), pp. 119-126; ́́b.: "Falsetistas y evirados: reflexiones sobre la tradición tímbrica hispánica y las partes de cantus y altus en el tránsito del Renacimiento al Barroco“, en Revista de Musicología, Xvi/5 (1993), pp. 2770-2782].

145 Esta estimación se ha realizado tomando como base los datos actualizados de salarios de 1546, se gún S CHWARTz, Roberta Freund: op. cit., pp. 295-296, 322-324. 
de doña Mencía de Mendoza, un bre ve período antes de la muerte de ésta, aunque su nombre no deja de estar presente en la catedral. Miquel Castan y, que había servido a la marquesa de Zenete en 1522, antes de su partida de Valencia en 1524, trabajó posteriomente para los duques, desde antes de 1546 hasta 1554. Luis López de Gara vatea sirvió en esa capilla en 1550 y 1551. Finalmente, Martín Ruiz, llegado a Valencia con Flecha, también perteneció a la capilla ducal desde antes de 1546 hasta 1552 , año en que se produjeron varias bajas en esa capilla que sugieren una reducción de efectios, momento en que retornó a la catedral ${ }^{146}$. Fue el único caso de movimiento de cantores en el sentido inverso, de la capilla ducal a la catedralicia, aunque parece que este retorno a la seo no fue totalmenteohuntario sino, posiblemente, forzado por una situación de desempleo. Los cuatro cantores mencionados arribaron a la catedral en el período de 1538 a 1541. El hecho de que, al menos, tres de los cuatro no fuesen naturales del reino valenciano, plantea la posibilidad de que su lle gada a la catedral pudiese estar pre viamente planificada como un estadio intermedio que les permitiera acceder posteriomente a la capilla de los duques, con superiores condiciones retributivas.

Sobre la actividad cotidiana de los cantores de la catedral en esta época se dispone de escasos datos. La consueta de 1527 es muy prolija en descripciones de indumentaria o de ceremonias pero muy parca en detalles musicales. No obstante, sí que nos informa que en la fiesta del Sitio de san Jaime, el martes de la octa va de Todos Santos, "la missa canten en lo altar major de vers la porta del sembori, y canten-la los chantres amb lo or gue"147, o que en las letanías "diu la missa lo Sr. Bisbe ab los chantres e lo escolà del altar serv eix a la missa" ${ }^{148}$. También se tiene constancia de su participación en el of icio de completas el día de la vir gen de la Esperanza en su propia capilla ${ }^{149}$. Como elementos constituti vos de las procesiones, la consueta nos muestra a los cantores en di versas ocasiones. En las que tenían como objeto las ple garias por lluvia, por ejemplo, la representación de la catedral se componía de "quatre mestres, y si més poden, més, dos domers, hun sots-cabiscol, dos rectors, sis beneficiats y los cantors" ${ }^{150}$. El subsacristán Pere Martí, autor de la consueta, además recuerda que en no viembre de 1526, con moti vo de una gran sequía, se ordenaron procesiones muy de votas en que "dos dels millors cantors que y anaven, servihen per sotscabiscols, ab capes y bordons ne gres"151. El 19 de diciembre de 1532, en la procesión del entierro del obispo de gracia Ausiàs Carbonell, iban los cantores de la seo

146 Ibíd. En los libros de cuentas del procurador mayor de lalmoina aparecen pagos a Martín Ruiz en el año administratio de 1551 y continúan ininterrumpidamente hasta, al menos, 1557 [E-V Ac, Almoina, Procura Major, $\mathrm{n}^{\circ}$ 5697]. Con el nombre de "Luis López de Gara vatea" aparecen dos personajes en la corte de Felipe II. El primero parece que fue cantorcico de la casa de Castilla desde 1556 hasta 1567 , por lo que no pudo ser el cantor de la seo valenciana. El segundo fue portero de cámara de la casa de Castilla desde 1570 hasta su muerte en 1574. Este dato es cronológicamente compatible con los datos conocidos del cantor de la catedral de Valencia, aunque no definitivo [Martínez Millán, J.: S. F ernández Conti y Carlos Morales C. J. de: "Relación alfabética de los miembros de las casa de Castilla y Boıgoña", en J. Martínez Millán y S. Martínez Conti (Eds.):La Monarquía de Felipe II: La Casa del Rey. Vol. II (Madrid, Fundación MAPFre Tavera, 2005), p. 262].

147 E-VAc, $\mathrm{n}^{\mathrm{o}} 70$, f. 97v.

148 Ibid., f. 62v.

149 Ibid., f. $167 \mathrm{v}$.

150 Ibid., f. $94 \mathrm{r}$.

151 Ibid., f. $95 \mathrm{v}$. 
delante del lecho del difunto "cantant ells hun vers, y la professó hun altre", en un claro ejemplo de práctica alternatim en un conte xto procesional. Pre viamente, en su casa habían cantado la letanía junto con el clero de santa Catalina, de donde el obispo era parroquiano ${ }^{152}$. Los cantores disponían de un atril especial para las procesiones, que era engalanado en la procesión de la misa mayor de la Pascua Granada con "la tovallola de carmesí obrada de personatges, que stà dalt, ab los vestiments de papa Alexandre" $"$.

En ocasiones e xtraordinarias de gran solemnidad los cantores de la catedral actuaron en este templo conjuntamente con los de la capilla de los duques de Calabria, que acompañaron a sus patronos en estos actos litúr gicos. El Libre d'Antiquitats nos menciona v arias de estas celebraciones en el período de estudio, aunque ello no e xcluye que pudiese haber tenido lugar alguna más. Los días 19 y 24 de mayo de 1527 festejaron conjuntamente la canonización de san Antonino, y cantaron un Te Deum por el nacimiento del príncipe Felipe, respecti vamente ${ }^{154}$. También, el 9 de octubre de 1538 se dijo "la missa de Sant Dionís ab molta solempnitat per los cantors del duch de Calàbria, y ab los de la Seu", en ocasión del tercer centenario de la conquista de Valencia ${ }^{155}$. Los cantores del duque, cantando “a fals bordó, ab l'or gue" intervinieron en la catedral, esta v ez en solitario en la misa y vísperas por la llegada de los frailes franciscanos que iban a fundar un convento en la ciudad bajo la protección de doña Julia, hermana del duque ${ }^{156}$.

\section{Organistas}

En el momento de la lle gada de Mateo Flecha a la catedral de Valencia en 1526, ocupaba la plaza de organista ${ }^{157}$ el presbítero Pere Vila [Villa]. Este músico de tecla fue el primer miembro de una destacada saga de músicos catalanes, fundamentalmente or ganistas $^{158}$. Los datos ahora disponibles

152 Martí Mestre, Joaquim (Ed.): op. cit., pp. 139-140.

153 E-VAc, $n^{\circ} 70$, f. 70v.

154 Martí Mestre, Joaquim (Ed.): op. cit., p. 118.

155 Ibid., p. 149.

156 Ibid., p. 146.

157 En la Valencia de la época, como en otros lugares de la Corona de Aragón, no se utilizaba casi nunca el término "organista" para referirse al músico que tocaba el ór gano, sino "sonador d'or gue" (o "d'òr guens") o, con menor frecuencia "músich d'orgue" (o "d'òr guens"). El término "or ganista" se utilizaba casi siempre para referirse al artesano f abricante de órganos u organero.

158 Josep Maria Gre gori ha estudiado en detalle la trayectoria catalana de Pere Vila y su familia. Según este autor, Pere Vila habría nacido hacia 1465 en Vic (actual provincia de Barcelona), en cuya catedral habría iniciado sus estudios antes de continuarlos en Barcelona. En 1502 disfrutaba de un beneficio en la catedral de Vic, donde, en 1519 lle gó a ser nombrado canónigo. Los datos de que se dispone, se gún Gregori, sobre su actividad como organista en dicha catedral se enmarcan en el período 1516-1527. Sobre su trabajo en la catedral de Valencia, hasta ahora era conocida su presencia desde el año 1534 hasta su fallecimiento en 1538. Desde Valencia gestionó la adquisición de la titularidad de la plaza de or ganista de la catedral de Barcelona para su sobrino indirecto Pere Alberch, alias Vila, quien, además, habría recibido sus enseñanzas musicales en la capital del reino junto a otro jo ven organista catalán llamado Gaspar Sagristà [G REGORI I CırRé, Josep Maria: "La nissaga dels organistes Vila i les famílies Vila, Alberch, Ferran i Ferrament de la ciutat de Vic al segle XVI", en Recerca Musicològica, VI-VII (1986-1987), pp. 50-55; Í D.: La Música del Renaixement a la Catedral de Barcelona, 1450-1580. Tesis Doctoral (Bellaterra, Publicacions de la Uni versitat Autònoma de Barcelona, 1987), pp. 316-322; Í D.: "Vila. 1. Vila, Pere", en Diccionario de la 
procedentes de la catedral de Valencia permiten completar algunas lagunas biográficas del músico vicense.

Pere Vila debió de haber comenzado a ejercer de organista en la catedral de Valencia a mediados de 1510, sucediendo a Joan Trossera y Pere Castell, quienes servían conjuntamente el oficio hasta la llegada de catalán ${ }^{159}$. El organista deVic cobraba por salario 30 libras de la administración déresoreria -divididas en dos pagas iguales que cobraba en san Juan y Naidad-, a las que se sumaban 20 libras de la de Fàbrica o Obra, pagaderas de la misma forma. Al llegar a la catedral, Vila poseía la rectoría de la iglesia parroquial de Les Lloses en la diócesis deVic, que aún conservaba en $1516^{160}$. Tras siete años de servicio, en el año administrativo de 1517 cobró las pagas de san Juan de ambas administraciones para después desaparecer de los correspondientes libros de cuentas hasta 1522 $2^{61}$. En ese ínterin actuó como organista el presbítero beneficiado de la catedral Joan Soler, quien también se ocupaba de pequeños trabajos de mantenimiento del instrumentd ${ }^{62}$, al cual suplió circunstancialmente el también beneficiado Francesc Burgonyó [Burgunyó] ${ }^{163}$.

En 1522, el organista Vila reaparece momentáneamente en el libro de cuentas deFàbrica, en el que se asientan dos pagos, uno de ellos con su correspondiente albarán autógrafo ${ }^{164}$. El mismo año, hace su primera aparición en los libros de cuentas Miguel [del] Villar [Miquel del Vilar], quien va a ir, progresivamente, asumiendo mayores responsabilidades en el órgano de la catedral hasta convertirse en el sucesor de PereVila después de su fallecimiento en 1538. Se desconoce su posible vinculación con Vila, aunque su llegada al mismo tiempo que él, la trayectoria ascendente

Música Española e Hispanoamericana, Emilio Casares Rodicio (Ed.), vol. 10 (Madrid, Sociedad General deAutores y Editores, 2002), pp. 885-886].

159 El último pago re gistrado de estos or ganistas fue en 1510, cuando recibieron 5 libras y 16 sueldos por prorrata de su salario de 30 libras anuales, que cobraban conjuntamente a partes iguales. Bajo las premisas de que el año administrati vo en la catedral comenza en 1 de mayo, y que la prorrata recibida correspondería a algo más de dos meses, el pago cubriría hasta ya entrado el mes de julio de 1510. [E-V Ac, Tresoreria, $\mathrm{n}^{\circ}$ 1292, año 1510, s.f.]. No obstante, no ha podido encontrarse el acta del nombramiento de Pere Vila como organista.

160 El 11 de septiembre de 1510 se pagaron 10 libras al "v enerable mossèn Pere Vila, prevere rector de la verge María de les Loces, sonador dels or guens" [E-VAc, Fàbrica, año 1510, n' 1487, f. 25v]. En 1516 aún es referido como "V enerabilis dominus Petrus Vila, presbiter rector parrochialis ecclesie de les Loces, diocesis vicensis, sonator or ganorum sedis Valencie" al cobrar 15 libras de la paga de san Juan de la Tresoreria [E-VAc, Not. Felip Abella, $\mathrm{n}^{\circ}$ 3700, 8 de julio de 1516]. Vila fue beneficiario de diferentes rentas eclesiásticas a lo lar go de su vida. Al menos poseía un beneficio en la catedral de Vic en 1502 y en 1519 disfrutaba en Barcelona de, al menos, dos más. El mismo año fue adjudicatario de una canongía en la seo de Vic. En 1536 era prepósito en la catedral de Barcelona [ Vid. Gregori I Cifré, Josep Maria: La Música del Renaixement..., op. cit., pp. 319-321].

161 E-VAc, Fàbrica, n 1487, año 1517, f. 25r; E-VAc, Tresoreria, n 1292, año 1517, s.f. Un albarán autógrafo fechado el 23 de junio de 1517 demuestra que en ese momento se encontraba aún en Valencia: "Jo, Pere Vila, prevere, atorch aver rebut de vos, molt venerable mossèn Anthoni Amorós, per lo celari del orgue de la paga de sant Johan, deu liures. Y perquè és veritat [que] les he rebudes de mà vostra, fas lo present albarà de mà mia a XXIII de juny del any 1517" [E-VAc, Fàbrica, nº 1512, f. 30r]. No obstante, según Gregori, en 1516 Pere Vila ya figuraba como organista en los libros de Aniversaris de la catedral de Vic [GREGORI I Cifré, Josep Maria: "La nissaga dels organistes...", op. cit., p. 54].

162 E-VAc, Fàbrica, n ${ }^{0}$ 1487, año 1517, ff. 20v, 30v, 31r, 31v, 41r; Ibíd., año 1518, f. 25v; Ibíd., año 1520, f. 25r; Ibíd., $\mathrm{n}^{\circ} 1488$, año 1522 , f. $18 \mathrm{v}$.

163 En el año administrati vo de 1519 se pagaron 3 libras y 3 sueldos a "mossèn Francés Bur gunyó per lo sonar dels orguens per la absència de mossèn Soler" [E-VAc, Fàbrica, no 1487, año 1519, f. 31r; Ibíd., nº 1488, año 1522, f. 26v]. Burgonyó había poseído hasta 1512 un beneficio en la parroquia de san Esteban deValencia [ADV, n 143/001, f. 98r]. Desde 1531 poseyó un beneficio en el altar de san Nicolás de la catedral [Ibid., f. 306v].

164 E-VAc, Fàbrica, no 1488 , año 1522, ff. 18v, 35 r. 
que tendrá bajo su tutela, y el hecho de que el apelliddilar no sea ajeno a la fimilia del organista titular ${ }^{165}$, no permiten descartar que existiese un nexo familiar.

La parquedad de los datos que suelen proporcionar los asientos de los libros de cuentas, no permiten en muchas ocasiones conocer con detalle y se guridad los períodos de ausencias del músico de Vic. No obstante, parece claro que, en parte del año administrati vo 1522, Pere Vila estuvo ausente, ya que dos personas más (Joan Soler y Miguel Villar), cobraron también por haber tañido los órganos de la catedral en ese $a_{n} 0^{166}$. Hasta el 1 de agosto de 1524 parece que Vila estuvo, al menos parcialmente, ausente de la catedral ${ }^{167}$. En este período, Francesc Bur gonyó y Miguel Villar sirvieron los órganos catedralicios ${ }^{168}$. A partir de 1525 y hasta su fallecimiento trece años despúes, Pere Vila aparece ya con re gularidad en los libros de cuentas, cobrando 30 libras por la Tresoreria y otras 30 libras (en ocasiones con 10 sueldos añadidos) por la Fàbrica, lo que significaba un aumento de 10 libras respecto a su primer salario. No obstante, Joan Soler y Joan Hervàs toda vía cobraron en 1526 y 1527 cantidades, se guramente atrasadas de años anteriores a 1525 , por tocar los ór ganos "quatuor mensium in absencia v enerabilis Petri Vila" o "en temps passat", respectivamente ${ }^{169}$.

Como ya ha observado Gregori, Vila había recibido un canonicato en la catedral deVic en $1519^{170}$. Esta condición canonical, que el músico hacía compatible con su actividad de organista en la catedral de Valencia, se refleja en la documentación de esta institución desde 1525 hasta $1528{ }^{171}$. En 1529, un par de documentos señalan e xplícitamente que había dejado de poseer tal canongía al referirse a él como "Petrus Vila, olim canonicus vicensis"172.

165 El marido de su sobrina Magdalena Vila se llamaba Llorenç Vilar, por lo que a Magdalena también se le conocía como "la Vilara" [Gregori I Cifré, Josep Maria: "La nissaga dels or ganistes...”, op. cit., p. 52]. A pesar de lo expuesto, hay que indicar que no está a favor de la posibilidad de vinculación de Pere Vila con Miguel Villar el hecho de que éste último redacta ba sus albaranes autógrafos siempre en castellano con el nombre "Miguel Villar", cuando Vila y los miembros de su f amilia que actuaron como procuradores siempre lo hacían en catalán. De todos modos, como se ha visto para Mateo Flecha, este hecho no puede considerarse decisivo.

166 E-VAc, Fàbrica, no 1488, año 1522, ff. 16v, 26v.

167 El 30 de septiembre de 1527, Pere Vila cobra 24 libras atrasadas del período del nueve meses desde el 1 de agosto de 1524 a 30 de abril de 1525 [E-VAc, Not. Gaspar Joan Abella, n 3705, 30 de septiembre de 1527].

168 Miguel Villar, además cobró por mo ver los fuelles del ór gano. [E-VAc, Fàbrica, nº 1488, año 1523, ff. 23v, 24v; E-VAc, Tresoreria, $\mathrm{n}^{\circ}$ 1292, año 1523, s.f.; Ibíd., año 1524, s.f.]. En el libro de cuentas de Tresoreria de 1523 también está cargado un pago a Pere Vila de 10 libras y 10 sueldos aunque lo cobró el 11 de abril de 1526 [E-VAc, Tresoreria, $\mathrm{n}^{\circ} 1292$, año 1523 , s.f.].

169 E-VAc, Not. Gaspar Joan Abella, nº 3704, 19 de marzo de 1526; E-VAc, Fàbrica, no 1488, año 1527, f. 27v.

170 Gregori I Cifré, Josep Maria: "La nissaga dels organistes...", op. cit., p. 54.

171 El primer documento es el albarán autógrafo fechado el 15 de septiembre de 1526 [E-V Ac, Tresoreria, $\mathrm{n}^{\circ}$ 1292 , año 1525, s.f.]. Ver transcripción completa en nota 173 y reproducción en Figura 4 . El último documento localizado en que se le ref iere como posesor del canonicato de Vic está fechada en 23 de mayo de 1528 [E-V Ac, Not. Gaspar Joan Abella, $n^{\circ}$ 3706, 23 de mayo de 1528]. Aproximadamente, ello encaja con el hecho de que hasta 1527 consta en los libros de las capas canonicales de la catedral de Vic [Gregori i Cifré, Josep Maria: "La nissaga dels organistes... ”, op. cit., p. 55].

172 E-VAc, Not. Gaspar Joan Abella, nº 3710, 19 de junio de 1529; Ibid., 15 de septiembre de 1529. 


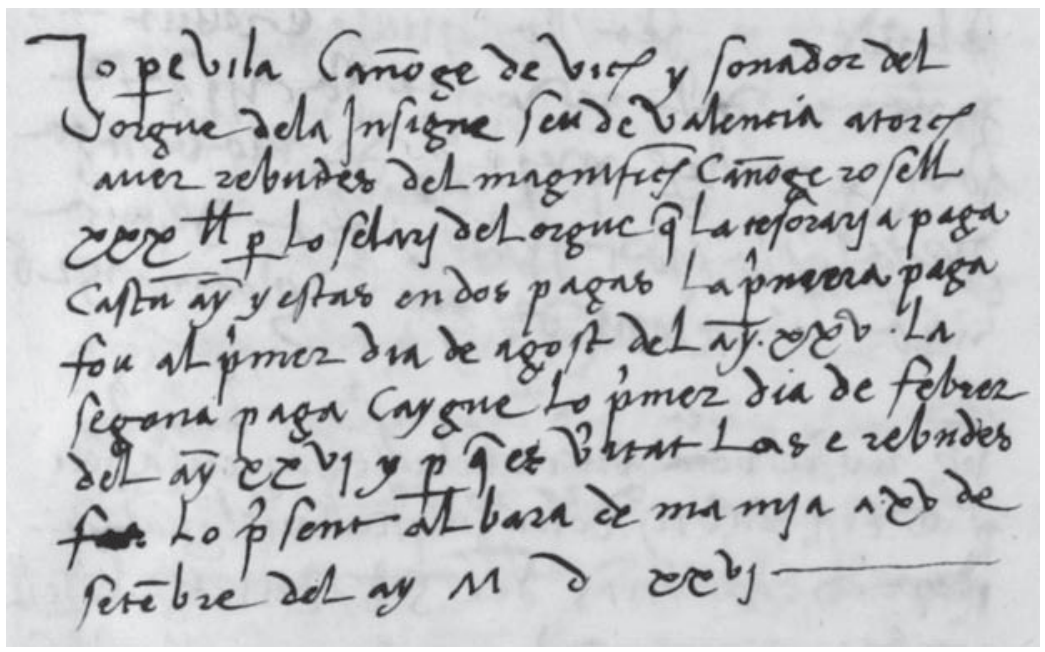

Figura 4. Albarán de Pere Vila en la catedral de Valencia (15-sep-1526) $)^{173}$

A partir de 1528, MigueVillar comienza a adquirir del cabildo derechos económicos por tañer el ǵano, sin que ello representase menguas en el salario que recibía Pere Vila, a quien además estaba subordinado. El 23 de mayo de 1528 se le concede el derecho a recibir los percances con e $\quad$ xpresa licencia de Vila ${ }^{174}$. Un nuevo logro para Villar tiene lugar el 14 de diciembre de 1530, cuando le es otor gada la cantidad anual de 15 libras pagaderas por la Fàbrica que le ase guraron unos ingresos fijos ${ }^{175}$. Sólo unas semanas después, el cabildo resolvió que "mossèn Miquel reba los percasos de sonar los orguens de mises votives si mossèn Vila no bol servir, y noresmenys la misa d'alba”, dejando así bastante claro que sus actuaciones tenían lugar en sustitución voluntaria de Pere Vila, quien ya contaría con alrededor de 65 años de edad ${ }^{176}$. Además de estas retribuciones consolidadas, Villar también recibió diversas subvenciones puntuales de la administración de la Almoina $^{177}$. En esta situación se mantuvo este organista hasta el fallecimiento de Pere Vila en 1538.

En 1534, Vila recibió dos pagos de su parte de salario de la Tresoreria a través de procuradores. El 8 de enero de 1534 fueron conjuntamente Gaspar Sagristà y Pere Alberch, los que cobraron 15 libras correspondientes a la paga de Na vidad de $1533^{178}$. Ambos eran alumnos del organista titular de

173 "Jo, Pere Vila, canonge de Vich y sonador del orgue de la insigne seu de València, atorch aver rebudes del magnífich canonge Rosell xxx lliures per lo selari del or gue que la tesoraria paga cascun an y, y estas en dos pagas. La primera paga fou al primer dia de agost del any Xxv. La segona paga caygué lo primer dia de febrer del any XxVI, y perquè és veritat las e rebudes, fas lo present albarà de mà mia a XV de setembre del a[n]y MDXXVI" [E-VAc, Tresoreria, n ${ }^{\circ}$ 1292, año 1525, s.f.].

174 E-VAc, Not. Gaspar Joan Abella, n 3706, 23 de mayo de 1528.

175 E-VAc, Not. Gaspar Joan Abella, no 3710, 14 de diciembre de 1530.

176 E-VAc, Not. Gaspar Joan Abella, no 3710, 15 de marzo de 1531.

177 E-VAc, Almoina, Procura Major, nº 5692, año 1528, f. 73r; Ibíd., año 1529, f. 48r; E-VAc, Not. Gaspar Joan Abella, $n^{\circ}$ 3706, 31 de enero de 1530; Ibíd., nº 3710, 26 de abril de 1530; E-V Ac, Almoina, Procura Major, nº 5692, año 1531, f. 147r; Ibíd., nº 5694, año 1535, f. 59v; Ibíd., año 1536, f. 49v; Ibíd., año 1537, f. 55v.

178 "Nosaltros, Gaspar Sagristà y Pere Alberch, procuradós del re verent mosèn Pere Vila, musich dels or guens de la present seu, consta de la procura ab acte reb ut per Paulo de la Cuesta en lo dia de air, en lo dit nom a vem rebut de vos, reverent 
la catedral. El primero era o había sido criado de Vila, mientras que el se gundo, apodado más tarde también "Vila" era sobrino no carnal, y quizá, el más brillante músico de la saga ${ }^{179}$. El 3 de noviembre del mismo año, el mismo Pere Alberch, esta vez en solitario, recibió en nombre de Pere Vila las 30 libras de la Tresoreria que correspondían anualmente a su tío ${ }^{180}$. Desde 1536, año en que Pere Alberch comenzó su actividad como organista de la catedral de Barcelona, fue otro sobrino llamado P au Vila quien ejerció de procurador ante la catedral de Valencia para recibir pagos por el salario de su tío, ya aquejado, seguramente, de problemas de salud ${ }^{81}$. El 1 de febrero de 1538, PereVila dictó su testamento en Valencia ante el notario LluísTrullench ${ }^{182}$. El organista de la catedral falleció en ese mismo año poco tiempo después, ya que Pau Vila "com a hereu de mossèn Vila, quondam sonador del orgue de la seu" recibía 4 libras, 10 sueldos y 8 dineros como parte del salario de su tío, según albarán fechado en 7 de agosto de $1538^{183}$.

Tras el óbito de Pere Vila, su sucesor en los órganos de la catedral de Valencia fue Miguel Villar, quien ya realizaba sustituciones del or ganista de Vic desde 1522. P ara ejercer dicho oficio percibió el mismo sueldo de 60 libras (30 pagaderas por la Tresoreria y 30 por la Fàbrica) que poseía su antecesor Vila en la última etapd ${ }^{84}$. Villar será, pues, el único oganista de la catedral durante el søundo magisterio de Mateo Flecha, continuando en el oficio tras la marcha de éste en 1541.

Para que el or ganista pudiese tañer el ór gano, era necesaria la presencia de un entonador que moviese los fuelles que insuflaban el aire al instrumento. Por este trabajo, el entonador de la catedral de

mestre Pere Martí, sots-sagristà de la seu re gent la present Tresoreria, quinse lliures, y són de la paga de Nadal proppasat qu e la Tresoraria respon al dit mosèn Vila per dobble penció de sonar l'orgue. E per la veritat, jo Gaspar Sagristà, fas lo present de pròpia mà sota escrit de mà de Pere Alberch a vuit de giner MDXXXIII. Jo, Pere Alberch, atorch lo sobredit estar e veritat fet de pròpia mà dit dia y any" [E-VAc, Tresoreria, $\mathrm{n}^{\circ} 1293$, año 1533, s.f.].

179 Gaspar Sagristà, natural de Manresa, era or ganista de la parroquia de san Esteban de Valencia en 1538, año en que, por mediación de Pere Alberch, obtuvó la plaza de organista de la catedral de Girona que mantuvo hasta su muerte, posiblemente en 1573 [G REgori i Cifré, Josep Maria: "Pere Alberch, artífex de la relació musical entre les seus de Girona i Barcelona en el Renaixement tardà", en Annals de l'Institut d'Estudis Gironins , 28 (1985-1986), pp. 281-298]. Pere Alberch i Ferrament, àlias Vila, nació en Vic en 1517. En abril de 1536 recibió el nombramiento de oganista de la catedral de Barcelona.A la muerte de Pere Vila, quien había adquirido pocos meses después la titularidad de dicho car go a cambio de un le gado de 600 ducados de oro a la catedral barcelonesa, heredó dicha titularidad, que mantuvo hasta su muerte en 1582. Según Gregori, Alberch habría realizado dos viajes a Valencia en 1537 y 1538; este último coincidiendo con los últimos días de PereVila. Mantuvo una notable actividad como consejero para varios templos catalanes en cuestiones de or ganería, y desarrolló una activa actividad pedagógica. La mayoría de sus obras de clara atribución están contenidas en dos libros de madrigales publicados bajo el título de Odarum, que vieron la luz en Barcelona en 1560 y 1561 [Gregori I Cifré, Josep Maria: "La nissaga dels organistes...", op. cit., pp. 61-72; ID.: La Música del Renaixement..., op. cit., pp. 330-342; ID.: "Vila. 2. Alberch i Ferrament, Pere [Pere Vila]", en Diccionario de la Música Española e Hispanoamericana, Emilio Casares Rodicio (Ed.), v ol. 10 (Madrid, Sociedad General de Autores y Editores, 2002), pp. 886887].

180 "Yo, Pere Alberch, nebot y procurador del v enerable mosèn Pere Vila, sonador del hor gue, e rebuts de vos, mestre Pere Martí, sots-sagristà regent la Tresoreria, trenta liures per lo salari que toca a la dita Tezoreria per lo sonar del orgue, enteza y compreza qualsevol cautela que lo dit mon honcle li haja fet. Fet de pròpia mà a tres de noembre a MDXXXIII" [E-VAc, Tresoreria, $\mathrm{n}^{\circ} 1293$, año 1534 , s.f.].

181 El 19 de noviembre de 1536 "Pau Villa, procurador y nebot del reverent mossèn Pere Villa, sonador dels orgens de la seu" recibe 15 libras por la paga de san Juan de ese año de laTresoreria. El 8 de enero de 1537 recibió las otras 15 libras de la paga de Navidad [E-VAc, Tresoreria, n $^{\circ} 1293$, año 1536, s.f.]. localizar.

182 Gregori i Cifré, Josep Maria: "La nissaga dels or ganistes...", op. cit., p. 51. Dicho testamento no se ha podido

183 E-VAc, Fàbrica, no 1489 , año 1537, s.f.

184 Pueden consultarse los pagos de los libros de Tresoreria (n 1293) y Fàbrica (n $\left.{ }^{\circ} 1489-1490\right)$ durante los años 1538 1541 para comprobar el cobro de dicho salario. 
Valencia recibía en este período la cantidad de 12 libras y 12 sueldos al año a trés de la administración de la Fàbrica. Durante el primer magisterio de Flecha, ejerció este oficio Joan Álv aro. En 1532 fue sustituido por Joan Camps, quien debió de marcharse en 1540, tomando entonces el rele vo Andreu Bleda, elegido por ser un antiguo escolán de la catedral ${ }^{185}$.

La consueta de 1527 indica, para algunos oficios, la necesidad o no de la intervención del órgano. La Tabla 2 sintetiza estas indicaciones en una relación. No recibe este aspecto un tratamientabaustivo en el manuscrito, por lo que no hay que considerar esta relación como cerrada. No obstante, se pueden observar ciertas costumbres como la presencia del ór gano en las misas dominicales y en los sábados de Cuaresma, así como la ausencia obligada del ór gano en los oficios del Sábado Santo, de amplia pervivencia en nuestros días.

\begin{tabular}{|c|c|c|c|}
\hline Festividad & Oficio & Sí/No & Fol. Consueta \\
\hline Domingos & Misa & SÍ & $106 \mathrm{v}$ \\
\hline Procesión de acción de gracias dentro de la seo & Te Deum & Sí & $96 \mathrm{r}$ \\
\hline Feria Quinta. Primera semana de Cuaresma & Misa de Corpus Christi & Sí & $27 \mathrm{v}$ \\
\hline Sábado de la primera semana de Cuaresma & Misa de la Virgen María & SÍ & $29 \mathrm{r}$ \\
\hline Sábado de la primera semana de Cuaresma & Vísperas & NO & $29 \mathrm{v}$ \\
\hline Sábado de la segunda semana de Cuaresma & Misa de la Virgen María & Sí & $31 \mathrm{v}$ \\
\hline Sábado de la cuarta semana de Cuaresma & Misa de la Virgen María & Sí & $32 \mathrm{v}$ \\
\hline Sábado Santo & Vísperas & NO & $54 \mathrm{v}$ \\
\hline Sábado Santo & Completas & NO & $54 \mathrm{v}$ \\
\hline Sábado Santo & Regina caeli & NO & $54 \mathrm{v}$ \\
\hline Pascua de Pentecostés & Maitines & SÍ & $69 \mathrm{v}$ \\
\hline Miércoles tras la Pascua de Pentecostés & Vísperas & SÍ & $71 \mathrm{v}$ \\
\hline Miércoles tras la Pascua de Pentecostés & Misa & SÍ & $71 \mathrm{v}$ \\
\hline Siti de sant Jaume & Misa & SÍ & $97 \mathrm{r}$ \\
\hline Navidad & Primeras vísperas & SÍ & $99 \mathrm{v}$ \\
\hline Octava de la Epifanía & Misa & SÍ & $108 \mathrm{r}$ \\
\hline San Pablo & Misa & SÍ & $136 \mathrm{v}$ \\
\hline Osunción de la Virgen María & Maitines & SÍ & $144 \mathrm{v}$ \\
\hline Circuncisión & Maitines & SÍ & $166 \mathrm{r}$ \\
\hline Maitines & SÍ & $194 \mathrm{r}$ \\
\hline
\end{tabular}

185 El 26 de junio de 1540, los miembros del cabildo "eligerunt in manchatorem or ganorum sedis Valencie Andream Bleda, attento quod fuit scolaris antiqus in dicta ecclesia" [E-VAc, Not. Gaspar Joan Abella, no 3713, 26 de junio de 1540]. Bleda, natural de Morella, había sido recibido como escolán el 5 de mayo de 1530 [E-VAc, n 70, f. 208r]. 


\begin{tabular}{|c|l|c|c|}
\hline Encarnación & Maitines & SÍ & $194 \mathrm{r}$ \\
\hline Resurrección & Maitines & SÍ & $194 \mathrm{r}$ \\
\hline Ascensión & Maitines & SÍ & $194 \mathrm{r}$ \\
\hline Pascua del Espíritu Santo & Maitines & SÍ & $194 \mathrm{r}$ \\
\hline Trinidad & Maitines & SÍ & $194 \mathrm{r}$ \\
\hline San Juan Bautista & Maitines & SÍ & $194 \mathrm{r}$ \\
\hline Todos los Santos & Maitines & SÍ & $194 \mathrm{r}$ \\
\hline
\end{tabular}

Tabla 2. Intervención del órgano en los oficios según la Consueta de 1527

\section{Instrumentistas de contratación esporádica: Ministriles, trompetas y atabales}

La catedral deValencia creó su grupo estable de ministriles en 1560, con la firma de capitulaciones con un grupo de cuatro de estos músicos de viento. En ellas se establecían claramente sus obligaciones a lo largo del año litúrgico y el salario que recibían a cambio ${ }^{186}$. Sin embargo, este hecho no significa que con anterioridad no hubiesen actuado ministriles para la catedral, tanto en el interior del templo como en el exterior. De hecho, en el período de estudio, situado precisamente en años precedentes a la institucionalización de estos músicos, han podido encontrarse, aunque ciertamente muy escasas, evidencias de ello.

Por lo que respecta a la intervención de instrumentos en el interior de la catedral en el período de estudio, la primera y única noticia que hemos podido hallarprocede de la consueta de 1527. Para el día de "la verge Maria de Sperança bisbal y quart dia de la Sapiència", se establece que:

E aprés de les primeres espres y completes, entre quatre y cinch comencen a la Sperança unes completes ab los chantres y salve, y aprés música de sonadors que dura fins a prop de les sis hores, la qual festa deà mestre Martí Enyego, canonge de València ${ }^{187}$.

Desafortunadamente, se desconocen los instrumentos que se tañían en esta suerte de pequeños "conciertos" instrumentales extralitúrgicos, precedentes de las siestas que se desarrollaron plenamente en los siglos siguientes ${ }^{188}$. La misma fuente establece con detalle las capas que la catedral prestaba a cantores y "sonadors" para la procesión de Corpus Christi"89.

186 Climent Barber, José: Juan Bautista Comes..., op. cit., pp. 62-63; ÍD.: “La capilla de música...”, op. cit., pp. 64-65.

187 E-VAc, $n^{\circ} 70$, f. $167 \mathrm{v}$.

188 Sobre el concepto y e volución de las siestas en España, v er especialmente EzQuERro Esteban, Antonio: "Siesta", en Diccionario de la Música Española e Hispanoamericana , Emilio Casares Rodicio (Ed.), v ol. 9 (Madrid, Sociedad General de Autores y Editores, 2002), pp. 1003-1007.

189 "Per als cantors y sonadors: les dalmàtiques de les steletes v erdes, les de cetí blanch de l'alba y les dos de v ellutat blanch de l'alba, les dos verdetes, les dos blaves, les tunicelles del senyor bisbe" [Ibíd., f. 76r] 
El entorno procesional de los ministriles es, precisamente, del que más datos disponemos. En la procesión de san Luis, la consueta indica que "ana ven en la professó sis bordons ab sis capes, y los cantors ab ses dalmàtiques entorn del llit ab los ministrés y sons del dia de la Verge Maria" ${ }^{190}$. La expresión anterior sugiere, además, que en una de las procesiones por festividades de la Virgen intervenían los ministriles con alguna confguración especial, que debiera de imitarse el día de san Luis. No obstante, no es sino hasta el año administrati vo de 1536 cuando se ha podido localizar el primer pago por parte de la seo a estos músicos. Este año se hace entre ga un ducado y medio a los ministriles que asistieron a la procesión de la Inmaculada Concepción, a la que es probable que se ref iriera la consueta en la cita anterior ${ }^{191}$. Dentro del período de estudio, se repetieron los pagos a ministriles por la asistencia a dicha procesión en los años 1538 y $1539^{192}$. Aunque no se indica en los correspondientes asientos de los libros de cuentas a qué ministriles se contrató, es probable que fueran los mismos que en 1542, representados por Miquel Pujol, cobraron por su intervención en el mismo acto ${ }^{193}$. Este ministril formaba parte en 1544 del conjunto de ministriles municipal omenestrils de la ciutat, grupo creado oficialmente en $1524^{194}$. En las capitulaciones para la institución de los ministriles de la ciudad se establecen una serie de procesiones de asistencia obligatoria (san Jor ge, Ángel Custodio, san Miguel, san Dionisio, Corpus Christi, Asunción de la Virgen y san Vicente Ferrer) entre las que no se encuentra la de la Inmaculada Concepción ${ }^{195}$. Por tanto, este hecho podría explicar que la música de ministriles en esta última procesión corriese económicamente a cargo de la catedral, contando con los mismos ministriles municipales que participaban en el resto de procesiones generales rele vantes, de las que se hacía cargo la ciudad.

La seo también sufragó en algunas ocasiones los costes de la música de trompetas y atabales para la misma festividad de la Inmaculada Concepción. El asiento más temprano encontrado de este tipo data del año administrativo de 1530, en que se pagaron 9 sueldos por un grupo que sonó en la torre de la catedral o del "Micalet" ${ }^{196}$. Más tarde, en los años 1538, 1539 y 1542 se repitieron los pagos a los trompetas y atabales, con una mayor cuantía, para acompañar la procesión. Incluso en este último año, la catedral contrató a un trompeta para realizar el pregón de dicho acto ${ }^{197}$.

190 Ibid., f. 171r.

191 "Ítem, pose en data que dit dia paguí als ministrés que hanaren en dita professó [de la Inmaculada Concepción] un ducat y mig per migà del senyor canonge Dassió" [E-VAc, Fàbrica, no 1489, año 1536, s.f.].

192 E-VAc, Fàbrica, n ${ }^{\circ} 1489$, año 1538, s.f.; Ibíd., año 1539, s.f.

193 E-VAc, Fàbrica, no 1490, año 1542, albaranes, f. 3r, 16 de diciembre de 1542.

194 RUIZ DE LIHORY, José: op. cit., pp. 138-139.

195 Ibid., pp. 135-137.

196 "Ítem per les trompetes e tabals que sonaren en lo campanar, nou sous" [E-VAc, Fàbrica, n 1489, año 1530, f. 34r].

197 En 1538 y 1539 se pagó 1 libra y 5 sueldos a los trompetas, más 12 sueldos a los atabaleros. En 1542 se pagó 1 libra y 1 sueldo al conjunto completo, más 5 sueldos al trompeta Joan Balaguer por hacer el pregón [E-VAc, Fàbrica, nº 1489, año 1538, s.f.; Ibid., año 1539, s.f.; E-VAc, Fàbrica, nº 1490, año 1542, s.f.]. 


\section{2. Órganos y Organería}

Cuando Mateo Flecha llegó a la catedral en 1526 existían, al menos, dos órganos, llamados mayor y menor, enfrentados uno a otro en el coro situado en la nave central en la zona que cubren los segundos arcos contando desde el crucero. El mayor había sido el reciente resultado de unas importantes obras realizadas entre 1511 y 1513 por los ganeros Diego Ortiz y PereAndreu Teixidor, junto a un gran número de artesanos y artistas ${ }^{198}$. Éste último maestro de ór ganos era, además, un presbítero beneficiado de la catedral, lo que se guramente facilitó que continuase posteriormente en contacto con los instrumentos, realizando labores de mantenimiento ${ }^{199}$. De hecho, el 4 de enero de 1527, el cabildó acordó que, en adelante, la administración de laFàbrica se hiciera cargo del pago aTeixidor de 2 ducados mensuales en concepto de salario por dichos trabajos ${ }^{200}$. Esta cantidad aumentó a 3 ducados mensuales, que percibió de febrero a abril de 1530, para desaparecer, a partir de ese momento, los pagos de su salario de los libros de cuentas de Fàbrica ${ }^{201}$. Pero Teixidor siguió realizando reparaciones o pequeñas mejoras y ocupándose de la afinación de los instrumentos hasta el año administrativo de 1538, al menos, por cuyos trabajos cobró de forma puntual ${ }^{202}$. A partir de 1541 aparece en los libros de cuentas de la Fàbrica el organero Pedro Serrano quien sustituyó a Teixidor en sus labores de afinación del órgano ${ }^{203}$.

Entre los trabajos realizados por PereAndreu Teixidor en el período de estudio, destacaron los que, por su relativamente alto coste, fueron incluso objeto de capitulaciones ante notario en $1533^{2}$. Se trataba

198 SAnchis y Sivera, José: op. cit., pp. 228-230.

199 El 21 de enero de 1514 consta su colación en el beneficio del altar de san Bernabé en la parroquia de santo Tomás de Valencia, al que el mismo día renunció por causa de permuta [ ADV, $\mathrm{n}^{\circ}$ 143/001, ff. 111v]. El 24 de enero de 1531 tiene lugar su colación en el beneficio de la catedral bajo la advocación de san Salvador [Ibíd., f. 313r].

200 " [...] et de cetero dictus suboperarius solut eidem donec deserviet organo dicte sedis pro quolibet mense duos ducatos pro salario conreando et reparandi et recognoscendi dictum or ganum" [E-VAc, Not. Gaspar Joan Abella, n 3704,4 de enero de 1527]. No obtante, los libros de cuentas re velan que anteriormente ya venía percibiendo esta cantidad, al menos, desde 1525 [EVAc, Fàbrica, no 1488 , año 1525, f. 33v].

201 E-VAc, Fàbrica, no 1488, año 1529, ff. 36v-37v.

202 Como ejemplos de trabajos de mantenimiento, los pagos a Teixidor de 8 sueldos por "una vigueta per al or gue" o de 4 sueldos por "una roda de corda de cànem per a les portes del or gue maior" [E-VAc, Fàbrica, no 1489, año 1533, s.f.; Ibíd., año 1539, s.f.]. Teixidor cobró 1 libra, 17 sueldos y 3 dineros por afinar el órgano [E-VAc, Fàbrica, no 1489, año 1536, s.f.]. No obstante, debieron de realizarse en el período bastantes más operaciones de afinación ya que e xisten pagos, algunos de ellos al propio Teixidor, por los trabajos del entonador en estas sesiones, que en algun ocasión se prolongaron hasta 22 días [E-VAc, Fàbrica, no 1488, año 1529, f. 37r; Ibíd., no 1489, año 1533, s.f.; Ibíd., año 1535, f. 34v; Ibíd., año 1538, s.f.].

203 Se han encontrado pagos a Serrano en 1541 y 1542. Por tanto, es probable que continuase en estas funciones durante más tiempo [E-VAc, Fàbrica, no 1490, año 1541, s.f.; Ibíd., año 1542, s.f.].

204 El texto de las capitulaciones en lengua vernácula fechadas el 19 de junio de 1533 para la reparación del ógano mayor, firmadas entre Jeroni Carròs, canónigo de la catedral nombrado síndico para este asunto, de una parte, y Pere Andreu Teixidor, beneficiado y organero, Francesc Joan Manresa, doctor en derecho, Melcior Sallit, ciudadano, y Miquel Pujades, mercaderde otra parte, es el siguiente:

"Et primo es stat pactat e concordat entre les dites parts, que lo dit re verent e noble senyor don Hierònim Carròs, canonge administrador de la dita sglésia sia tengut e obligat, com ab los presents se obliga, de donar e pagar al dit mossèn Pere Andreu Texidor, mestre de or guens qui dessús, les quantitats da vall scrites per afinar, concordar e ab ef fecte fer sonar lo or gue maior de la dita sglésia e los jochs en aquell $\mathrm{f}$ abricat, çò és: lo joch maior de vint y quatre palms e lo or gue de dotze palms apel·lat de la Sperança, e lo orgue més alt de dotze palms compartits entre castells o mitres, e encara lo orgue de dotze palms de la cuberta, los quals quatre jochs tots estan constituits en lo mateix orgue principal, les quals quantitats pagadores són les infrasegüents:

Primo, lo dit senyor canonge Carròs, l'administrador qui dessús, a de donar o fer donar al dit mossèn Pere Andreu Texidor, organiste, dos quintars de stany per obs de adobar los canons del dit or gue. E més trenta jornals de fuster si seran menester p er a fäbrica e restauració del dit orgue. 
de realizar todos los trabajos de reparación necesarios para dejar en perfecto estado de funcionamiento el nuevo órgano mayor, que veinte años después de su construcción debería estar un tanto deteriorado. Asimismo, el contrato incluía la posterior afinación del instrumento, supervisada por expertos organeros y organistas que nombraría el cabildo. Es interesante la descripción que en las capitulaciones se hace este órgano, donde se señala la existencia de cuatro jue gos, correspondientes a otros tantos "ór ganos", uno de 24 palmos y tres de 12 palmos, uno de los cuales llamaban "de la Sperança" 205.

La catedral también hizo uso de órganos portativos en las procesiones. Se tiene la certeza del uso de un pequeño órgano en la procesión de Corpus Christi durante el período 1534-1539. El instrumento iba situado delante de la custodia, portado por dos hombres y con la presencia imprescindible del oganista y entonador. Al parecer, la seo no disponía de la propiedad de estos pequeños ór ganos durante estos años, ya que los alquilaba, pagando además los costes del transporte al domicilio del arrendadorSe conocen los nombres de dos de los propietarios: "mossèn Soler" (1535 y 1536) y "mestre Diego" (1534 y 1537) ${ }^{206}$.

\subsection{LIBROS DE MÚSICA}

La administración de la Fàbrica se hacía cargo en esta época de los pagos relacionados con los libros de música práctica, tanto en lo que se refería a la adquisición de ejemplares ya acabados, como a la confección de nuevos libros bajo la tutela de la catedral y, por supuesto, a la conserv ación de los ejemplares que ya existían en la librería.

Ítem, més ha de donar e pagar lo dit senyor canonge y administrador al dit mossèn Pere Andreu, organiste, axí per les mans e treballs de aquell sustenidors en refinar e redreçar dit or gue, com encara per altres despeses com són cuyros, claus, cola, fusta e ajudants per a la refinació del dit orgue, per totes despeses, salaris e treballs, trenta ducats de or, los quals li haia de donar en lo principi de la refinació del dit orgue, sots les penes davall scrites.

Ítem, més és stat pactat e concordat entre les dites parts que lo dit mossèn Pere Andreu Teixidor sia tengut e obligat, com ab los presents se obliga, de donar acabat e affinat lo dit or gue sonant juxta la proporció de aquell a juhí de or ganistes experts en semblant offici, e axí mateix de persones expertes en lo exercici de la música, eligidores a ordinació del reerent capítol puix no sia lo venerable mossèn MiquelVilar, prevere, per a la festa de Nadal primer vinent e ay mil cinch-cents y trenta-quatre, segons se pertany a bons mestres de orguens, sots les penes davall scrites." [E-VAcp, Not. Pere Ferrando, no 22013, 19 de junio de 1533]. Aunque se señala el precio de 30 ducados de oro en el texto de las capitulaciones, otros documentos relacionados con el pago de estos trabajos indican que fueron realmente 50 ducados de oro los que recibió Teixidor. Además, el cabildo hizo frente al pago de 7 libras, 17 sueldos y 6 dineros por tres arrobas de estaño, así como 7 sueldos y 3 dineros por 15 libras de plomo para los trabajos [E-Ncp, Not. Pere Ferrando, n 22013, 20 de junio de 1533; Ibíd., 26 de junio de 1533; E-VAc, Fàbrica, no 1489, año 1533, ff. 10r, 10v].

205 Esta descripción no parece ajustarse exactamente a las capitulaciones para su construcción de 1510, en que se indica que "los canons majors sien de XXV palms de la basa en amunt ..., en los de fusta detras de XXX palms" [citado en S ANCHIS Y SIVERA, José: op. cit., pp. 228-230]. La palabra "or gue" se empleaba, desde época medie val para designar, tanto el instrumento completo como cada uno de sus juegos de tubos. Debido a que el primitivo órgano gótico estaba compuesto por dos o más cuerpos diferenciados entre sí, que sonaban con diferentes teclados e incluso podían estar afinados en diversos diapasones, en ocasiones se utilizaba la forma en plural "oguens" para referirse a la totalidad del instrumento y la singular de "gue" a cada uno de loscuerpos de que estaba compuesto. Esta denominación convivió desde principios del siglo xv con la que empleaba el singular "orgue" para referirse a todo el instrumento, la cual fue ganando terreno progresivamente [SAURA BuIL, Joaquín: Diccionario Técnico-Histórico del Órgano en España (Barcelona, Institución "Milà i F ontanals", Consejo Superior de In vestigaciones Científicas, 2001), pp. 337-338].

206 E-VAc, Fàbrica, no 1489, año 1534, f. 34r;Ibid., año 1535, ff. 26v, 27v; Ibíd., año 1536, s.f.; Ibíd., año 1537, s.f.;Ibíd., año 1538, s.f.; Ibíd., año 1539, s.f. El primer nombre podría corresponderse con el oganista Joan Soler, quien actuó como tal en la catedral durante las ausencias de Pere Vila, mientras que el segundo es posible que fuese el organero Diego Ortiz, quien junto con Pere Andreu Teixidor, firmó las capitulaciones del órgano de 1510. 
En el período de estudio se tiene constancia de la compra de dos libros de canto de ór gano. El primero, "hun llibre de cant de orgue per al cor", fue comprado por el precio de 6 libras al librero Joan Huguet con fecha de 18 de no viembre de 1526, al poco tiempo de iniciar Mateo Flecha su primer magisterio en la catedra ${ }^{207}$. El segundo, "un libro de canto dórgano" de formato bastante más reducido a juzgar por su precio de sólo 10 sueldos, fue adquirido a un presbítero de la parroquia de san Andrés llamado Antoni Marquès, por provisión del cabildo de 14 de octubre de $1531^{208}$.

Asimismo, la catedral promovió la confección de libros de canto. Durante los años 1532 y 1533 constan diversos pagos que testimonian el encargo que recibió el cantor Jaume Asensi para copiar un número indeterminado de libros de canto de ór gano, así como para añadir música a otros e xistentes, entre los que son citados expresamente el "libre dels magnificats" y el "libre dels motets" 209. La copia de un libro que contenía la Pasión -desconocemos si en canto de ógano o en canto llano- fue realizada en 1526 por el mismo Jaume Asensi, quien también se encargó de la compra del papel y de su pautado previo. Ninguno de los libros de canto de ór gano citados se puede identificar con alguno de los que conserva actualmente el archivo de la catedraf ${ }^{10}$. Del mismo modo, la librería de canto llano se aumentó en este período con libros elaborados por encar go de la catedral. En 1529, se copiaron unos salterios para el coro por Joan de Céspedes, para lo cual se utilizaron al menos tres docenas de penaminos ${ }^{211}$. En 1538 , se confeccionaron más libros para el coro, uno de los cuales contenía los invitatorios ${ }^{212}$.

Por último, se realizaron trabajos de reparación y encuadernación de los libros e xistentes, encomendados hasta 1535 al librero Pere Borbó ${ }^{213}$. En 1537, el propio sochantre Verdú [Verduch]

207 "Ítem més pose en data VI lliures que he donat e pagat a mestre Johan Huguet, llibrer, per hun llibre de cant de orgue per al cor. Consta ab àpoca rebuda per Gaspar Abella, notari, a XVIII de nohembre DXXVI" [E-VAc, Fàbrica, n 1488, año 1526, f. $25 \mathrm{v}]$.

208 "Ítem, a quatorce de otubre fue pro veído por el reverendo capítulo que diese dies sueldo a un capellán que se llama Antoni Marquès, prevere que canta en sant Andreu, por un libro de canto dórgano para la seu, del qual tengo albalá de su mano" [E-VAc, Fàbrica, no 1489 , año 1531, f. 32r].

209 "Ítem, a mossèn Asensi per a notar hun libre de cant en diverses partides, vint y huna liura, quatorze sous, tres diners"' [E-VAc, Fàbrica, no 1489, año 1532, f. 30r]; "Ítem, pose en data III lliures XV sous, les quals he pagat per lo paper e paltar dels llibres de cant d'orgue que's feren nous. Consta ab cautela de la mà de mossèn Cristòfol, chantre e mestre de la capella." [E-VAc, Almoina, Procura Major, $\mathrm{n}^{\circ}$ 5693, año 1532, f. 50v]; "Ítem, pose en data que haxvIII de maig paguí a mossèn Assensi, cantor, deu sous y mig per una resta que li era deguda de uns libres que notà de cant de orgue en lo any 1532 " [E-VAc, Fàbrica, n 1489 , año 1533, s.f.]; "Ítem, pose en data que ha 12 de joliol paguí a mossèn Jaume Asensi, prevere, per notar una partida en lo libre de ls magnificats, set sous." [Ibid.]; "Item, pose en data que haviI de nohembre paguí a mossèn JaumeAsensi, cantor de la seu, quaranta quatre sous y huyt per una partida que notà en los libres de cant de or gue [Ibíd.]; "Ítem, pose en data que ha 23 de maig paguí a mossèn Jaume Asensi, cantor, dihuyt sous y mig per notar una partida en lo libre dels motets.” [Ibíd.].

210 Se entregaron 10 libras y 6 sueldos "a mossènAsensi, cantor, per a comprar lo paper per al Pasi, pautar e notar aquell" [E-VAc, Fàbrica, no 1488, año 1526, f. 26v]. El catálogo de fondos musicales de la catedral de Valencia puede consultarse en Climent Barber, Josep: Fondos Musicales de la Región Valenciana, I, Catedral Metropolitana de Valencia (Valencia, Instituto de Musicología, Institución Alfonso el Magnánimo, Diputación Provincial de Valencia, 1979).

211 Se pagaron: 1 libra y 18 sueldos a "Anthoni Gay, aluder, per dos dotzenes de pre gamins per a començar los saltiris del cor a raó de XVIIII [sueldos] la dotzena" [E-VAc, Fàbrica, n' 1488, año 1529, f. 34r]; 4 libras y 4 sueldos a "Joan de Céspedes, per començ dels psaltiris per al cor" [Ibíd., f. 34v]; 3 libras y 3 sueldos a "Joan de Céspedes, en part del que havia de haver per los saltiris que fa per a la seu" [Ibid., f. 36r]; 1 libra y 1 sueldo al mismo por el mismo concepto [Ibíd., f. 36v]; 19 sueldos a "Anthoni Guay, aluder, per una dotzena de pregamins per a fer lo dit psaltiri” [Ibíd.].

212 "Item, a mossèn Reguart per quatre dotzenes de pregamins per fer los llibres de cor. IIII lliures, IIII sous."; "Ítem, pose en data dos lliures, deu sous per obs de quernar lo llibre novament fet dels invitatoris." [E-VAc, Fàbrica, no 1489, año 1538, s.f.].

213 En 1529 se le pagaron 13 sueldos y 8 dineros "per uns libres que ligà per al cor déalència." [E-VAc, Fàbrica, nº 1488, año 1529 , f. $34 \mathrm{v}$ ]. "Ítem, pose en data que haxvIII de juny paguí a mestre Borbó, per adobar lo libre de pregamí dels diputats, onze 
recibió un sueldo "per cosir uns querns de un llibre y v eta per a giradors" ${ }^{214}$, mientras que el año siguiente fue un librero llamado Modardis el que puso a punto los libros del coro ${ }^{215}$.

\section{NUEVAS PERSPECTIVAS EN TORNO AL CONTEXTO CREATIVO DE ALGUNAS DE LAS ENSALADAS DE MATEO FLECHA}

El interés musical y literario del corpus de ensaladas de Mateo Flecha ha animado a di versos autores de las últimas décadas a tratar de realizar acercamientos al conte xto creativo de las obras. En estos trabajos, basados fundamentalmente en el contenido de los te xtos o en aspectos de técnica composicional, se han tratado aspectos como su cronología, lugar y moti vo de composición. Sin embargo, la falta de datos biográficos del autor ha sido siempre un obstáculo que ha obligado a tratar estas cuestiones con elevadas dosis de especulación ${ }^{216}$.

Los nuevos datos sobre los magisterios de Flecha en la catedral deValencia, por sí solos, no permiten dilucidar de forma definitiva ninguno de los aspectos mencionados. No obstante, sí abren nves perspectivas para continuar en esa labor de acercamiento. En este apartado, por tanto, no se pretende sino e xponer brevemente algunas nuevas ideas o posibilidades que sur gen a la luz de los datos ahora presentados, que puedan sumarse a las ya formuladas o hacer reflexionar sobre la necesidad de su revisión. Por consiguiente, no se trata, en absoluto, de un estudio sistemático y en profundidad de la cuestión.

Son varias las ensaladas que se han vinculado a la ciudad de Valencia y, en concreto, a la corte de los duques de Calabria. Romeu fue el primer analista de la cuestión. En su opinión, era v erosímil que "Flecha compusiera en Valencia sus ensaladas conocidas, o por lo menos la casi totalidad de las mismas", señalando un hipotético período de presencia en Valencia, de 1534 a $1544{ }^{217}$, que se ha demostrado posteriomente a todas luces incorrecto a tenor de los datos procedentes de Sigüenza y Valencia, ya expuestos en este trabajo. No obstante, Romeu sólo reconoce indicios que apo yen esta vinculación en las tituladas La Viuda, Los Chistes, La Negrina y El Jubilate ${ }^{218}$. Ferran Muñoz, por su parte, estableció cone xiones valencianas, con diferente grado de no vedad y consistencia, para la totalidad de las ensaladas conocidas de Flecha cuya autoría estáxplícitamente indicada en las fuentes ${ }^{21}$. El estudio integral más reciente de Maricarmen Gómez Muntané, rebaja a sólo tres el número de estas

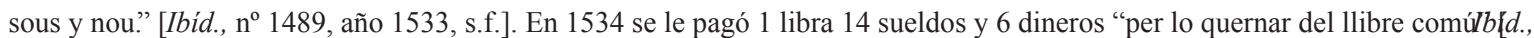
año 1534, f. 26r]. En 1535 recibió 8 sueldos y 6 dineros "per adovar hun libre del cor" [Ibíd., año 1535, ff. 29v, 34v].

214 E-VAc, Fàbrica, no 1489, año 1537, s.f. El mismo Verdú encargó “adobar y quernar hun libre del cor” en 1539 [Ibíd., año 1539 , s.f.].

215 Se entregaron 4 libras y 5 sueldos a “mestre Modardis, llibrer, en dues partides per lo adobar dels llibres del cor." [EVAc, Fàbrica, no 1490 , año 1540, s.f.].

216 Destacan en sus análisis Romeu Figueras, Josep: "Mateo Flecha el Viejo...”, op. cit.; MuÑoz, Ferran: op. cit.; Flecha, Mateo: Las Ensaladas (Praga, 1581) con un Suplemento..., op. cit., vol. I, pp. 47-78.

217 Romeu Figueras, Josep: “Mateo Flecha el Viejo...”, op. cit., pp. 53, 55.

218 Ibid., pp. 52-53.

219 MuÑoz, Ferran: op. cit., pp. 26-64, 109-117. Éstas son las que llevan por título El Fuego, La Bomba, La Negrina, La Guerra, La Justa, La Viuda, Los Chistes, Las Cañas (todas ellas incluidas en el impreso Praguense), El Jubilate y La Caza.
} 
obras probablemente relacionadas con la ciudad: La Viuda, Los Chistes y La Negrina, las dos últimas con mayor grado de incertidumbre ${ }^{220}$.

De todas las ensaladas, la na videña titulada La Viuda es la que, por unanimidad de todos los autores, presenta una más clara vinculación con Valencia. La aparición explícita en su texto del duque de Calabria, citado como último de los protectores de la música, y del cabildo de la ciudad en el papel de juez de la querella interpuesta por la Música contra el mal gusto musical, son indicadores evidentes. Los nuevos datos de archivo, junto con los contenidos en su propio texto, apuntan a que su composición tuvo lugar con moti vo de la Na vidad de 1539 ó 1540. De hecho, siguiendo la razonada hipótesis de Muñoz, la viuda, además de la Música, era doña Mencía de Mendoza, viuda de Enrique de Nassau y residente en Valencia desde 1538, quien finalmente casó con el duque de Calabria en enero de 1541. Mantuvo, pues, su condición de viuda residente en Valencia en las fiestas navideñas de 1538 a 1540. Por tanto, teniendo en cuenta que el nombramiento de Flecha como maestro de capilla de la catedral se produjo el 1 de febrero de 1539 y marchó a Castilla a finales de octubre de 1541, el músico estuvo presente en Valencia únicamente en las na vidades de 1539 y 1540. Hay que descartar que su composición tuviese lugar durante la primera etapa de Flecha en la ciudad (1526-1531?), puesto que la ensalada fue compuesta con se guridad después de la muerte del arzobispo de Toledo Alonso de Fonseca, que aconteció en $1534{ }^{221}$. Otra incógnita que ya tiene e xplicación es el moti vo del trato preferente que Flecha otorga al cabildo en la ensalada, que se justifica por ser en esta época el maestro de capilla de la catedral.

A diferencia del resto de ensaladas, en el te xto de La Viuda se citan di versos personajes del mundo real y de gran altura política o religiosa, cuyo nombre aparece de forma totalmente explícita: el papa León x, el rey Fernando el Católico, Diego Hurtado de Mendoza -duque del Infantado-, Alonso de Fonseca -arzobispo de Toledo-, el duque de Calabria, e incluso el órgano colegiado del cabildo de Valencia. A ellos se dedica la mayor parte del texto en tono laudatorio como protectores de la música, lo cual propicia que hasta el verso 80 , de un total de 97222, no se descubra el carácter sacro de la pieza. Asimismo, el texto parece que oculta segundas interpretaciones que involucran a, al menos, Mencía de Mendoza, otro ilustre personaje real del estamento nobiliario. Por tanto, es de suponer que la pieza fuese dirigida a un entorno buen conocedor de todos estos personajes y suficientemente cultivado para que fuese entendido y tuviese el efecto deseado, como era la corte del duque de Calabria.Verdaderamente, es difícil pensar que la pieza fuese dirigida a otro contexto cuando, además, entre los cinco protectores de la música citados, el único vivo y citado en último lugar, es el propio Fernando de Aragón.

Sin embar go, la mayoría de las ensaladas de Mateo Flecha, no comparten estas características. Los personajes que aparecen no son reales, siendo casi todos rústicos estereotipados, o sacros, como los que habitualmente aparecen en los villancicos navideños de la época. Por otro lado, el carácter religioso

220 Flecha, Mateo: Las Ensaladas (Praga, 1581) con un Suplemento..., op. cit., pp. 77-78.

221 "«Arzobispo de Toledo, / óigovos y non vos veo,» / El de Fonseca sería, / que en música se perdía / por tomalla y por dexalla." [Tomado de Flecha, Mateo: Las Ensaladas (Praga, 1581) con un Suplemento ..., op. cit., vol. I, p. 120].

222 Para el cómputo de versos, ver ibíd. 
y catequizador de las piezas suele estar más o menos presente a lo lar go de todas ellas, apo yado en simbolismos o argumentos de comprensión relativamente sencilla para un amplio sector de la población. Por consiguiente, teniendo en cuenta además que ahora se conoce con seuridad que Mateo Flecha sirvió a la seo durante su estancia en la ciudad de Valencia, no se debería de descartar que una parte de sus ensaladas hubiesen sido creadas para ese conte xto catedralicio, y no para el cortesano del duque de Calabria, como hasta el presente únicamente se había planteado. En este sentido, no con viene pasar por alto que existen testimonios de interpretación de ensaladas en el medio catedralicio hispánico del siglavi durante las fiestas navideñas, como en Granada, donde se sabe que, al menos en 1565 y 1566, se pagaron diversas cantidades relacionadas con la composición de "chanzonetas y ensaladas", así como con la preparación de los seises para la danza de éstas últimaš ${ }^{23}$. Es más, incluso la práctica de la música profina en este conte xto navideño debía de estar ciertamente e xtendida cuando el canonista na varro Martín de Azpilcueta (*1492; †1586) consideró en 1545 que "peccan también los que aquel día [Nati vidad], y otros, cantan cantiones vulgares, y prophanas, aunque de suyo no sean desonestas y v anas durante el officio divino"224. Más detalles nos da el mismo autor sobre prácticas que nos recuerdan las onomatopeas características del género ensalada, aplicado aquí a la guerra, así como su origen francés:

El XXIII. Ser poco agradable a Dios cantar en las yglesias y mezclar con la sp[irit]ualidad, y gxædad del officio divino la prophanidad y liviandad de una invenctión francesa muy recebida ya en España, con que cantando reprehesentan el son de los atambores y trompetas, el ca valgar, el tomar de la lança, el pelear y los golpes dellartillería, con el alv oroto de la guerra. Ca aunque esta representatión de suyo no sea deshonesta, y para convites, y passatiempos seglares sea buena, pero muy agena es de los divinos officios, y su fin, que es levantar las almas y spiritus a pensar, contemplar, y afficionarse a Dios, y amarlo más que a todo lo amable y aborrecer el peccado mortal, que dél nos aparta más que a todo lo aborrecible ${ }^{225}$.

Desconocemos si con la expresión "invención francesa muy recebida ya en España” Azpilcueta se refiere a una pieza en concreto o a una práctica francesa adaptada en España. En el primer caso, se trataría, con poco margen de error, de la famosa chanson titulada La Guerre de Clément Janequin (*1485c; †1558p), compuesta para celebrar la victoria francesa en la batalla de Marignano (1515). En el segundo, se estaría refiriendo a las onomatopeyas introducidas en los textos, en este caso de guerra, tan frecuentes en las ensaladas.

Una de las ensaladas cuyo te xto -sin demasiada complicación conceptual y e xento de referencias a personajes de la realidad-, parece apto para haber sido cantado en una catedral es la tituladaEl Fuego, que figura en el primer lugar del impreso praguense. El propio te xto explica el simbolismo en que se basa la obra casi desde el mismo principio ("Este fuego que se enciende / es el maldito pecado") 226 y sólo emplea

223 López CALO, José: La música en la catedral de Granada en el siglo XVI, vol. I (Granada, Fundación Rodríguez Acosta, 1963), pp. 257-258 [Citado en Flecha, Mateo: Las Ensaladas (Praga, 1581) con un Suplemento..., op. cit., vol. I, p. 42].

224 AzPILCueta, Martín de: Commento en romance a manera de repetición latina y scholástica de iuristas, sobre el capítulo Quando... de consecratione. Distintio prima (Coimbra, s.e., 1545), pp. 277-278.

225 Ibid., p. 278.

226 En concreto son los v ersos con número 5 y 6 se gún la edición FleCHA, Mateo: Las Ensaladas (Praga, 1581) con un Suplemento..., op. cit., vol. I, p. 97. 
la lengua castellana, además de la latina, factores que facilitan la comprensión de la letra a un auditorio no demasiado cultivado. Teniendo en cuenta los nuevos datos de la biografía de Flecha, se puede plantear la posibilidad de que esta ensalada se hubiese compuesto en Valencia para la Navidad de 1526, quizá en la catedral deValencia ${ }^{227}$. De hecho, el 9 de octubre de 1526, recién llgado Mateo Flecha tras la licencia de 30 días otorgada por el cabildo inmediatamente después de su primer nombramiento en la catedral, se produjo un gran incendio en la calle del Trench de la ciudad de Valencia, recogido por los principales dietarios de la época, en el que, se gún versiones, se quemaron de 20 a más de 40 casas y 9 personas perecieron. La catedral tomó parte activa haciendo sonar sus campanas y sacando a la calle el Santísimo Sacramento y el Lignum Crucis ante la desesperada población ${ }^{228}$. El simbolismo de la pieza tiene un e vidente paralelismo con la opinión del subsacristán de la catedral Pere Martí cuando escribió que:

Pense que tantes punicions que Nostre Sen yor Déu nos ha donat de VIII anys ençà, de aygua, guerres, fam, set, ayres, sequedat, peste, modorilla, y ara aquest foch tant cruel, qu'és per $\mathrm{f}$ alta de justícia y per nostres peccats, axí en los ecclesiàstichs com en los seculars ${ }^{229}$.

De ser cierta esta posibilidad, sería El Fuego la primera ensalada escrita por Flecha en Valencia. Por ello, quizá no sea casualidad que también sea la primera que aparece en el impreso de 1581, sobretodo al considerar la hipótesis apuntada por Gómez Muntané de que el material base para el impreso pudiese haber lle gado a su editor, Mateo Flecha el Jo ven, de manos del beneficiado de la catedral valenciana Pere Pujol ${ }^{230}$.

227 Romeu propuso el año de 1542 para la composición de esta pieza basándose en un análisis estilístico del te xto, mientras que Gómez Muntané ha anticipado esta fecha hasta 1531/1534 basándose no sólo en el texto sino también en la música, aunque reconoce su vínculo con ensaladas anteriores [Romeu Figueras, Josep: "Mateo Flecha el Viejo...", op. cit., pp. 46-49, 5255; Flecha, Mateo: Las Ensaladas (Praga, 1581) con un Suplemento..., op. cit., vol. I, pp. 54-55, 77-78]. Ambos autores realizan acercamientos cronológicos basados en el establecimiento de etapas temporales, en cada una de las cuales se incluyen ensaladas con análogas características estilísticas. No obstante, otro factor diferente a la cronología que es razonable que pueda influir en el estilo, fundamentalmente del texto, es el destinatario de la obra. De este modo, es posible que semejantes características estísticas encontradas en ciertas ensaladas no puedan explicarse exclusivamente por pertenecer a una misma etapa cronológica, sino también por haber sido escritas para un mismo destinatario con exigencias o pretensiones concretas como, por ejemplo, las catequizadoras de la catedral o las más mundanas de la corte del duque de Calabria. De momento, no obstante, es difícil profundizar en esta cuestión sin salir del mundo de las conjeturas.

228 "Lo dia de Sent Dionís, a mijanit, de l'an y MDXXVI, a VIII de octubre, se guí una gran desa ventura, y fon que·s pe gà foch en una casa del Trench, que stava en lo cantó del carrer dels Manyans, devers lo Mercat, la qual pocehiha hun especier que·s dia En Johan Fuster. E per spay de una hora y men ys fon lo foch en tot lo Trench a una part y altra fins al Mercat, sens poder-lo remediar. Y cremà's tot lo Trench de sòl y de rahel, y les altres cases fins al cantó de la Pelleria y dels Giponés, y la major part, o quasi tota, de la hilleta qu·està entre lo carrer dels Man yans y de la Pelleria, en lo qual se cremaren quaranta cases o més, y set persones en casa del dit En Fuster, hon principià lo foch [...] E a mija hora que fon lo foch, dihent matines, arribà la noa a la Seu, y despertaren lo sot-sagristà, qui havia poch que s'era gitat. Y manà als escolans que tocassen a foch, axí com qui toca a l'ama, ab totes les campanes, de una en una.Y respongueren totes les parròquies y monestirs. E leà̀ $\cdot$ lo sot-sagristà y envihà per lo vicari de Sent Pere. Y ab huns quants capellans que s'i trobaren y lechs tragueren lo Corpus de Sent Pere ab lo pali y leignum Crucis que·s mostra tempore Passionis, ab una stola y capa. Y no tornà fins a prop de les set hores del dia. E més, tragueren lo Corpus de totes les més parròquies y monestirs, y reliquies, ab innumerable gent que ana va per les carreres, y lums a les finestres. Y de pas a pas era tan gran la crita del «Senyor ver Déu, misericòrdia» que paria que tot se n'entrava. E a les set hores lo foch fon remediat algun tant, en part miraculosament, per a segons era lo foch.” [MARTí Mestre, Joaquim (Ed.): op. cit., p. 113]. También aparece reseñado el incendio en otros dietarios: CARRERES, Salvador (Ed.): op. cit., pp. 807-808; SoRIA, Jeroni: op. cit., p. 106.

229 Martí Mestre, Joaquim (Ed.): op. cit., p. 114.

230 El 16 de agosto de 1557, Pere Pujol recibió licencia real para imprimir "todas las más obras de canto" de Mateo Flecha el Viejo, aunque no parece que lle gase a realizar tal impresión. [M ADURELL, José María: "La imprenta musical en España", en 
La ensalada El Jubilate sirvió a Romeu como punto de referencia para establecer su cronología de todo el ciclo, formulando la hipótesis de que hubiese sido escrita para la Naidad de 1538 como réplica irónica del acontecimiento histórico de la Paz de Niza (1538) -acordada entre Carlosv y Francisco I de Francia- y de la obra de Cristóbal de Morales escrita para conmemorar el tratado, que se inicia con el mismo verso latino. La hipótesis se apoyaba también en el argumento de la victoria de la Virgen -que se expresa en una "mezcla de francés e italiano"- sobre Lucifer , y en la e xpresión francesa "Poltrón François" (cobarde Francisco) que utiliza aquélla para dirigirse al pecado original, en una probable alusión al rey francés ${ }^{231}$. Por su parte, Gómez Muntané la sitúa cronológicamente bastante antes (hacia 1525-1526), y plantea la posibilidad de que el hecho de incluir parte de texto en italiano pueda deberse a una hipotética composición en Nápoles ${ }^{232}$. Una nueva posibilidad a considerar es que pudiese haber sido compuesta para la Navidad de 1529. En ese año Flecha se encontraba en Valencia, donde, como el texto de La Viuda sugiere con fuerza, debió de tener contactos con la corte del duque de Calabria. Los textos en italiano y la referencia despectiva al rey de Francia son totalmente compatibles con ese cultivado e imperialista auditorio cortesano. El 5 de agosto de 1529 se firmó la Paz de Cambrai, que detuvo las hostilidades momentáneamente entre Carlos v y Francisco I. El tratado fue firmado por Luisa de Sabo ya, madre de Francisco I, y Margarita de Austria, tía de Carlos v, por lo que también se llamó la $\mathrm{P}$ az de las Damas. El emperador renunciaba a sus derechos sobre el ducado de Bor goña y otros territorios, mientras que el re y francés hacía lo mismo para el caso de Flandes y Artois, al tiempo que abandonaba sus pretensiones italianas. Ello significaba obtener la supremacía imperial en Italia y una buena excusa para acusar de cobarde al rey francés por su retirada de estos territorios. La interpretación del tratado en cla ve de éxito imperial en una corte como la del duque podría también explicar la expresión "El diablo que lo oyó, / se temió, / porque no pudo creer / que lo que mujer perdió / lo cobremos por mujer”, en posible alusión a las dos mujeres protagonistas de la firma del tratado.

A pesar de lo e xpresado en el presente capítulo, el conte xto creativo de las ensaladas de Flecha continúa siendo una cuestión totalmente abierta al planteamiento de nue vas posibilidades y a la presentación de datos que permitan confirmarlas o descartarlas.

Recibido: $11 / 11 / 2008$

Aceptado: 10/07/2009

\begin{abstract}
Anuario Musical, VIII (1953), pp. 230-231]. En cambio, sí coincidiría enValencia con Flecha el Joven, quien profesó en el convento del Carmen desde 1552, según los historiadores carmelitas, y que fue el que imprimió las ensaladas finalmente. Pujol podría haber conseguido la música de Flecha en la corte de doña Mencía de Mendoza - donde parece ser que sirvió como capellán-, entre cuyos libros de música existía "un libro de ensaladas", según apunta Gómez Muntané [FLechA, Mateo: Las Ensaladas (Praga, 1581) con un Suplemento..., op. cit., vol. I, pp. 17-18, 25, 32-33, 87-88]. Sin embar go, también pudo haber comenzado su recopilación de obras en la misma catedral, donde era beneficiado desde 1510, coincidiendo con Flecha el Viejo durante todo el tiempo que éste sirvió allí, y cuya primera ensalada hubiese podido ser El Fuego. [La aparición del nombre de Pere Pujol como beneficiado de la catedral fue puesta de manifiesto con precaución en MuÑoz, Ferran: op. cit., p. 252].
\end{abstract}

231 Romeu Figueras, Josep: "Mateo Flecha el Viejo...”, op. cit., p. 54.

232 Flecha, Mateo: Las Ensaladas (Praga, 1581) con un Suplemento..., op. cit., vol. I, p. 77. 